\title{
Avaliação clínica de inlays e onlays \\ confeccionadas com dois tipos de cerâmica \\ após 02 anos
}

Maria Jacinta Moraes Coelho Santos

Tese apresentada à Faculdade de

Odontologia de Bauru, Universidade de

São Paulo, como requisito para a

obtenção do título de Doutor em

Odontologia, Área de Dentística.

(Edição Revisada)

Bauru

2003 


\title{
Avaliação clínica de inlays e onlays
}

\section{confeccionadas com dois tipos de cerâmica}

\author{
após 02 anos
}

Maria Jacinta Moraes Coelho Santos

Tese apresentada à Faculdade de Odontologia de Bauru, Universidade de São Paulo, como requisito para a obtenção do título de Doutor em Odontologia, Área de Dentística.

Orientador:

Prof. Dr. Rafael Francisco Lia Mondelli

(Edição Revisada)

\section{Bauru}

2003 
11 de abril de 1966 Nascimento - Itambé - Bahia

$1984-1988$

Curso de Odontologia - Faculdade de Odontologia Universidade Federal da Bahia -FOUFBA

$1990-1990$

Curso de Especialização em Dentística

Restauradora pela Profis, Bauru, SP

1993

Professora Auxiliar do Curso de Odontologia da

Universidade Federal da Bahia

$1993-1994$

Curso de Especialização em Periodontia pela APCD, Bauru, SP

$1994-1995$

Curso de Aperfeiçoamento em Prótese Fixa pela APCD, Bauru, SP

$1995-1999$

Curso de Pós-Graduação em Clínicas

Odontológicas, em nível de Mestrado, na FOUFBA

$1996-1999$

Professora do Curso de Especialização em

Dentística pelo CEBEO, Salvador, BA

1999

Professora Assistente do Curso de Odontologia da Universidade Federal da Bahia

1999

Curso de Pós-Graduação em Dentística, em nível de Doutorado, na Faculdade de Odontologia de Bauru, USP

Universidade de Toronto - Canadá (Sanduíche)
Associações
ABO - Associação Brasileira de Odontologia - Bahia GBPD - Grupo Brasileiro de Professores de Dentística SBPqO - Sociedade Bras. de Pesq. Odontológica IADR - International Association of Dental Research 
Santos, Maria Jacinta Moraes Coelho

Sa59a Avaliação clínica de inlays e onlays confeccionadas com dois tipos de cerâmica após 02 anos / Maria Jacinta Moraes Coelho Santos -Bauru, 2003.

xviii, 180 p. : il. ; $30 \mathrm{~cm}$.

Tese (Doutorado) -- Faculdade de Odontologia de Bauru. Universidade de São Paulo.

Orientador: Prof. Dr. Rafael Francisco Lia Mondelli

Autorizo exclusivamente para fins acadêmicos e científicos, a reprodução total ou parcial desta tese por processos fotocopiadores e/ou meios eletrônicos.

Assinatura do autor (a):

Data:

Projeto de pesquisa aprovado pelo Comitê de Ética em Pesquisa da Faculdade de Odontologia de Bauru da Universidade de São Paulo na reunião do dia 31/03/2000. 
Dedico este trabalho:

A Deus e agradeço pelos momentos de criação, de inspiração, de prazer e de aprendizado que pude desfrutar durante esta minha jornada. Acredito que toda experiência nos traz uma nova oportunidade de entendimento, ajudando-nos a compreender parte do enigma da vida.

Ao meu marido, pelo exemplo, apoio e igual necessidade em percorrer caminhos inexplorados, no intuito de tentar saciar-se com o conhecimento. É maravilhoso ter o seu apoio incondicional e saber que olhamos na mesma direção. Já não sei se nosso amor é conseqüência ou causa dessas afinidades.

À minha mãe, pelo estímulo àbusca pelo saber, do qual ela também jamais acredita ter exaurido.

Ao meu pai (in memorian), que sempre foi um exemplo de determinação, coragem e responsabilidade. Seu investimento e apoio constantes foram responsáveis pela minha formação e evolução.

Aos meus irmãos, Rita e Luciano, por acreditarem no meu trabalho e me incentivarem na busca dos meus objetivos. 
Ao meu orientador, Prof. Dr. Rafael Francisco Lia Mondelli, agradeço pelo apoio e confiança em mim depositados ao longo desses anos. Sua capacidade de ouvir e a sua disposição em ajudar, a qualquer tempo, sempre me fez apreciar a sua disponibilidade e amabilidade. Espero que esta parceria possa permanecer. 
À Prof ${ }^{a}$. Dr ${ }^{a}$. Maria Fidela de Lima Navarro, Diretora da Faculdade de Odontologia de Bauru, USP, agradeço imensamente pelo seu exemplo de luta, empreendimento, amor e dedicação à Faculdade e aos alunos. Seu espírito altruísta sempre contribuiu enormemente para o nosso crescimento pessoal e profissional, permitindo-nos galgar caminhos mais distantes.

Ao Prof. Dr. João Carlos Pereira, coordenador do Doutorado da Faculdade de Odontologia de Bauru, USP. Agradeço pelo conciliador, sábio e inegável apoio que sempre nos ofereceu em todos os momentos. Meus sinceros agradecimentos.

Aos Profs. do Departamento de Dentística da FOB-USP, Dr. Mondelli, Dr. Áquira, Dr. Eduardo, Dr. Ricardo, Dr. Mário Honorato, Dr. Rafael, Dr. Pereira, Dr. Carlos Francischone, Dra. Fidela e Dra. Tereza Atta, pela acolhida, compreensão, preciosos ensinamentos e exemplo de dedicação à vida acadêmica.

Ao Prof. Dr. Luiz Fernando Pegoraro, Vice-Diretor da Faculdade de Odontologia de Bauru, USP, pelo apoio e cordialidade constantes.

Aos Profs. Doroty McComb, Laura Tam e Omar El-Mowafy da Faculdade de Odontologia, Universidade de Toronto, Canadá, pelo afável acolhimento e notável contribuição no desenvolvimento da nossa pesquisa. 
Ao Prof. Dr. Edmar Santana, Diretor da Faculdade de Odontologia da UFBA, que pelo seu empenho na criação do curso de pós-graduação na FOUFBA, gerando o estímulo e oportunidade na vida acadêmica dos professores da entidade.

À Profa. Aparecida Marques, chefe do Departamento de Odontologia Restauradora da UFBA, pela amizade e apoio oferecidos de forma constante durante todo este período.

Às amigas Rebeca Bezerra e Márcia Nóya, Professoras colegas do curso de Especialização de Dentística, CEBEO, pela amizade e oportunidade de somar o conhecimento docente.

Aos colegas do curso de Doutorado em Dentística pela oportunidade de termos compartilhado este caminho juntos, somando diferenças e gerando amadurecimento.

Aos protéticos Rosângela Saqueto e Carlos Romanini pelo excelente trabalho prestado na confecção das restaurações cerâmicas utilizadas na Tese de Doutorado.

Ao Prof. Lauris pela realização dos testes estatísticos e pela disponibilidade e presteza nos atendimentos. 
À Ivoclar-Vivadent nas pessoas de Herbert Mendes e Éderson Pereira e à Dentsply-Degussa, em especial à Maria Takeshita, pelo fornecimento dos materiais utilizados nesta pesquisa.

Aos protéticos Nelson Queiroz, Dito e Júnior, do Departamento de Dentística e a Edmauro, funcionário do Departamento de Endodontia, pela constante cordialidade e disposição em ajudar.

Aos funcionários da Pós-Graduação, Giane, Aurélio, Letícia, Ana Maria, Cleusa e Solange, pela dedicação e presteza.

Aos funcionários da Biblioteca, pela amabilidade e ajuda prestada durante o curso de Doutorado.

Às funcionárias do Departamento de Dentística, Karen, Ângela, Rita, Bete e Heloísa pelo carinho e afeição.

Aos funcionários da Faculdade de Odontologia, Universidade de Toronto, Canadá, Jian e Robert pelo apoio na condução das pesquisas.

A todos os amigos e familiares que me incentivaram e apoiaram durante este período longe de casa. E a todos que direta ou indiretamente contribuíram para a execução deste trabalho. 
Agradeço em especial:

À Universidade Federal da Bahia pelo incentivo à capacitação docente.

À Capes pelo auxílio à pesquisa concedido para a realização do Doutorado sanduíche através do processo BEX 1252/01-01. 


\section{SUMÁRIO}

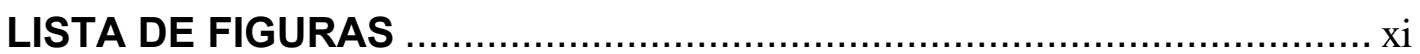

LISTA DE ABREVIATURAS E SÍMBOLOS ................................... XV

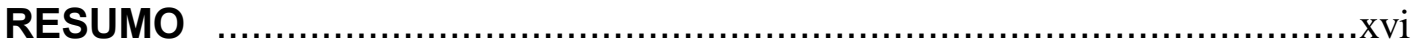

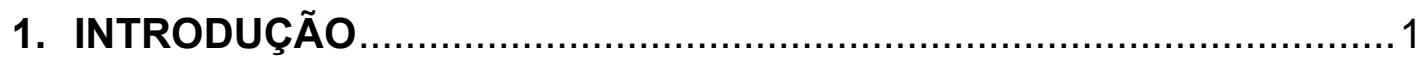

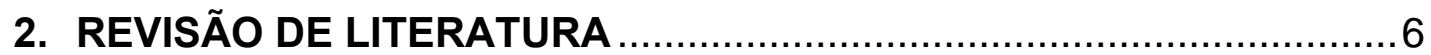

2.1 - CARACTERÍSTICAS GERAIS DA CERÂMICA ............................ 7

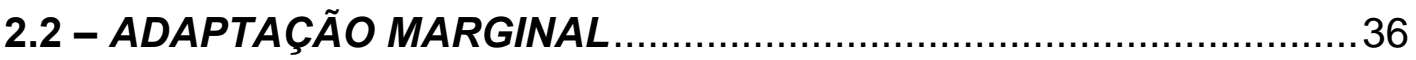

2.3 - AGENTES DE CIMENTAÇÃO ................................................ 48

2.4 - ESTUDOS DE AVALIAÇÃO CLÍNICA ..................................67

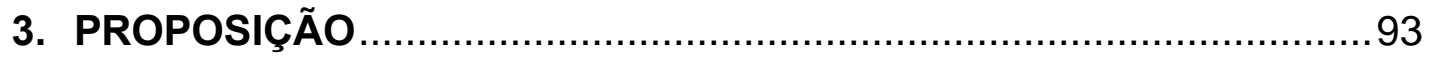

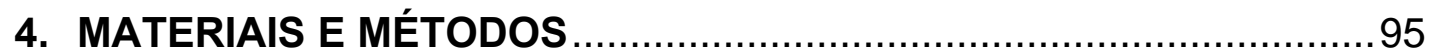

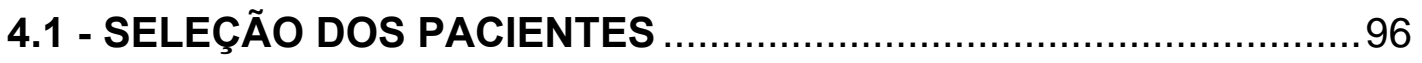

4.2 -PREPARO DAS CAVIDADES E PROTEÇÃO DO

COMPLEXO DENTINA/POLPA .......................................... 97

4.3 - CONFECÇÃO DAS RESTAURAÇÕES PROVISÓRIAS .................101

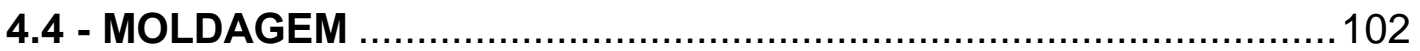

4.5 - FABRICAÇÃO DAS INLAYS/ONLAYS -

PROCEDIMENTOS LABORATORIAIS ................................ 103

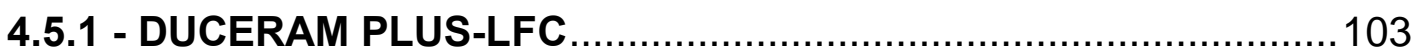

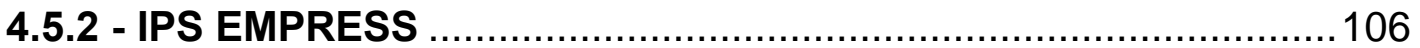


4.6.1 - TRATAMENTO PRÉVIO DAS RESTAURAÇÕES …...................109

4.6.2 - TRATAMENTO PRÉVIO DOS DENTES …................................109

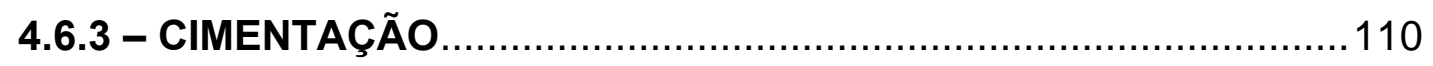

4.7 - AVALIAÇÃO CLÍNICA DAS RESTAURAÇõES ..........................111

4.8 - CONFECÇÃO DAS RÉPLICAS E OBSERVAÇÃO EM MEV .........117

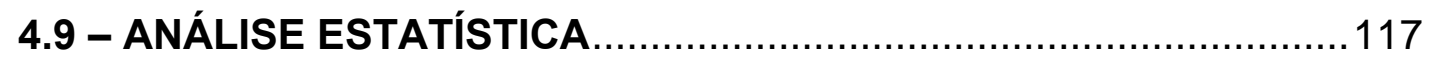

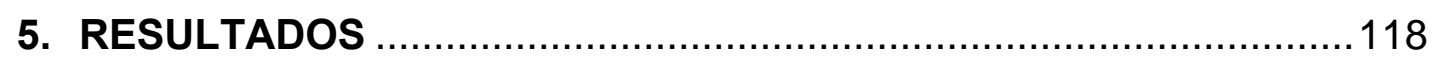

5.1 - RESULTADOS DAS AVALIAÇÕES POR ESCORES …................119

5.2 - RESULTADOS DO TESTE DE KAPPA …………....................129

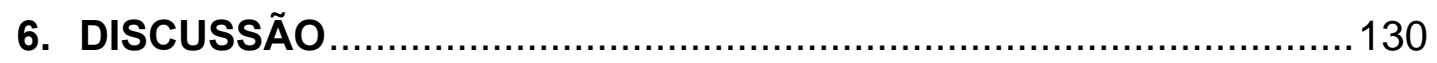

6.1 - Escolha dos sistemas cerâmicos ……...........................131

6.2 - Fatores relacionados à cimentação ……….....................135

6.3 - Fatores relacionados ao sucesso das restaurações cerâmicas 138

6.4 - Discussão dos resultados 145

7. CONCLUSÕES

8. ANEXOS

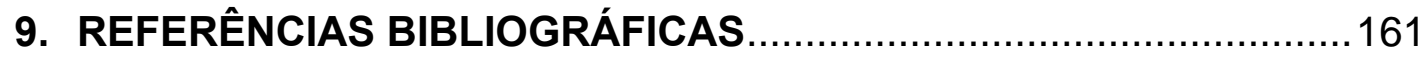

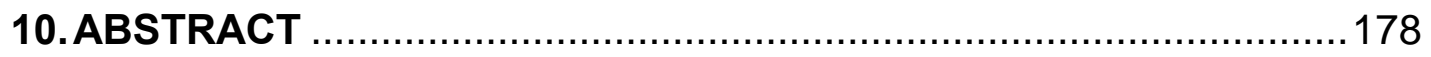




\section{LISTA DE FIGURAS}

Figura 4.1 - Q Quadro do número total de restaurações cerâmicas (IPS Empress e Duceram) de acordo com o tipo (inlay e onlay) e região (pré-molares - PM e molares $-M)$

Figura 4.2 - Quadro das características gerais do preparo cavitário. 99

Figura 4.3 - Unidades com preparos para onlay e inlay. 99

Figura 4.4 - Quadro dos principais materiais utilizados 101

Figura 4.5 - Pó e líquido da cerâmica Duceram (a) - Troquel refratário posicionado no modelo original (b) Cerâmica aplicada sobre o refratário (c) - Cerâmica sinterizada sobre o troquel refratário (d). 105

Figura 4.6 - Forno EP 500 - IPS Empress (a) - Pastilhas préceramizadas IPS Empress (b) - Inlay em cera sobre o troquel de gesso (c) - Inlay em cerâmica prensada (d)

Figura 4.7 - Quadro com os critérios, características e escores do método direto de avaliação clínica (USPHS modificado) para inlays e onlays de cerâmica 113 
Figura 4.8 - Unidades 45 e 46 preparadas para receber inlays em cerâmica pura IPS Empress (45) e Duceram (46) (a); baseline - (b); 01 ano - (c) e 2 anos - (d). Ambas as cerâmicas receberam escore "Alfa" para todos os aspectos avaliados

Figura 4.9- Unidade 17 preparada para receber inlay em cerâmica pura IPS Empress - (a); baseline - (b); 01 ano - (c) e 02 anos - (d). Nas figuras (c) e (d), as setas indicam o escore "Bravo" obtido pelo item descoloração marginal

Figura 5.1 - Q Quadro dos resultados "Alfa" da investigação clínica de acordo com o critério USPHS modificado para os dois tipos de cerâmica

Figura 5.2 - G Gáfico ilustrativo dos resultados "Alfa" obtidos pelas cerâmicas IPS Empress e Duceram frente aos diversos aspectos analisados no baseline. Os valores foram estatisticamente semelhantes. 120

Figura 5.3 - Gráfico ilustrativo dos resultados "Alfa" obtidos pelas cerâmicas IPS Empress e Duceram frente aos diversos aspectos analisados após 01 ano. Os valores foram estatisticamente semelhantes. 121

Figura 5.4 - G Gáfico ilustrativo dos resultados "Alfa" obtidos pelas cerâmicas IPS Empress e Duceram frente aos 
diversos aspectos analisados após 02 anos. Os

valores foram estatisticamente semelhantes

Figura 5.5 - $\quad$ Quadro dos resultados "Alfa" da investigação clínica das restaurações do tipo inlay, de acordo com o critério USPHS modificado, nas regiões de prémolares (PM) e molares (M)

Figura 5.6 - Gráfico ilustrativo da média dos resultados "Alfa" obtidos pelas restaurações cerâmicas do tipo inlay nas regiões de pré-molares e molares frente aos diversos aspectos analisados nas três avaliações de forma conjunta. Os valores foram estatisticamente semelhantes

Figura 5.7 - Q Quadro dos resultados "Alfa” da investigação clínica, de acordo com o critério USPHS modificado para restaurações do tipo inlay (IN) e onlay (ON) realizadas na região de molares 124

Figura 5.8 - Gráfico ilustrativo da média dos resultados "Alfa" obtidos nas três avaliações pelas inlays e onlays realizadas na região de molares, frente aos diversos aspectos analisados. Os valores foram estatisticamente semelhantes 125

Figura 5.9 - Gráficos das restaurações cerâmicas IPS e D classificadas com base na porcentagem de escores 
("Alfa" e "Bravo") com relação à descoloração marginal. Letras iguais representam valores estatisticamente semelhantes 126

Figura 5.10 - Gráficos das restaurações cerâmicas IPS e D classificadas com base na porcentagem de escores ("Alfa" e "Bravo") com relação à reprodução de cor. Letras iguais representam valores estatisticamente semelhantes

Figura 5.11 - Gráficos das restaurações cerâmicas IPS e D classificadas com base na porcentagem de escores ("Alfa" e "Bravo") com relação à integridade marginal. Letras iguais representam valores estatisticamente semelhantes 128

Figura 5.12 - Gráficos das restaurações cerâmicas IPS e D classificadas com base na porcentagem de escores ("Alfa" e "Bravo") com relação à textura superficial. Letras iguais representam valores estatisticamente semelhantes

Figura 6.1 - Imagens por MEV das réplicas para a verificação do desgaste do cimento resinoso (C) da mesma restauração cerâmica (IPS) em diferentes tempos. Esmalte (E). Aumentos de $100 \mathrm{X}$ (a) e $200 \mathrm{X}$ (b) 134 


\section{LISTA DE ABREVIATURAS E SÍMBOLOS}

\begin{tabular}{ll} 
ANOVA & Teste estatístico de variância \\
CAD-CAM & Computer-aided-design - computer-aided-manufacturing \\
CEREC & Ceramic Reconstruction \\
CDA & California Dental Association \\
${ }^{\circ} \mathrm{C}$ & Graus Celsius \\
$\%$ & Por cento \\
$\mathrm{GPa}$ & Gigapascal \\
$\mathrm{Hz}$ & Hertz \\
$\mathrm{HF}$ & Ácido Fluorídrico \\
$\mathrm{kg}$ & Kilogramas \\
$\mathrm{LFC}$ & Low Fusing Ceramic \\
$\mathrm{MEV}$ & Microscopia Eletrônica de Varredura \\
$\mathrm{mm}$ & Milímetro \\
$\mathrm{mW} / \mathrm{cm}{ }^{2}$ & Miliwatt por centímetro quadrado \\
$\mathrm{MPa}$ & Megapascal \\
$\mathrm{N}$ & Pound per square inch \\
$\mathrm{nm}$ & Micrometros \\
$\mathrm{pH}$ & United States Public Health Service \\
$\mathrm{psi}$ & Potencial de hidrogenação \\
$\mathrm{USPHS}$ & Petros \\
\hline
\end{tabular}




\section{RESUMO}




\section{RESUMO}

As restaurações em cerâmica pura têm sido uma opção restauradora largamente utilizada em dentes posteriores devido a sua excelente estética. Diversos tipos de sistemas cerâmicos estão disponíveis no mercado para a fabricação de restaurações parciais e coroas. Este trabalho teve o objetivo de avaliar o comportamento clínico de restaurações, do tipo inlay e onlay, confeccionadas com dois sistemas cerâmicos: cerâmica convencional (Duceram, Dentsply-Degussa) - D e cerâmica prensada (IPS Empress, IvoclarVivadent) - IPS pelo período de 02 anos. Oitenta e seis restaurações, sendo 44 IPS e 42 D, foram cimentadas em 35 pacientes de ambos os sexos, com idade média de 35 anos. Vinte e sete pré-molares e cinqüenta e nove molares receberam preparos cavitários classe II, num total de 33 onlays e 53 inlays. Todas as restaurações foram fixadas com cimento resinoso dual (Variolink II, Ivoclar-Vivadent) e sistema adesivo Syntac (Primer e Adhesive) e Heliobond (Ivoclar-Vivadent), sob isolamento absoluto. Os procedimentos operatórios foram realizados por apenas um operador. As avaliações foram realizadas por dois examinadores independentes no baseline, após 01 e 02 anos mediante 0 critério USPHS modificado, quanto aos aspectos: sensibilidade pulpar, reincidência de cárie, fratura, reprodução de cor, descoloração marginal, integridade marginal e textura superficial. Adicionalmente, radiografias e slides foram feitos. Após 02 anos, 100\% das restaurações foram reavaliadas e consideradas clinicamente excelentes ou aceitáveis. Dentre os itens analisados os seguintes apresentaram critério Bravo: descoloração marginal - IPS $(31,82 \%) ;$ D (23,81\%); integridade marginal - IPS (18,18\%); D (11,9\%); reprodução de cor - IPS (4,55\%); D (9,52\%) e textura superficial - IPS (2,27\%); D (14,29\%). Nenhum escore "Charlie" ou "Delta" foi atribuído æ̀ restaurações. Os resultados obtidos foram submetidos ao Teste Estatístico de Fisher e McNemar. Não houve diferença estatisticamente significante entre as cerâmicas testadas após 02 anos. Dentre os aspectos avaliados, o item descoloração marginal apresentou uma crescente porcentagem de escores "Bravo", para ambas as cerâmicas. Comparando-se esses dados com os 
obtidos no baseline verificou-se uma diferença estatisticamente significante ( $p$ > 0,05). Não houve diferença entre as restaurações do tipo inlay e onlay ou entre as restaurações fixadas nas regiões de pré-molares e molares. Na avaliação de 02 anos, o percentual de concordância entre os examinadores resultou em valores de Kappa acima de 0,8 para todos os critérios avaliados. Pôde-se concluir que os dois tipos de restaurações em cerâmica pura demonstraram um excelente desempenho clínico no período de dois anos. 


\section{1 - INTRODUÇÃO}




\section{1 - INTRODUÇÃO}

A busca pela odontologia estética tornou-se uma realidade no século XX. A crescente procura por materiais restauradores estéticos tem direcionado as pesquisas, na área odontológica, para o desenvolvimento de sistemas que permitem a restauração do sorriso, livre de metal, sem seqüelas aparentes da doença cárie. $\mathrm{O}$ aspecto estético dos dentes passou a ser valorizado pelos pacientes como um fator de diferenciação na conquista das relações pessoais e profissionais ${ }^{60}$.

Dentre os materiais restauradores estéticos, as cerâmicas têm se destacado em função das suas excelentes propriedades ópticas, biocompatibilidade e durabilidade ${ }^{60,92}$. A cerâmica é considerada o material sintético que mais se assemelha àaparência natural dos dentes, devido a sua capacidade em reproduzir as sombras e translucidez da estrutura dental ${ }^{69,} 102$. As restaurações em cerâmica pura foram introduzidas na odontologia no século XIX ${ }^{25,105}$, mas devido à inexistência de cimentos adequados que permitissem a união da cerâmica à estrutura dental, bem como, inovações técnicas para a fabricação de cerâmicas mais resistentes, estas apresentavam alto índice de fraturas e deixaram de ser utilizadas ${ }^{95}$.

A partir de 1960 as coroas metalo-cerâmicas foram introduzidas no mercado com o intuito de associar a estética da cerâmica com a resistência promovida pela infra-estrutura metálica. De acordo com MABRITO; ROBERTS $^{70}$ (1995), as coroas metalo-cerâmicas foram a única opção restauradora para dentes posteriores quando a resistência e a estética eram 
requisitos necessários. Em 1965, Mc LEAN; HUGHES ${ }^{75}$ deram o primeiro passo para o desenvolvimento de cerâmicas mais resistentes, com a introdução de coroas de cerâmica pura reforçadas com alumina. No entanto, só a partir da década de 80 novos sistemas cerâmicos começaram a surgir no mercado, a exemplo dos sistemas Cerestone (Biomedical) e Dicor (Dentsply $)^{106}$. Nos últimos anos, diversos tipos de cerâmica, com altos valores de resistência à flexão têm sido desenvolvidos, os quais, associados ao progresso das técnicas adesivas, têm permitido novas oportunidades no uso deste material em dentes anteriores e posteriores, até próteses fixas de três elementos. Este fato, aliado ao grande anseio estético por parte da população, tem levado ao uso, cada vez mais consistente, das cerâmicas puras 92, 98,104, 111 .

Os sistemas cerâmicos atualmente disponíveis no mercado apresentam constituição, resistência àflexão e formas de confecção distintas. As cerâmicas a base de óxido de silício (feldspáticas), óxido de alumínio e de óxido de alumínio reforçadas com óxido de zircônio são as mais utilizadas ${ }^{5,106}$. As técnicas de confecção das inlays e onlays podem ser realizadas pela aplicação convencional da cerâmica sobre um modelo refratário, ou podem ser fundidas, prensadas, infiltradas ou usinadas ${ }^{102}$. De acordo com ROSENBLUM; SCHULMAN ${ }^{102}$ (1997), todos os sistemas podem ser utilizados com sucesso em restaurações parciais unitárias.

O sucesso das restaurações em cerâmica pura está diretamente relacionado ao aprimoramento na fabricação de cerâmicas mais resistentes, com a introdução de elementos de reforço, a exemplo da leucita, alumina, magnésio, zircônio e fluoreto de lítio ${ }^{9,12,76}$, bem como, ao excelente estágio de 
desenvolvimento das técnicas adesivas, as quais permitem uma interação efetiva entre a cerâmica e a estrutura dental ${ }^{43,57}$. A união da cerâmica ao cimento resinoso têm sido exaustivamente descrita na literatura $7,22,58,66,107,120$ e tem sido considerada como um fator de reforço à cerâmica, por permitir a transferência das forças oclusais para a estrutura dental ${ }^{47,53,60}$. Por outro lado, o desenvolvimento de sistemas adesivos com forças de resistência de união elevadas tem permitido uma adesão eficiente dos cimentos resinosos à estrutura dental ${ }^{29}$.

Os estudos laboratoriais têm sido aliados essenciais no fornecimento de dados que possibilitem o conhecimento das propriedades mecânicas e químicas dos materiais cerâmicos, permitindo que estes possam ser utilizados na clínica com maior confiabilidade e previsibilidade. No entanto, o sucesso real de um material só pode ser comprovado quando este é testado sob as exigências mastigatórias, mudanças térmicas, dieta, umidade e variações individuais. Apesar de envolverem tempo para que os primeiros resultados possam traduzir o efeito desses fatores no material testado, as pesquisas clínicas têm sido consideradas essenciais por avaliarem o desempenho dos materiais restauradores, a curto e longo prazo, sendo o estudo mais completo para determinar as reais vantagens, desvantagens e indicações clínicas.

Diversas pesquisas clínicas têm sido relatadas na literatura, no intuito de avaliar o comportamento de inlays e onlays em cerâmica pura. Diferentes sistemas têm sido investigados e os resultados têm mostrado que os principais motivos das falhas são por fratura. Estas estão geralmente associadas à 
espessura insuficiente da cerâmica, forma do preparo, oclusão do paciente, agentes cimentantes e defeitos internos da cerâmica ${ }^{62,68}$.

Com o intuito de avaliar o comportamento clínico de diferentes sistemas cerâmicos nas regiões de pré-molares e molares pelo período de dois anos, restaurações em cerâmica pura, inlays e onlays, foram confeccionadas com os sistemas IPS Empress e Duceram. 


\section{2 - REVISÃO DE LITERATURA}




\section{2 - REVISÃO DE LITERATURA}

\section{1 - CARACTERÍSTICAS GERAIS DA CERÂMICA}

As cerâmicas dentais sempre despertaram um grande interesse na classe odontológica, em função do excelente potencial estético destes materiais. A primeira incrustação em cerâmica pura foi feita em 1837, por John Murphy, na Inglaterra ${ }^{105}$. O termo cerâmica vem do grego "Keramos" que significa matéria queimada. A porcelana é considerada um tipo específico de cerâmica ${ }^{102}$, no entanto, geralmente os dois termos são usados indistintamente ${ }^{2,93}$.

As cerâmicas dentais são constituídas por sílica, a qual pode ser encontrada na forma de vidro amorfo (sílica fundida) ou na forma cristalina (quartzo). O feldspato é o mineral utilizado na fabricação da maioria das cerâmicas dentais. Este mineral é constituído por potassa $\left(\mathrm{K}_{2} \mathrm{O}\right)$, alumina $\left(\mathrm{Al}_{2} \mathrm{O}_{3}\right)$ e sílica $\left(\mathrm{SiO}_{2}\right)$ e, quando aquecido em altas temperaturas, pode formar cristais de leucita (potássio-alumínio-silicato), importante no reforço das cerâmicas ${ }^{93}$. A cerâmica $\left(\mathrm{SiO}_{2}-\mathrm{Al}_{2} \mathrm{O}_{3}-\mathrm{K}_{2} \mathrm{O}-\mathrm{CaO}-\mathrm{Na}_{2} \mathrm{O}-\mathrm{B}_{2} \mathrm{O}_{3}\right)$ é constituída por uma estrutura amorfa, semelhante ao vidro, cujas moléculas apresentam-se distribuídas ao acaso em forma desordenada. A incorporação de um material cristalino aumenta a resistência destes materiais, impedindo que a linha de fratura se propague tão facilmente pelas partículas cristalinas, como o faz no vidro ${ }^{93}$.

Diversos sistemas cerâmicos foram desenvolvidos na última década, com o intuito de aumentar a resistência destes materiais mediante a 
incorporação de cristais de reforço. As cerâmicas dentais podem ser classificadas de acordo com a sua constituição em: cerâmicas feldspáticas; cerâmicas reforçadas com leucita; cerâmica enriquecida com alumina; alumina infiltrada por vidro e cerâmica de vidro. Os sistemas cerâmicos também podem ser classificados de acordo com a técnica de fabricação, sendo eles:

- $\quad$ Cerâmica convencional - consiste em um pó, no qual o técnico irá adicionar água ou outro veículo para constituir uma massa que formará a restauração por camadas, ex: Duceran Plus e LFC (Degussa); Optec HSP (Jeneric-Pentron); Fortune (Willians), etc.

- $\quad$ Cerâmica fundida - consiste de barras cerâmicas sólidas, as quais são usadas para construir as restaurações pelo processo da cera perdida e centrífuga para fundição. Geralmente a restauração é fabricada em apenas um tom de cerâmica, sendo esta depois recoberta por pintura extrínseca ou por cerâmica feldspática pelo método convencional, a fim de promover a caracterização final, ex: Dicor (Dentsply);

- Cerâmica computadorizada - o produto consiste de diversas barras cerâmicas de diferentes tons, usinadas através do sistema CAD-CAM (Computer-aided-design $\quad-$ Computer-aided-manufacturing), ex: CEREC (Siemens). Mais recentemente surgiu o sistema Procera (Nobel-Biocare) no qual o copping, com alto teor de alumina, é usinado pelo sistema CAD-CAM e posteriormente recoberto por uma cerâmica feldspática pelo método convencional; 
- $\quad$ Cerâmica prensada - também está disponível na forma de barras sólidas de cerâmica, as quais são fundidas sob alta temperatura e pressionadas dentro do molde criado através do processo da cera perdida, ex: Optec OPC (Jeneric-Pentron); IPS Empress e IPS Empress 2 (Ivoclar-Vivadent).

- $\quad$ Cerâmica infiltrada - é composta por 2 componentes: um pó, rico em óxido de alumínio, o qual é aglutinado sobre o troquel de gesso para formar um substrato poroso, pelo processo de capilaridade; e um vidro de lantânio, o qual é infiltrado dentro deste substrato poroso em alta temperatura para formar um copping, altamente resistente. Este copping será posteriormente recoberto por uma cerâmica de revestimento pela técnica convencional. Ex: In Ceram (Vident).

As principais desvantagens das cerâmicas são a sua fragilidade e a baixa resistência à tração ${ }^{93}$, as quais vêm sendo superadas com a introdução de sistemas mais resistentes e utilização de agentes de cimentação resinosos. As principais vantagens da utilização dos sistemas cerâmicos embasam-se no potencial estético e reforço do remanescente dental promovido pela técnica de cimentação adesiva ${ }^{43,57,70,112}$. Diversos artigos científicos foram publicados no intuito de elucidar as características destes materiais.

JACKSON; FERGUSON ${ }^{56}$, em 1990, consideraram que as Inlays e onlays fabricadas em resina composta e cerâmica além de estéticas têm apresentado um reforço adicional à estrutura dentária remanescente, devido ao seu potencial de adesão ao dente. Relatou que as indicações das inlays 
estéticas são semelhantes às de ouro, adicionando-se o desejo dos pacientes em obterem estética. Considerou-as superiores na conservação da estrutura dental, uma vez que se torna desnecessário sacrificar cúspides para proteger o remanescente dental como se faz nas restaurações metálicas, devido à característica de reforço da técnica de cimentação adesiva. Entretanto, alertou para as diferenças entre os preparos das inlays estéticas e das restaurações metálicas indiretas, considerando a preparação para as inlays estéticas bem mais fáceis de serem executadas. Comentou que as paredes da cavidade devem divergir de 10 a $15^{\circ}$ e os ângulos internos devem ser arredondados para permitir um melhor assentamento e evitar a concentração de estresse. As margens podem ter chanfros profundos, mas não bisel. A profundidade de desgaste deve ser de no mínimo 1,5 a 2 mm e a largura do istmo deve estar em torno de $2 \mathrm{~mm}$. Advogou o uso do cimento de ionômero de vidro como base e enfatizou que os cimentos provisórios não devem conter eugenol, para não interferir na polimerização do cimento resinoso. Para moldagem, indicou o polivinil siloxano ou o poliéter.

BANKS ${ }^{8}$, em 1990, relatou que a resistência da cerâmica é comprometida pela presença de defeitos na superfície, os quais podem favorecer à propagação de trincas pelo corpo do material. Ressaltou que o objetivo do cimento resinoso é promover a união íntima entre a cerâmica, o esmalte e a dentina; formando de um corpo único que permite a transferência de tensões da restauração para a estrutura dental, sendo um eficiente meio de aumentar a resistência da cerâmica. Enfatizou ainda que, devido à natureza 
frágil deste material, muita atenção deve ser dada ao preparo cavitário a fim de minimizar esta fragilidade pelo aumento da espessura da cerâmica. Preconizou uma redução oclusal entre 1,5 a $2 \mathrm{~mm}$ e axial de 1,5 mm; arredondamento dos ângulos para prevenir a concentração de estresse; evitar biséis e regularizar as depressões nas paredes da cavidade com cimento de ionômero de vidro. Recomendou a prova pré-cimentação para verificação de possíveis excessos de contato nas faces proximais e considerou clinicamente aceitável a adaptação marginal destas restaurações.

Em revisão literária sobre as inlays de cerâmica pura, QUALTROUGH; WILSON; SMITH ${ }^{95}$, em 1990, enfatizaram as excelentes propriedades destas restaurações, principalmente com relação à estética, biocompatibilidade, durabilidade química e propriedades ópticas. Observaram que, apesar de essas restaurações estarem presentes na odontologia há mais de 100 anos, inovações técnicas, tais como, instrumentos cortantes diamantados, materiais de moldagem adequados, cimentos de ionômero de vidro e técnicas adesivas, somados, vieram influenciar no aprimoramento das inlays cerâmicas. No entanto, consideraram como desvantagens a dificuldade técnica, o tempo consumido e o custo de fabricação. Os autores relataram ainda que, apesar do grande fascínio que estas restaurações exerciam desde a sua descoberta, não haviam, na época, cimentos adequados que permitissem a adesão à estrutura dental e à cerâmica, bem como inovações técnicas que permitissem o fortalecimento das cerâmicas. 
Segundo McLEAN ${ }^{74}$, em 1991, as cerâmicas são o único grupo de materiais que resiste àcorrosão, àabrasão e à dissolução até por ácidos fortes. Salientou que novos tipos de cerâmicas puras reforçadas têm sido indicados como substitutos das tradicionais coroas metalo-cerâmicas. Entretanto, considerou que todos estes novos materiais possuem limitações, particularmente em relação à precisão, à resistência à fratura e à capacidade de manter a superfície livre de trincas. Comparando a cerâmica aos metais, advogou que os metais não dependem da condição da sua superfície para aumentar o seu potencial de fratura. Já as cerâmicas dependem da integridade da sua superfície para que as restaurações tenham longevidade. Observou que a durabilidade clínica é maior em uma cerâmica menos resistente, mas com uma superfície íntegra, do que o contrário. Afirmou também que as restaurações cerâmicas estão limitadas por problemas clínicos, tais como, espaço e força oclusal. E ressaltou que uma forma eficaz de reforçar a cerâmica é adicionar cristais, os quais atuam dificultando a propagação de trincas pelo corpo da cerâmica.

BURKE et al. ${ }^{15}$, em 1991, se propuseram a estudar as restaurações indiretas do tipo inlay/onlay e consideraram que as restaurações metálicas fundidas, apesar de não estéticas, possuem maior longevidade clínica, maior durabilidade e melhor polimento de superfície quando comparadas às restaurações de resina e de cerâmica. No entanto, observaram que, diante da necessidade estética do paciente, essas restaurações podem ser utilizadas. Consideraram que as inlays de cerâmica são superiores às inlays de resina 
devido à estética superior, biocompatibilidade e maior resistência ao desgaste. Com relação às inlays de resina, afirmaram que estas são superiores às de cerâmica na facilidade de reparo, no menor desgaste do dente antagonista, na possibilidade de ser modificada ou repolida e na maior facilidade da técnica laboratorial.

WALTON ${ }^{134}$, em 1992, relatou que apesar da popularidade das inlays de cerâmica e de resina composta, principalmente em função do potencial estético destes materiais, alguns outros fatores devem ser avaliados, tais como, custo, necessidade de provisórios, moldagem, cimentação e sensibilidade da técnica. No entanto, ressaltou como aspectos positivos a facilidade do trabalho fora da boca, a melhora nas propriedades físicas das resinas, a menor contração de polimerização e a maior resistência ao desgaste desta. Com relação às cerâmicas, alertou para o fato de algumas cerâmicas serem menos abrasivas, a exemplo do sistema Dicor (Dentsply), e outras mais abrasivas, como o sistema Optec HSP (Jeneric-Petron), o qual possui aproximadamente $40 \%$ a mais de leucita do que as cerâmicas convencionais utilizadas nas próteses metalocerâmicas.

LUTHY; WOHLWEND; SCHÁRER ${ }^{69}$, em 1992, consideraram que as cerâmicas translúcidas, a exemplo das cerâmicas feldspáticas, apresentam características similares à do esmalte dental. No entanto, salientaram que as restaurações de cerâmica feldspáticas confeccionadas pelo sistema convencional apresentam maior número de microporosidades, podendo 
facilmente levar a propagação de fraturas. No sistema de cerâmica fundida (Dicor), apesar das porosidades terem sido reduzidas, ainda apresentam a desvantagem da contração adicional durante a cristalização. Reportaram que o sistema de cerâmica prensada, IPS Empress, desenvolvido na Universidade de Zurique, veio superar as desvantagens apresentadas pelos sistemas supracitados. Os autores verificaram, mediante um estudo in vitro, que o processo de aquecimento e pressão utilizados na fabricação das restaurações cerâmicas pelo sistema IPS Empress resultou no aumento da resistência flexural da cerâmica final obtida. $\mathrm{O}$ aumento da resistência é devido à distribuição mais homogênea dos cristais de leucita na matriz de vidro após o processo de fabricação. Observaram ainda que após o processo de obtenção da cerâmica por pressão, se esta for submetida a queimas adicionais resultará no aumento da resistência flexural, a qual pode chegar a até $182 \mathrm{Mpa}$.

ANUSAVICE ${ }^{4}$, em 1993, relatou que, desde a introdução da primeira coroa de cerâmica pura produzida em 1903, importantes avanços têm sido dados com relação ao desenvolvimento e à modernização das cerâmicas dentais. Um importante passo foi dado em 1965 com a introdução das coroas de jaquetas em cerâmica enriquecidas com óxido de alumínio. De acordo com o autor, as taxas de falhas destas coroas situavam-se em torno de $15,2 \%$ em molares e 2,1\% em incisivos, restringindo o seu uso para dentes anteriores. Citou que o mais novo sistema cerâmico In-Ceram (Vident) produzido através da infiltração do vidro no copping de alumínio tem sido considerado promissor, pois apresenta alta resistência à fratura $(442 \mathrm{MPa})$ devido ao alto teor de alumina 
$\left(\mathrm{Al}_{2} \mathrm{O}_{3}\right)$. Acrescentou que este novo sistema tem sido aceito para a confecção de coroas anteriores, uma vez que supera em resistência os antigos sistemas utilizados para a mesma situação. Descreveu o uso do sistema computadorizado CAD-CAM (Siemens) para a confecção de inlays e onlays. Neste sistema o dentista necessita cobrir o preparo com um pó reflectivo a fim de que a imagem possa ser capturada pela microcâmara e identificada pelo monitor do computador. Esta técnica dispensa a moldagem e a confecção da restauração provisória, uma vez que a restauração é usinada na mesma sessão do preparo, via computador. No entanto, esta técnica foi considerada pobre em adaptação marginal com discrepâncias, às vezes, acima de $100 \mu \mathrm{m}$. Outros sistemas foram citados, mas necessitam, segundo o autor, de maior número de estudos e avaliação clínica.

DONOVAN; CHEE ${ }^{28}$, em 1993, alertaram para o grande fascínio da sociedade por estética, juntamente com o desejo de eliminar restaurações metálicas. Neste estudo, os autores procuraram comparar restaurações áuricas com restaurações de cerâmica e relataram que ambos os tipos de restaurações são resistentes ao desgaste, biocompatíveis e promovem a conservação da estrutura dental. No entanto, enfatizaram que as restaurações de ouro são superiores às restaurações de cerâmica, com relação ao potencial de abrasão ao dente antagonista, uma vez que possuem uma taxa de desgaste semelhante à estrutura dental. No caso do uso da cerâmica, deve-se atentar para a oclusão do paciente, a fim de evitar interferências nos movimentos protrusivos e de lateralidade, como forma de evitar desgastes excessivos na estrutura dental 
antagonista. Da mesma forma, salientaram que ambos os tipos de restaurações são resistentes às forças compressivas, mas alertaram para a necessidade de uma espessura adequada da cerâmica, em torno de 1,5 a 2,0 mm, bem como a ausência de bisel nas margens, como forma de promover uma adequada resistência àfratura destas restaurações. Os autores chamaram a atenção para o fato de não existir um tipo de preparo padronizado para as restaurações cerâmicas e relataram que estas são realizadas de maneira empírica. Com relação àadaptação marginal e a estabilidade, consideraram as restaurações de ouro superiores e salientaram que as restaurações áuricas podem também ser unidas ao dente por meio de técnicas adesivas. No entanto, enfatizaram a excelente estética provida pelas restaurações cerâmicas.

A popularidade das inlays estéticas foi relatada por HOARD, em 1993, que considerou que as restaurações de amálgama e de ouro vêm sendo substituídas por inlays e onlays cerâmicas em pacientes que valorizam a estética. Enfatizou que o sucesso das inlays cerâmicas está diretamente relacionado ao preparo cavitário, devendo este apresentar paredes com expulsividade média de $6^{\circ}$ e ângulo cavo-superficial em $90^{\circ}$, sem bisel. Afirmou que, quanto mais conservadora for a restauração, maior será o tempo de sucesso clínico desta.

ROULET; LÖSCHE; NOACK ${ }^{104}$, em 1993, relataram que atualmente os pacientes estão muito envolvidos com a saúde e estética bucal. Consideraram a resina composta como a primeira alternativa para substituir as restaurações de 
amálgama sempre que as cavidades forem conservativas, mas devido aos problemas que podem advir de uma restauração larga de resina num dente posterior, principalmente devido à contração de polimerização, sugeriram as restaurações indiretas para os casos mais extensos. Enfatizaram que as restaurações indiretas de resina e cerâmica, fixadas ao dente por meio de cimentos resinosos e sistemas adesivos, parecem ser boas alternativas devido ao pequeno volume de componentes resinosos na cavidade, provenientes apenas da fina camada do cimento resinoso. Com relação æ̀̀ inlays cerâmicas, lembraram que este tipo de restauração data de 1862. No entanto, devido à fragilidade das cerâmicas havia uma alta incidência de falhas. O mínimo estresse levava à indução de trincas, as quais se espalhavam por todo o corpo da restauração. Na época, as restaurações eram fixadas aos dentes com cimento de fosfato de zinco, o qual não reforçava a união. Consideraram que dois fatores levaram ao ressurgimento das cerâmicas: o aprimoramento técnico na construção das restaurações cerâmicas e a adesão permanente desta ao dente através dos novos sistemas adesivos e cimentos resinosos.

Segundo MABRITO; ROBERTS ${ }^{70}$, em 1995, durante anos, as coroas metalo-cerâmicas foram a única opção para restaurar dentes posteriores quando resistência e estética eram necessárias. Os autores avaliaram por 09 anos restaurações em cerâmica pura e consideraram que, apesar dos erros no preparo, da primeira geração de adesivos dentinários e da existência de cimentos resinosos apenas fotopolimerizáveis, este tipo de restauração apresentou resultados satisfatórios, com longevidade clínica quase semelhante 
à das coroas convencionais metalo-cerâmicas. Outra vantagem das inlays de cerâmica é o reforço promovido à estrutura dental remanescente próximo à resistência do dente hígido. Esta resistência é duplicada quando a onlay é utilizada. Enfatizaram ainda que embora a adaptação marginal das restaurações cerâmicas não seja tão efetiva quanto æ̀ das restaurações em ouro, uma técnica adequada de fabricação pode produzir adaptações marginais satisfatórias, sendo imperativo o uso de um bom laboratório.

NASEDKIN ${ }^{83}$, em 1995, relatou que as inlays e onlays cerâmicas têm tido destaque devido ao interesse, cada vez maior, dos pacientes por restaurações com aparência natural e devido às preocupações com a presença do mercúrio nas restaurações de amálgama. Com relação ao preparo, considerou que espessuras de cerâmica inferiores a $1 \mathrm{~mm}$ podem gerar fraturas devido à concentração de estresse. Desta forma, aconselhou uma espessura superior a 1,5 mm e contra-indicou os biséis. Alertou que as margens do preparo não devem localizar-se em áreas de contato funcional, mas devem situar-se aquém ou além destas áreas. $O$ autor descreveu alguns outros tipos de cerâmica e citou que, na Universidade de Zurique, foi desenvolvida uma cerâmica denominada Celay, considerada como uma versátil e precisa máquina com 8 eixos, comparada com uma máquina de fazer chaves, extremamente precisa. No entanto, considerou-a limitada com relação àadaptação marginal da restauração. 
CHRISTENSEN ${ }^{19}$, em 1996, considerou que embora as restaurações de ouro gerem menor desgaste no dente antagonista, apresentem menor índice de fratura, melhor adaptação e maior estabilidade química, estas não têm boa aceitação por parte dos pacientes devido àexigência estética atual.

KELLY; NISHIMURA; CAMPBELL ${ }^{60}$, em 1996, enfatizaram que o desejo por materiais estéticos e duráveis é antigo. A maioria das culturas tem atribuído à aparência dos dentes o aspecto de jovialidade, saúde, beleza e dignidade. Descreveram diversos sistemas para a confecção de restaurações de cerâmica pura e consideraram que a maioria dos avanços dos sistemas atuais foi obtida graças à ajuda da engenharia. Consideraram que a cimentação adesiva é um fator fundamental no reforço da cerâmica, uma vez que a superfície interna das restaurações cerâmicas é a região mais sujeita ao estresse e a iniciação de trincas. O condicionamento ácido e o recobrimento da superfície com monômeros resinosos atuam como um mecanismo de reforço, evitando a formação de trincas ou reduzindo a sua propagação. Com relação aos sistemas cerâmicos, relatou que o sistema IPS Empress veio solucionar o problema de contração das cerâmicas feldspáticas convencionais, as quais necessitam de aplicação e queima adicionais para atingir o contorno e adaptação ideais da restauração final. No sistema IPS Empress, as restaurações são fabricadas através da injeção da cerâmica fundida dentro de um molde, onde a mudança dimensional ocorrida durante o resfriamento é controlada pela apropriada expansão do revestimento. 
Revisão de Literatura 20

ANUSAVICE ${ }^{5}$, em 1997, considerou que os dentistas devem analisar não só o potencial estético do sistema cerâmico, mas também a capacidade de resistência à fratura e abrasão ao dente antagonista. Relatou que a melhor forma de se avaliar a resistência da cerâmica é através do teste de resistência à propagação de fraturas (fracture toughness), o qual mede a energia necessária para propagar uma microfenda pré-existente. Relatou que o sistema de cerâmica prensada, IPS Empress, é fornecido em pastilhas de cerâmica préceramizadas, as quais são injetadas dentro do molde, sob pressão e alta temperatura, num tempo de aproximadamente 45 minutos. Destacou o sistema In-Ceram como altamente resistente, tendo uma resistência à propagação de fraturas (fracture toughness) 3,5 vezes superior aos sistemas IPS Empress e Optec HSP; e 4,6 a 5,8 vezes superior à cerâmicas feldspáticas convencionais. No entanto, apesar da maior resistência dos sistemas com alto teor de alumina, tais como, In-Ceram e Procera, estes apresentam como desvantagens o baixo grau de translucidez e a inabilidade de serem condicionados com ácidos. Aconselhou, como meios de diminuir o risco de fraturas, restringir o uso das restaurações cerâmicas em dentes anteriores e pré-molares; não as utilizar em pacientes com bruxismo e promover um adequado ajuste oclusal. Ressaltou que os sistemas detentores de menor resistência flexural devem ser fixados com cimentos resinosos, no intuito de aumentar a resistência àfratura.

ROULET; DEGRANGE ${ }^{103}$, em 1996, ressaltaram que as inlays são geralmente indicadas para os mesmos tipos de cavidades, nas quais o amálgama estaria indicado. Contra-indicaram o uso destas restaurações nos 
casos em que há presença de facetas de desgaste extensas e parafunção. Advertiram para a necessidade de os pontos de contato localizarem-se a, pelo menos, $1 \mathrm{~mm}$ dentro da inlay ou fora desta, evitando a coincidência destes pontos com as margens da restauração. Com relação ao material utilizado na confecção da inlay, ressaltaram que as restaurações em ouro possuem maior resistência, quando comparadas às restaurações cerâmicas. No entanto, consideraram que a longevidade das inlays cerâmicas são superiores às inlays de resina composta. Os autores salientaram que modificações no preparo cavitário devem ser consideradas quando se utiliza uma inlay estética. A cavidade deve ser tão simples quanto possível, devido às dificuldades das cerâmicas em copiarem detalhes, além da não necessidade de retenções adicionais, uma vez que a técnica da cimentação adesiva será usada. Ângulos internos arredondados e ângulo cavo-superficial em $90^{\circ}$, sem bisel, devem ser utilizados para evitar margens finas. Para a cimentação, indicaram o condicionamento com ácido fluorídrico durante 60 segundos para criar retenções na superfície interna da inlay e silanização para promover a união química da cerâmica com o cimento resinoso.

Segundo ROSENBLUM; SCHULMAN ${ }^{102}$, em 1997, cerâmica é o termo usado para definir materiais não metálicos e não orgânicos usados pelo homem para fazer objetos sólidos em alta temperatura. A tradicional cerâmica é obtida através da união de 3 diferentes minerais naturais: caolim, quartzo (sílica) e feldspato. A cerâmica aluminizada é constituída por cerâmica feldspática e óxido de alumínio. Um dos componentes principais desta cerâmica é a leucita (mistura 
de potássio, alumínio e sílica), a qual modifica as propriedades óticas, expansão térmica, resistência e dureza da cerâmica. Os cristais de leucita são formados durante a cocção da cerâmica feldspática em temperaturas elevadas. Os autores classificaram os sistemas cerâmicos de acordo com a técnica de fabricação, denominando-os: cerâmica convencional, fundida, computadorizada, prensada e infiltrada. Consideraram que todos os sistemas cerâmicos promovem adequada resistência para coroas unitárias e que a habilidade da união da cerâmica com o dente pode ser considerada como um mecanismo adicional para inibir fraturas na restauração. Com relação à técnica de fabricação, afirmaram que, com exceção do sistema convencional, todas as outras cerâmicas necessitam de técnica e equipamento especial e que isto pode ser considerado uma desvantagem devido ao custo adicional pago ao laboratório. Com relação à adaptação marginal, relataram que, com exceção do sistema fabricado em computador (CAD-CAM), todas as outras cerâmicas puderam ser consideradas extremamente adaptadas. Para compensar as discrepâncias e valas recomendaram o uso dos cimentos resinosos. Analisaram ainda estes sistemas com relação ao desgaste do dente antagonista e afirmaram que apesar de não haver estudos clínicos comparando os desgastes destes cinco sistemas, a capacidade de abrasão está diretamente correlacionada à presença dos cristais de leucita. Assim, consideraram que os sistemas com maior conteúdo de leucita (IPS Empress, Optec HSP e Optec OPC) poderão gerar maior desgaste no dente antagonista. 
BROWN ${ }^{12}$, em 1998, descreveu sobre os diversos tipos de materiais restauradores indiretos que podem ser utilizados na cavidade oral e considerou que as restaurações indiretas trazem a expectativa de serem mais duradouras e capazes de reproduzirem o contorno anatômico do dente, sendo o custo compensado pela longa vida útil deste tipo de restauração. Como alternativas restauradoras considerou os metais preciosos, as ligas básicas, as cerâmicas e as resinas indiretas. Com relação æ̀̀ cerâmicas relatou que as principais desvantagens relacionam-se à fragilidade e à necessidade de um técnico habilidoso para a confecção deste tipo de restauração.

Até a década de 60 a única cerâmica disponível era a cerâmica feldspática, a qual consistia basicamente da junção de vários tipos de cristais de alumínio-silicato unidos com vidro. Apesar da sua excelente estética eram altamente frágeis. Um dos princípios utilizados para reforçar a cerâmica é através da união desta a um material mais resistente, como por exemplo ao metal, ou limitando a propagação das trincas mediante a adição de uma substância diferente, ou ainda, gerando um estresse compressivo. A cerâmica aluminizada possui $50 \%$ de cristais de alumina fundidos junto com a cerâmica. É importante que o material incorporado à cerâmica como reforço possua o mesmo coeficiente de expansão térmica e seja quimicamente compatível, para que não funcione como um corpo estranho, atuando como uma cunha dentro do material. As partículas de alumina são efetivas no reforço da cerâmica, uma vez que fazem parte da estrutura do vidro cerâmico. Uma técnica utilizada para criar um estresse compressivo na superfície da cerâmica baseia-se na troca de íons. 
A matriz vítrea da cerâmica dental é rica em íons de sódio, os quais são considerados relativamente pequenos quando comparados aos íons de potássio. Nesta técnica a cerâmica é coberta com um sal de potássio e é aquecida a $500^{\circ} \mathrm{C}$ por 30 minutos com a finalidade de que os íons de potássio tomem o lugar dos íons de sódio. Estes íons por serem mais largos irão gerar um estresse compressivo na superfície, fortalecendo-a. O autor considerou que novas pesquisas são necessárias para aumentar a resistência das cerâmicas à fratura e citou outros materiais que podem ser incorporados à cerâmica, tais como, o zircônio, magnésio, fluoreto de lítio, etc.

MOSCOVICH et al. ${ }^{82}$, em 1998, mediante um trabalho in vitro, no qual dentistas experientes transformavam cavidades preparadas para amálgama em cavidades para inlays estéticas, concluíram que os operadores removeram uma quantidade de estrutura dentária significativamente maior do que o necessário. Consideraram que as paredes e áreas socavadas devem ser preenchidas com resina composta, como forma de evitar o desgaste desnecessário da estrutura dentária. No entanto, desaconselharam o uso do cimento de ionômero de vidro como base, em função das suas precárias propriedades mecânicas.

QUALTROUGH; PIDDOCK ${ }^{98}$, em 1999, mediante uma revisão de literatura, relataram os avanços relacionados às restaurações cerâmicas nos últimos anos. Consideraram que alguns sistemas se sobressaíram em função da sua inovação técnica, permitindo uma melhor qualidade da cerâmica produzida. Descreveram o sistema IPS Empress, primeiramente relatado em 1990, como 
uma cerâmica feldspática prensada que possibilita a confecção de coroas, inlays e onlays mediante o processo da cera perdida. Já a cerâmica In-Ceram (Vita) permite a inclusão de $85 \%$ de material cristalino, através da confecção de uma infra-estrutura formada por um fino pó de alumina sobre uma matriz refratária. Os poros residuais são preenchidos pelo vidro, por uma ação de capilaridade, formando uma densa estrutura, com alto módulo de elasticidade. A parte estética final é concluída com uma cerâmica convencional. Infelizmente, o alto conteúdo de alumina desse sistema dificulta o condicionamento ácido, reduzindo a união micromecânica. Consideraram que os sistemas computadorizados, CAD-CAM, continuam sendo aprimorados, com a inclusão de um novo software; a introdução de um novo tipo de bloco cerâmico com menor potencial de abrasão ao dente antagonista; até a inclusão de uma turbina elétrica no sistema, com melhor controle de corte, resultando numa melhor adaptação. Relataram ainda os sistemas Techceram (Teckceram, UK), Celay (Mikrona, Suíça), Procera All Ceram e Procera All Titan (Nobel Biocare, Suécia) e enfatizaram que o sucesso das restaurações cerâmicas dependem do aprimoramento dos agentes de cimentação resinosos.

De acordo com a ADEPT REPORT ${ }^{2}$, em 1999, as cerâmicas dentais podem ser definidas como uma matriz vítrea de baixa fusão associada àóxidos metálicos de alta fusão. São materiais vítreos de estrutura amorfa com baixa resistência ao estresse. As estruturas cristalinas, entretanto, são mais resistentes devido ao seu arranjo molecular definido. Desta forma, o reforço da cerâmica pode ser feito pela adição de óxidos ou pela indução da cristalização. 
O termo cerâmica é genérico e inclui na sua denominação o vidro, a cerâmica, os óxidos, etc.

A cerâmica possui como vantagens a sua capacidade de adesão à estrutura dentária e resistência à corrosão. Como desvantagens destaca-se a sua fragilidade, a qual é significantemente aumentada quando há a presença de trincas na superfície, ressaltando-se a importância de um adequado polimento, principalmente quando o glaze é removido pelo ajuste oclusal. Um preparo com características adequadas e atenção aos detalhes são fatores determinantes para a longevidade. Neste artigo foram ressaltados alguns tipos de cerâmicas com alto teor de alumina, a exemplo da In-Ceram (Vita), com resistência flexural de $442 \mathrm{MPa}$ e do sistema Procera All Ceram (Nobel), cuja infra-estrutura possui um teor de aproximadamente $99,5 \%$ de óxido de alumínio $\left(\mathrm{Al}_{2} \mathrm{O}_{3}\right)$. No entanto, estes sistemas com alto teor de alumina não são condicionados pelo ácido, prejudicando a cimentação adesiva. Outra forma de reforçar a cerâmica é mediante $\mathrm{o}$ uso da leucita nas cerâmicas feldspáticas. A leucita $\left(\mathrm{K}_{2} \mathrm{O} \quad \mathrm{Al}_{2} \mathrm{O}_{3}\right.$ $4 \mathrm{SiO}_{2}$ ) é formada durante a fusão do feldspato que, devido ao seu alto coeficiente de expansão térmica, produz contração quando o material é resfriado. O mecanismo de reforço é dado a partir do estresse compressivo criado pela diferença de expansão térmica entre a leucita (alta) e a matriz vítrea (baixa). O tratamento térmico induz a formação adicional de leucita nas cerâmicas feldspáticas. O aumento do conteúdo de leucita melhora a resistência da cerâmica e é utilizada em diversos sistemas, a exemplo do IPS Empress (Ivoclar-Vivadent). 
Com relação aos sistemas de cerâmicas prensadas, tais como, o IPS Empress e o OPC (Jeneric/Pentron), considerou-se como vantagens a excelente adaptação, adequada translucidez e capacidade de serem condicionados pelo ácido. Já o sistema IPS Empress 2 possui uma infra-estrutura formada por uma cerâmica vítrea de dissilicato de lítio, a qual é finalizada com uma cerâmica de cobertura vítrea a base de fluorapatita. Este novo sistema possui um alto conteúdo de cristais de dissilicato de lítio (60\%) exibindo melhores propriedades químicas e maior translucidez. Podem ser condicionados pelo ácido, por 20 segundos e silanizados.

CULP ${ }^{20}$, em 1999, relatou que as restaurações metalo-cerâmicas foram desenvolvidas e começaram a ser utilizadas há aproximadamente trinta anos atrás. Com o avanço nas pesquisas, as cerâmicas puras começaram a ocupar o lugar das metalo-cerâmicas. Em 1990 foi introduzido nos Estados Unidos o sistema IPS Empress para a confecção de inlays, onlays, coroas e laminados. Este tipo de cerâmica prensada é rica em cristais de leucita (30 a 40\%), com 5 ìm de diâmetro, homogeneamente distribuídos na matriz vítrea. Devido à baixa resistência flexural, este sistema se limita àconfecção de restaurações unitárias. Recentemente, foi introduzido no mercado o sistema IPS Empress 2, cuja composição é totalmente diferente. Este novo sistema possui uma cerâmica para a confecção da infra-estrutura a base de cristais de dissilicato de lítio (60 a 80\%), os quais possuem o mesmo índice de refração da luz que a matriz vítrea, possibilitando maior translucidez do copping, ao contrário dos outros sistemas. A cerâmica de cobertura é rica em cristais de fluorapatita, proporcionando 
propriedades físicas e ópticas semelhantes à estrutura dental. $\mathrm{O}$ autor apresentou um caso clínico de uma ponte de três elementos, de canino à segundo pré-molar, confeccionada pelo sistema IPS Empress 2. A infra-estrutura foi primeiramente confeccionada em cera e as pastilhas de dissilicato de lítio foram fundidas e injetadas a $920^{\circ} \mathrm{C}$. A cerâmica de cobertura foi esculpida e queimada a $800^{\circ} \mathrm{C}$.

SINDEL, et al. ${ }^{117}$, em 1999, mediante um estudo in vitro, procurou verificar a influência do uso do cimento de ionômero convencional e modificado por resina na indução de fraturas em coroas de cerâmica pura, em função da expansão higroscópica desse material. Para isto utilizou 56 molares humanos, os quais foram preparados para coroa total. Após o preparo, $60 \%$ da dentina foi removida e reconstruída com diferentes materiais para núcleo de preenchimento: Dyract Cem; Tetric; Dyract AP; Hytac e Fuji II. A seguir, as coroas de cerâmica (IPS-Empress) foram fixadas com diferentes agentes de cimentação (Dyract Cem; Variolink Low; Fuji Plus) e foram armazenadas por 12 meses em solução salina à $37^{\circ} \mathrm{C}$. Os autores verificaram que quando o cimento de ionômero de vidro era utilizado como núcleo de preenchimento e/ou como material de cimentação, ocorriam fraturas nas cerâmicas, em função da expansão higroscópica deste material. Quando a resina composta foi utilizada como núcleo de preenchimento, associada aos cimentos resinosos para a fixação das coroas, nenhuma fratura foi observada no período de doze meses. 
Revisão de Literatura 29

GÜREL ${ }^{48}$, em 2000, relatou que os avanços tecnológicos permitiram o desenvolvimento de novas técnicas e materiais e considerou que o amálgama deixou de ser uma boa opção como material restaurador, não apenas por não ser estético, mas devido æ̀ resinas compostas e æ̀ cerâmicas promoverem uma melhor adesão à estrutura dental. Relatou que o sistema IPS Empress é utilizado para a construção de restaurações pelo processo da cera perdida, na qual esta é injetada no molde por pressão. Esta cerâmica é rica em fase vítrea e, após um processo de tratamento térmico, cristais de leucita com tamanhos de 1 a 3 ìm são gerados, formando uma estrutura heterogênea dentro da matriz vítrea, responsável pelo reforço do material. Enfatizou a necessidade da profundidade mínima de 1,5 mm na parede pulpar e redução cuspídea em torno de $2 \mathrm{~mm}$.

GORMAN; McDEVITT; HILL ${ }^{46}$, em 2000, realizaram um estudo com o propósito de determinar as propriedades mecânicas de duas cerâmicas prensadas, IPS Empress (Ivoclar-Vivadent) e OPC (Jeneric Pentron) e verificar se havia diferença entre elas. Foi utilizado RX por difração para analisar as fases das cerâmicas antes e após o processamento. Paralelamente, verificaram a resistência flexural biaxial, a dureza (teste de dureza Vickers) e registraram o comprimento das fraturas produzidas pelo teste de endentação de dureza. Através do uso do RX por difração observaram que o sistema IPS Empress apresentou a mesma fase cristalina, rica em leucita, antes e após o processamento, indicando a pré-ceramização deste material. Já o sistema OPC apresentou-se como um pó compacto cristalino, o qual transformou-se em 
cerâmica de vidro, rica em leucita, somente após o processamento. Não houve diferença estatisticamente significante entre as propriedades estudadas, tendo o IPS Empress apresentado uma resistência flexural biaxial de 134,4 $(11,5) \mathrm{MPa}$ e o OPC de 153,6 $(17,8)$ MPa. A dureza Vickers do OPC foi de 7,28 $(0,62)$ GPa e do IPS Empress foi de 6,94 (0,79) GPa. A fratura por endentação registrada no OPC foi de 1,36 $(0,29) \mathrm{MPam}^{0,5}$ e do IPS Empress foi de $1,33(0,08) \mathrm{MPam}^{0,5}$. Os autores concluíram que não houve diferença entre os materiais testados. Consideraram que as vantagens desse sistema sobre o sistema convencional estabelecem-se pela redução da porosidade, aumento da resistência e melhora na adaptação marginal.

HAYASHI et al. ${ }^{52}$, em 2000, realizaram um estudo in vitro com o objetivo de avaliar a influência da divergência das paredes do preparo cavitário, bem como, a expansão de presa dos revestimentos refratários na adaptação de inlays de cerâmica (G-Cera Cosmotech II). Foram realizadas cavidades de classe II (MO e MOD) em blocos de resina epóxica, variando-se a divergência das paredes cavitárias em 10 e $20^{\circ}$. As cavidades foram moldadas com polivinilsiloxano e cinco modelos refratários foram confeccionados, para cada tipo de cavidade, controlando-se a expansão de presa, de 0,04\% a 1,14\%, variando-se a quantidade de sílica coloidal. As inlays foram confeccionadas sobre seus respectivos modelos refratários e posteriormente colocadas sobre o modelo mestre de resina epóxica para avaliação da adaptação. A adaptação foi determinada mediante a mensuração das distâncias mínimas entre a inlay e as margens da cavidade, em 28 a 30 pontos pré-selecionados (MO e MOD). A 
seguir a inlay era cimentada ao modelo de resina epóxica com adesivo a base de cianocrilato e então seccionada longitudinalmente em duas partes, para verificação da adaptação interna. Para as restaurações do tipo MO obteve-se uma melhor adaptação quando utilizou-se refratários com expansão de presa de 0,32\% ou menos. Já para as restaurações do tipo MOD obteve-se uma melhor adaptação quando utilizou-se refratários com expansão de presa de $0,87 \%$ ou mais. Os autores consideraram que para a obtenção de uma boa adaptação das inlays convencionais, a expansão de presa do revestimento está na dependência da forma da cavidade. A forma da cavidade MOD é mais complexa do que das cavidades de classe I e classe II (MO). Nas cavidades MOD os elementos externos são mais importantes para a obtenção de uma correta adaptação do que os elementos internos, tendo por isso, os revestimentos com maior expansão de presa, obtido os melhores resultados neste tipo de cavidade. Com relação àinclinação das paredes cavitárias constatou-se que as cavidades com $20^{\circ}$ de divergência apresentaram um número significantemente menor de fendas marginais do que as com $10^{\circ}$, para ambas as cavidades.

PEUTZFELDT ${ }^{92}$, em 2001, considerou que o aspecto estético dos dentes tem gradativamente se tornado um fator de suma importância para os pacientes, o que tem levado à pesquisa e ao desenvolvimento de materiais capazes de satisfazer esta exigência estética atual. Relatou que embora a cerâmica apresente algumas características indesejáveis, tais como, susceptibilidade àfratura e potencial de desgaste do dente antagonista, continua sendo um dos materiais mais populares para a confecção de inlays devido a sua 
alta qualidade estética, biocompatibilidade e durabilidade. As cerâmicas são formadas por uma fase vítrea reforçada por estruturas cristalinas dispersas na matriz, tais como, leucita, alumina e mica. O termo "cerâmica de vidro" tem sido usado para designar as cerâmicas nas quais a fase cristalina é gerada na fase vítrea, tendo os cristais sido produzidos pelo tratamento do vidro, ao invés de serem adicionados. Diversos sistemas têm sido introduzidos no mercado nos últimos dez anos, com o intuito de melhorar as características das cerâmicas. Sistemas com alto conteúdo de cristais, como por exemplo, In-Ceram e Procera All-Ceram, foram desenvolvidos com o objetivo de aumentar a resistência do material e impedir a propagação de fraturas. Considerou que o índice de falhas das restaurações diretas é similar ao das restaurações indiretas de resina composta, cerâmica e ouro. Como conseqüência, ponderou que a longevidade não deve ser o critério decisivo para a escolha do material restaurador, mas outros critérios, tais como, preço e estética podem orientar melhor na decisão do tratamento a ser executado.

ROULET ${ }^{106}$, em 2001, classificou as cerâmicas de acordo com a composição em cerâmicas de óxido de silício (feldspáticas), cerâmicas de óxido de alumínio, cerâmicas de óxido de alumínio reforçadas com zircônio e cerâmica de óxido de zircônio. Como exemplo de cerâmicas de óxido de silício citou o sistema Optec HSP, no qual a cerâmica é aplicada sobre um modelo refratário; os sistemas IPS Empress, IPS Empress 2, Optec OPC e Finesse All Ceramic, nos quais a cerâmica é injetada e moldada sobre pressão; os sistemas CEREC e Celay, nos quais a cerâmica é usinada. Dentre as cerâmicas de óxido de silício 
considerou o sistema IPS Empress 2 (dissilicato de lítio) o mais resistente, com resistência flexural em torno de $300 \mathrm{MPa}$. Com relação æ̇̀ cerâmicas enriquecidas com óxido de alumínio, relatou que estas podem ser aplicadas sobre um modelo refratário e em seguida infiltradas (ex. Sistema In-Ceram; InCeram Spinell e In-Ceram $\mathrm{ZrO}_{2}$ reforçada) ou usinadas (Procera e Cícero).

Relatou que as cerâmicas enriquecidas com óxido de alumínio e zircônio são as mais indicadas quando a resistência é o fator mais importante, no entanto, os sistemas com cerâmica feldspáticas devem ser os preferidos quando a estética é primordial. Por esta razão as cerâmicas de alumínio e zircônio são recobertas com cerâmica feldspática. Para aumentar a resistência das cerâmicas, duas formas são preconizadas: 1- aumentar a resistência do material cerâmico ou 2- utilizar as técnicas adesivas que permitem a união do cimento à cerâmica e à estrutura dental, reforçando o sistema final. Salientou que as cerâmicas de óxido de silício contém uma fase vítrea que permite o condicionamento com ácido fluorídrico, expondo os cristais e criando microretenções. E que estas podem ter uma excelente longevidade se cimentadas corretamente.

McLEAN ${ }^{76}$, em 2001, considerou que pelo menos duas décadas foram necessárias para que aprimoramentos na obtenção de cores e nas técnicas de fabricação de restaurações cerâmicas culminassem nas restaurações cerâmicas com as qualidades estéticas atuais. Ressaltou que a incorporação de cristais na matriz vítrea é uma técnica utilizada para a aumentar a resistência da cerâmica. 
A incorporação de partículas de alumina, silicato de zircônio ou alumínio são responsáveis pelo efeito de opalescência da cerâmica, que é a capacidade de emitir o espectro das cores, com variações de acordo com a posição do observador. Relatou que as cerâmicas com alto teor de alumina (99,9\% de óxido de alumínio $-\mathrm{Al}_{2} \mathrm{O}_{3}$ ) são tão resistentes que podem substituir o metal na fabricação de coroas. O sistema Procera All Ceram é confeccionado através da compactação de um pó de alumina pura, sobre um modelo usinado em tamanho mais largo para compensar a contração do pó sinterizado à $1550^{\circ} \mathrm{C}$, por uma hora. Já o sistema In-Ceram apresenta uma concentração de $72 \%$ de alumina. Considerou que o desafio deste século será produzir cerâmicas com alta resistência, mas sem sacrifício da translucidez, porém acredita que as coroas metalo-cerâmicas provavelmente continuaram sendo utilizadas por um longo tempo.

BLATZ; DENT ${ }^{9}$, em 2002, creditaram às técnicas adesivas e ao surgimento de cerâmicas mais resistentes, o alto índice de sucesso das avaliações clínicas. No entanto, considerou difícil a comparação entre os diferentes estudos clínicos, uma vez que um grande número de variáveis estão incluídas. Relataram que as cerâmicas convencionais aumentaram a resistência à fratura pelo acréscimo de cristais às cerâmicas feldspáticas. Dentre esses cristais destacam-se a leucita (ex. Optec HSP, Jeneric/Pentron), a alumina (ex. Hi-Ceram, Vita) e o óxido de zircônio (ex. Mirage II, Mirage). Relataram que as cerâmicas são biocompatíveis, estéticas e duráveis, devendo a escolha do material restaurador basear-se na indicação, extensão da cavidade e 
necessidade do paciente. Salientaram, entretanto, que quando a escolha recair sobre as cerâmicas, esta será uma opção que está cientificamente bem documentada.

QUALTROUGH; PIDDOCK ${ }^{97}$, em 2002, relataram que novos materiais cerâmicos continuam sendo introduzidos no mercado no intuito de aumentar a resistência e a longevidade clínica. Os materiais mais recentemente lançados no mercado possuem um alto conteúdo de alumina na sua composição e objetivam a confecção de uma infra-estrutura altamente resistente (In-Ceram e Procera AllCeram). Entretanto, devido ao alto conteúdo de alumina e pequeno conteúdo de sílica, tornou-se mais difícil criar microretenções através do condicionamento ácido ou união química pelo silano. 


\section{2 - ADAPTAÇÃO MARGINAL DE RESTAURAÇÕES CERÂMICAS}

A adaptação das restaurações indiretas é considerada primordial para a longevidade clínica das restaurações. A presença de uma margem contínua aliada a uma excelente união à estrutura dental são fatores essenciais para minimizar a microinfiltração ${ }^{18}$. As desadaptações marginais são responsáveis pelo acúmulo de bactérias, manchamento e possível microinfiltração ${ }^{136}$.

Vários métodos têm sido propostos para avaliar a adaptação interna e marginal, in vivo e in vitro, das restaurações. Diferentes valores tem sido relatados. No entanto, a extensão ideal da fenda marginal de restaurações estéticas não está claramente definida na literatura ${ }^{6,80,119}$. Torna-se claro, entretanto, que quanto maior for a área de exposição do cimento, maior será o desgaste deste ${ }^{49,59,86,115}$.

MCLEAN; von FRAUNHOFER ${ }^{77}$, em 1971 , mensuraram in vivo a espessura da linha de cimento em restaurações indiretas antes da cimentação, utilizando um elastômero entre o dente e a restauração. Foram investigadas inlays e coroas de ouro, coroas metalo-cerâmicas e coroas de cerâmica pura (jaqueta). Radiografias e investigação clínica com sonda foram também utilizadas. Discrepâncias na margem cervical externa de 10 a 169 ìm foram mensuradas. Não foram encontradas diferenças estatisticamente significantes entre as restaurações testadas. Após 5 anos de avaliação clínica de 1000 restaurações, os autores reportaram que apesar da desadaptação marginal, estas apresentaram-se clinicamente satisfatórias. Consideraram que 
desadaptações na ordem de até $80 \mathrm{ìm}$ ou menos $\mathrm{s}$ ão difíceis de serem detectadas clinicamente por sonda ou radiograficamente.

DIETSCHI; MAEDER; HOLZ ${ }^{26}$, em 1992, consideraram que devido ao desgaste dos cimentos resinosos deve-se atentar ao máximo para a obtenção de uma boa adaptação marginal, no intuito de reduzir a camada de cimento exposto ao meio bucal. Mediante um estudo in vitro estes autores avaliaram a influência dos materiais cerâmicos e da habilidade do técnico na adaptação marginal de inlays. Cavidades MOD foram preparadas em terceiros molares humanos e as inlays foram fabricadas com dois tipos de cerâmica (Vitadur N Vita e Ceranco II -DeTrey/Dentsply). A Cerâmica Ceranco II foi confeccionada em dois diferentes laboratórios. As inlays foram assentadas nas cavidades e moldagens foram feitas para a análise das réplicas em $M E V$, sem a presença do cimento. Durante a avaliação da adaptação marginal em MEV, dois parâmetros foram observados: 1 - espessura da fenda marginal e 2- morfologia da margem da cerâmica (sobre-contorno, sub-contorno ou fratura). A avaliação mostrou que não houve diferença na espessura da fenda marginal entre as áreas oclusal e proximal. Os maiores defeitos da cerâmica foram observados na face oclusal, provavelmente devido àforma mais complexa desta face. A espessura da fenda marginal variou entre 46 e 57 ìm. Concluiu-se que a habilidade do técnico tem maior influência na adaptação marginal do que o sistema cerâmico utilizado.

van MEERBEECK et al. ${ }^{133}$, em 1992, avaliaram, in vivo, mediante a utilização de réplicas, a adaptação marginal de diferentes sistemas para a 
confecção de inlays estéticas por MEV, através da análise quantitativa auxiliada por computador. Trinta e duas inlays, classe II, foram confeccionadas em prémolares e molares com quatro sistemas e fixadas com seus respectivos agentes cimentantes: CEREC - Dicor MGM/Dicor MGM luting cement (Caulk-Dentsply); CEREC - Vita Porcelain (Vita)/Kulzer Microfil (Kulzer); CEREC - Vita Porcelain (Vita)/Duo Cement (Còltene); resina composta P-50 (3M Dental)/3M luting composite (3M Dental). Os pacientes foram moldados no baseline e após 06 meses e réplicas em resina epóxica foram feitas. A qualidade da adaptação marginal foi avaliada e os dados foram agrupados de acordo com os critérios pré-estabelecidos e submetidos àtestes estatísticos não paramétricos. Após 06 meses, contatou-se um significante decréscimo na qualidade marginal da interface inlay-cimento, indicando um severo desgaste do cimento resinoso. A inlay de resina composta P-50 mostrou a melhor adaptação marginal na interface inlay-cimento, provavelmente devido à taxa de desgaste semelhante entre a inlay e o cimento resinoso permitindo uma visão de continuidade. No entanto, a interface esmalte-cimento não mostrou-se superior quando comparada ao sistema CEREC - Vita Porcelain.

MOLIN; KARLSSON ${ }^{80}$, em 1993, acessaram in vitro e in vivo a adaptação interna e marginal de inlays confeccionadas por três sistemas cerâmicos e um em ouro. Vinte pacientes foram selecionados e tratados com uma inlay de ouro e três inlays cerâmicas dos sistemas CEREC CAD-CAM (Siemens); IPS Empress (Ivoclar Vivadent) e Mirage (Myron). Oitenta inlays foram cimentadas em 35 pré-molares e 45 molares, na mandíbula. Previamente 
à cimentação, a adaptação das inlays foi verificada através da interposição de um elastômero de baixa viscosidade entre a inlay e o modelo e, posteriormente, entre a inlay e o dente. Após a mensuração das discrepâncias nas regiões oclusal, axial e marginal (mesial ou distal) verificou-se que a melhor adaptação foi obtida pelas inlays de ouro na região oclusal (30 ìm, variando de 0 a 153 ìm). A pior adaptação foi obtida pelo sistema CEREC (195 ìm, variando de 59 a 391 ìm). As cerâmicas Mirage e IPS Empress não apresentaram diferenças estatisticamente significantes na adaptação. Os autores consideraram que a melhor adaptação obtida pelas inlays de ouro pode ter tido influência da terminação do preparo em bisel, o qual facilita um melhor acabamento do que a terminação em ombro, necessária às cerâmicas. Enfatizaram que a discrepância marginal aumenta o risco de desgaste do cimento, podendo levar à cárie secundária e descoloração. No entanto consideraram que espessura ideal de cimento exposto nas inlays de cerâmica ainda não foi reportada.

SJÖGREN ${ }^{119}$, em 1995, determinaram in vitro a adaptação interna e marginal de quatro sistemas cerâmicos após a cimentação. Cinqüenta prémolares receberam cavidades $\mathrm{MOD}$, as quais foram restauradas com as cerâmicas CEREC (Siemens), IPS Empress (Ivoclar-Vivadent), In-Ceram Spinell (Vita) e Celay (Mikrona). Após a silanização, todas as inlays foram fixadas com cimento resinoso (Kerr Porcelite Dual, Kerr). A análise em microscópio com 10X de aumento revelou que não houve diferença estatisticamente significante entre as cerâmicas com relação à adaptação gengivo-proximal. As inlays confeccionadas com o sistema IPS Empress apresentaram a melhor adaptação 
na face oclusal. Com relação a adaptação interna, o sistema Celay obteve o melhor resultado. Os autores relataram que a espessura de cimento aceitável para as restaurações cerâmicas cimentadas com cimento resinoso ainda não foi claramente definida.

SORENSEN; MUNKSGAARD $(a)^{121}$, em 1996, avaliaram in vitro a influência da utilização de diferentes sistemas adesivos na eliminação ou redução da fenda marginal em restaurações de cerâmica. Superfícies planas de dentina foram expostas nas superfícies proximais de molares humanos através de discos de lixa. Sobre estas superfícies planas, cavidades com 4,5 mm de diâmetro e 0,9 $\mathrm{mm}$ de profundidade foram preparadas. Um degrau interno foi confeccionado na intenção de criar um suporte para a inlay e permitir uma espessura interna de cimento de 0,2 mm. Após a moldagem da cavidade com silicona de adição, discos de cerâmica foram confeccionados e tratados com ácido fluorídrico e silano. Doze sistemas adesivos foram utilizados juntamente com o cimento resinoso Dual Cement (Vivadent) para a fixação dos discos de cerâmica nas cavidades. Seis discos de cerâmica foram utilizados para cada grupo. Após armazenagem em água, os dentes foram seccionados através da superfície proximal e analisados em microscópio (800 X). As fendas foram mensuradas em cinco pontos distribuídos pela parede pulpar. Nenhuma fenda foi observada entre a inlay cerâmica e o cimento resinoso, demonstrando a superioridade da adesão do cimento à cerâmica, quando comparado à dentina. Nenhum dos agentes dentinários testados foi capaz de impedir completamente a formação de fendas na interface dentina-cimento na cavidade pulpar. No 
entanto, não foi detectada a presença de fendas nas margens externas das restaurações, provavelmente devido à presença de superfícies livres que permitiram o relaxamento do estresse de contração nestas regiões. A dimensão média das fendas não foi estatisticamente diferente entre os sistemas. Este trabalho permitiu concluir que embora tenha havido redução das fendas com a utilização dos sistemas adesivos (21 a 92\% comparado ao grupo controle - sem adesivo), não foi possível eliminar completamente a formação de fendas causadas pela contração de polimerização. Salientaram que a sensibilidade pulpar pós-cimentação provavelmente ocorre devido aos fluídos presentes na fenda da interface dentina-cimento, os quais são submetidos à compressão durante as forças mastigatórias.

No mesmo ano, SORENSEN; MUNKSGAARD $(b)^{122}$, dando continuidade ao estudo citado anteriormente, procuraram verificar a influência de combinações entre sistemas adesivos e cimentos resinosos na redução da fenda formada entre a dentina e o cimento, na região da parede pulpar. Quatro cimentos resinosos foram associados à cinco sistemas adesivos durante a cimentação dos discos de cerâmica. Verificou-se uma redução das fendas em torno de 46 a 93\% quando comparou-se os grupos que utilizaram adesivos com o grupo controle (sem adesivo). A extensão da fenda mostrou-se dependente da combinação sistema adesivo e agente cimentante. Os agentes adesivos All Bond 2, Tenure e Gluma mostraram-se mais efetivos na redução da fenda do que os sistemas Syntac e Scotchbond MP. 
SULAIMAN et al. ${ }^{126}$, em 1997, avaliaram a adaptação marginal de três sistemas: In-Ceram (Vita), IPS Empress (Ivoclar-Vivadent) e Procera (Nobel Biocare). Um modelo mestre em forma de incisivo central foi confeccionado em liga metálica, sobre o qual cinco linhas verticais foram impressas para orientar os pontos a serem mensurados em microscópio digital. Após moldagem do modelo mestre e confecção das cerâmicas, estas foram avaliadas e os resultados estabelecidos. Uma desadaptação marginal de 62,77 e 82,88 ìm foi obtida para os sistemas IPS Empress e Procera, respectivamente. Estes valores foram considerados aceitáveis dentro do critério de discrepância marginal de até 120 ìm, previamente estabelecido. O sistema In-Ceram apresentou uma discrepância marginal de 160,66 ìm. Os autores ponderaram que os diferentes métodos de fabricação, os quais envolveram passos distintos, podem ter influenciado no resultado final e relataram que quanto maior o número de passos para a confecção da restauração, maior será a probabilidade de erros serem embutidos.

AUDENINO et al. ${ }^{6}$, em 1999, compararam a adaptação marginal de três sistemas cerâmicos: IPS Empress (Ivoclar-Vivadent) - cerâmica prensada; Colorlogic (Ceramco) - cerâmica convencional; e Celay (Vita) - cerâmica computadorizada. Um total de 20 pré-molares e 20 molares recém extraídos foram selecionados e divididos aleatoriamente em 4 grupos de 10 dentes (5 prémolares e 5 molares), os quais receberam preparos para as inlays cerâmicas (class II, MO). Todas as inlays foram condicionadas e silanizadas. O sistema adesivo Syntac Classic foi utilizado durante a fixação das peças com cimento 
resinoso (Dual Cement, Ivoclar-Vivadent). Os dentes foram seccionados no sentido mesio-distal, passando pelo centro da restauração, e a espessura do cimento foi avaliada em alguns pontos pré-selecionados, sob estereomicroscópio (100 X). Os resultados evidenciaram uma melhor adaptação média (interna e externa) para o sistema IPS Empress (53 \pm 21 ìm), seguido pelos sistemas Colorlogic $(85 \pm 32$ ìm) e Celay (129 \pm 11 ìm). A melhor adaptação marginal foi obtida pelo sistema Colorlogic ( $43 \pm 31$ ìm) e IPS Empress (45 \pm 15 ìm), seguido pelo sistema Celay (114 \pm 13 ìm). Entretanto, apenas os sistemas IPS Empress e Celay apresentaram o cimento homogeneamente distribuído ao longo de todo o preparo. Os autores consideraram que embora o valor ideal de adaptação das margens das restaurações cerâmicas ainda não tenha sido claramente definido, uma espessura de cimento uniforme entre $<50$ até 100 ìm pode ser considerada satisfatória. Consideraram que o sistema IPS Empress apresentou as melhores características para situar-se dentro destas condições. Consideraram que fatores como integridade marginal e força de união do sistema adesivo podem influenciar na longevidade das restaurações.

FRANKENBERGER et al. ${ }^{39}$, em 1999, avaliaram a influência da polimerização prévia de agentes adesivos dentinários na adaptação marginal e na resistência de união em restaurações estéticas diretas e indiretas. Para este estudo 260 terceiros molares livres de cárie foram selecionados. Discos de 2 $\mathrm{mm}$ de diâmetro foram cortados a partir do terço médio-coronal dos dentes e cavidades com formato cônico foram preparadas em cada disco. Sessenta cavidades foram preenchidas com resina composta direta (Tetric - Vivadent) 
utilizando cinco diferentes tipos de agentes adesivos de $3^{\circ}$, $4^{\circ}$ e $5^{\circ}$ geração. Nestes grupos os agentes adesivos foram fotoativados antes da inserção das resinas compostas. Outros 60 discos tiveram suas cavidades tratadas da mesma forma, com exceção da forma de fotoativação do agente adesivo. Dez discos tiveram suas cavidades restauradas sem o uso do agente adesivo, como controle negativo. Para as restaurações indiretas 130 discos foram usados. As cavidades foram tratadas da mesma forma que as restaurações diretas, com e sem a fotoativação prévia do agente adesivo. As cerâmicas do sistema IPS Empress foram condicionadas e silanizadas. $\mathrm{O}$ agente adesivo Heliobond foi aplicado na superfície interna dos discos de cerâmica e estes foram fixados com o cimento resinoso Variolink (Ivoclar-Vivadent) e fotoativados por 60 segundos pelos dois lados. Após armazenamento por 7 dias em água destilada, os espécimes foram submetidos a ciclagem térmica ( 5 e $55^{\circ} \mathrm{C} \times 1150$ ciclos). Réplicas foram confeccionadas e analisadas em microscópio $(40 \mathrm{X})$ para a mensuração da espessura da linha de cimentação. A seguir, o teste de resistência àtração (push-out) foi realizado na máquina de testes universal. Os resultados evidenciaram que quando os agentes adesivos foram fotoativados previamente à inserção dos materiais restauradores houve um aumento significativo da resistência à tração, para ambos os grupos de restaurações diretas e indiretas. Os espécimes que tiveram os agentes adesivos fotoativados previamente a inserção dos materiais restauradores apresentaram menor fenda marginal, quando comparado aos espécimes em que os agentes adesivos não foram fotoativados. No entanto, o espaço da linha de cimentação nos espécimes 
com fotoativação prévia foram significativamente maiores. Em geral, adesivos da terceira e quarta geração produziram forças de união mais elevadas que os adesivos de frasco único.

DIETSCHI; MOOR ${ }^{27}$, em 1999, investigaram in vitro a adaptação interna e marginal de inlays de resina composta e cerâmica submetidas à ciclagem mecânica e térmica. Cinqüenta e seis dentes receberam cavidades MOD (término em esmalte e dentina) e foram divididos em sete grupos de acordo com o material restaurador, sistemas adesivos e agentes cimentantes. Após a fabricação das inlays, estas foram jateadas com partículas de óxido de alumínio de 50 ìm. Adicionalmente as inlays de cerâmica foram condicionadas e silanizadas. Passadas 24 horas da cimentação, as inlays foram submetidas ao estresse mecânico (80 N a 1,5 Hz x 250.000 ciclos) e térmico $\left(5\right.$ e $\left.55^{\circ} \mathrm{C} \times 5.000\right)$. Completados os ciclos, as restaurações foram analisadas em MEV, mediante o uso de réplicas. Posteriormente, as unidades restauradas foram seccionadas no sentido M-D para a confecção de novas réplicas e análise da adaptação interna. A porcentagem de margens contínuas em esmalte variou de 85 a 98\%, sem diferença estatisticamente significante entre os sistemas. A adaptação marginal em dentina variou de 63,3\% (In-Ceram - Panavia) a 96,1\% (Duceram LFC Panavia). Não houve diferença estatística significante entre os sistemas quanto a adaptação marginal em esmalte. A adaptação interna variou de 32,1\% (Tetric - Variolink) a 87\% (Duceram LFC - Panavia). Os autores ressaltaram que a rigidez do material restaurador (cerâmica x resina) não influenciou na qualidade da adaptação das inlays, não tendo sido observada diferença estatística entre as 
inlays de resina composta e de cerâmica em termos de adaptação interna ou marginal. As inlays confeccionadas com a cerâmica Duceram LFC e cimentadas com Panavia obtiveram uma adaptação superior às cimentadas com Variolink, provavelmente em função do módulo de elasticidade mais baixo do cimento resinoso Panavia.

HAHN et al. ${ }^{50}$, em 2000 , avaliaram o efeito da polimerização prévia de agentes adesivos dentinários na adaptação e integridade marginal de inlays cerâmicas. Sessenta terceiros molares foram aleatoriamente distribuídos entre 4 grupos. Em cada dente, cavidades MOD padronizadas foram preparadas utilizando uma turbina acoplada a um paralelômetro. A largura de $2 \mathrm{~mm}$ foi estabelecida e as margens cavitárias foram situadas em esmalte, $1 \mathrm{~mm}$ acima da junção amelo-dentinária. Todos os grupos foram restaurados com inlays de cerâmica (IPS Empress) usando um cimento resinoso híbrido (Variolink Vivadent). No grupo I o esmalte foi condicionado com ácido fosfórico a $37 \%$ e tratado com o sistema adesivo (Syntac Classic e Heliobond). Este grupo serviu como controle, sem fotoativação prévia do sistema adesivo, de acordo com as instruções do fabricante. No grupo II, as inlays foram cimentadas usando os mesmos materiais do grupo I, porém com fotoativação do sistema adesivo, previamente à cimentação. No grupo III, o agente dentinário Syntac Classic foi utilizado sem o Heliobond, sem fotoativação prévia. No grupo IV utilizou-se o sistema adesivo Prime \& Bond 2.0, sem fotoativação prévia do adesivo. A adaptação das inlays foi verificada antes e após a cimentação, através da mensuração da discrepância horizontal sob exame em microscópio ótico (40 X). 
Os espécimes foram armazenados em saliva artificial por 80 dias a $37^{\circ} \mathrm{C}$. Subseqüentemente, os espécimes foram imersos em solução de fucsina básica a $0,5 \%$ por 24 horas a $37^{\circ} \mathrm{C}$. Os grupos II e IV, com fotoativação do adesivo previamente àcimentação das inlays, mostraram menor penetração de corante, mas revelaram uma espessura da linha de cimentação significantemente mais alta. Este fato foi associado à maior espessura da camada de adesivo fotopolimerizado.

ESQUIVEL-UPSHAW et al. ${ }^{32}$, em 2001, compararam in vitro a resistência à fratura de inlays confeccionadas em metal-cerâmica (Goldtech + Ceramco) e em cerâmica pura (IPS Empress), bem como, avaliaram a influência do grau de divergências das paredes circundantes e da extensão da fenda marginal na resistência à fratura das inlays. Sessenta inlays foram confeccionadas, sendo 30 de cada grupo, os quais foram subdivididos de acordo com o grau de divergência das paredes (5, 10 e 20\%). A desadaptação das margens foi analisada em microscópio (30 X). Após a fixação com cimento de ionômero de vidro (Protec CEM), as inlays foram armazenadas em água por duas semanas e então submetidas àfratura na máquina de testes universal. As inlays do sistema IPS Empress foram significantemente mais resistentes à fratura, provavelmente devido ao baixo módulo de elasticidade do metal usado para suportar a cerâmica do outro grupo. A divergência de $5^{\circ}$ das paredes circundantes gerou aumento significativo de resistência à fratura, quando comparado à $20^{\circ}$. Nenhuma relação foi observada entre a largura da fenda marginal e a resistência àfratura das inlays. 


\section{4 - AGENTES DE CIMENTAÇÃO}

O sucesso das restaurações indiretas, principalmente das restaurações cerâmicas, depende primordialmente dos agentes cimentantes, o qual é responsável pela efetiva adesão entre a inlay e a estrutura dentária, e pela qualidade da adaptação marginal ${ }^{91}$. Os cimentos resinosos começaram a ser utilizados na década de 80, com a introdução das pontes de Maryland e tiveram as suas indicações ampliadas na década de 90, com a expansão do uso das restaurações em cerâmica pura ${ }^{11}$.

Os cimentos resinosos são divididos em três grupos, de acordo com o modo de ativação: - quimicamente ativados - indicados para a fixação das pontes de Maryland e de pinos intra-radiculares; - fotopolimerizados - para a fixação de facetas; - dualmente ativados - para a fixação de inlays, onlays e coroas em cerâmica pura. Os cimentos resinosos duais apresentam como vantagens o controle do tempo de trabalho e a possibilidade de permitir uma adequada polimerização nas áreas não atingidas pela luz. Os cimentos resinosos duais possuem componentes peróxido-amina para a polimerização química e o fotoiniciador, conforoquinona, para a polimerização por luz. Geralmente eles são compostos pelo sistema do monômero dimetacrilato a exemplo do Bis-GMA, uretano dimetacrilato (UDMA), tri-etileno glicol dimetacrilato (TEGDMA), etc. E contém partículas inorgânicas que auxiliam na redução do coeficiente de expansão térmica, contração de polimerização, além de aumentarem a resistência ao desgaste ${ }^{67}$. 
Diversos trabalhos têm procurado investigar a resistência, grau de conversão, desgaste e resistência à tração dos cimentos resinosos disponíveis no mercado, no intuito de verificar as propriedades destes materiais e tentar prever o desempenho clínico, uma vez que o agente de cimentação é uma peça fundamental no sucesso da restauração indireta.

DIETSCHI et al. ${ }^{24}$, em 1990, avaliaram a resistência à fratura de inlays cerâmicas fixadas aos dentes com dois agentes cimentantes: cimento resinoso dual (Dicor, De Trey / Dentsply International) e cimento de ionômero de vidro (Aqua-Cem, De Trey / Dentsply International). Sessenta terceiros molares receberam preparos cavitários, MOD, e foram divididos em cinco grupos de acordo com os agentes de cimentação e os tipos de cerâmica utilizadas na confecção das inlays (Vitadur N, Vitadur N reforçada com partículas de óxido de alumínio e Ceramco II). Dez dentes foram mantidos hígidos para constituírem o grupo controle. Nos grupos que utilizaram o cimento resinoso, as inlays foram condicionadas com ácido fluorídrico a $40 \%$ por 3 minutos e silanizadas. O teste de resistência à fratura foi realizado em uma máquina de ensaios universal, por meio de uma esfera de $2 \mathrm{~mm}$ de diâmetro que foi pressionada no centro da face oclusal de cada amostra até a fratura. A maior resistência àfratura foi obtida nos dentes hígidos (362 kg), seguido pelos dentes restaurados com inlays de cerâmica Vitadur N, reforçadas com partículas de alumínio e fixadas aos dentes com cimento resinoso $(273,5 \mathrm{~kg})$. Mediante a análise das amostras em MEV foi possível observar que a adesão do cimento resinoso à cerâmica excedeu a adesão deste à dentina. A adesão do cimento resinoso ao esmalte excedeu a 
coesão do esmalte, resultando em microfratura deste. Verificou-se também a presença de falha adesiva entre o cimento de ionômero e a cerâmica, apesar da união deste ao esmalte e àdentina.

NOACK et al. ${ }^{86}$, em 1992, realizaram um estudo in vitro para avaliar o índice de desgaste sofrido pelos cimentos resinosos associados às restaurações cerâmicas. Os resultados evidenciaram uma taxa de desgaste 5 a 10 vezes maior quando os cimentos resinosos estavam expostos em fendas marginais largas (> 150 ìm) do que em fendas marginais estreitas (< 50 ìm). A viscosidade e tamanho de partículas dos cimentos testados não influenciaram no desgaste. Observaram ainda que o desgaste dos cimentos foi menor junto às restaurações de cerâmica sinterizadas (Duceram) do que nas fundidas (Dicor) ou prensadas (IPS Empress).

REES; JACOBSEN ${ }^{99}$, em 1992, avaliaram o estresse de contração gerado pelos cimentos resinosos ao redor de inlays, classe I, de resina composta e cerâmica, mediante um modelo de elemento finito. Espessuras de cimento de 100, 200 e 300 ìm foram estabelecidas. Verificaram que o maior estresse foi obtido em margens cujo cimento possuía alto valor de contração (7\%) associado à espessura de 300 ìm. As inlays de resina composta apresentaram menor estresse de contração e movimento das cúspides. Este fato esta provavelmente ligado ao maior módulo de elasticidade das cerâmicas, as quais, devido a maior rigidez, ao invés de absorverem, transferiram o estresse para a interface dente-cimento. No entanto, a flexão das cúspides foi 
reduzida com a redução da fenda marginal e valor da contração de polimerização do cimento. Salientaram, entretanto, que a flexão das cúspides foi menor nas restaurações indiretas do que nas restaurações confeccionadas pela técnica direta.

RUEGGEBERG; CAUGHMAN ${ }^{108}$, em 1993, testaram o grau de conversão de cimentos resinosos duais, quando submetidos a diferentes formas de ativação. As pastas base e catalisador foram misturadas sobre uma placa de vidro e receberam os seguintes tratamentos: - ausência de luz e - fotoativação por 60 segundos sobre uma matriz mylar. Um segundo grupo de amostras foi preparado e as amostras foram cobertas com um espaçador confeccionado em resina composta, com 1,5 $\mathrm{mm}$ de espessura. Este grupo recebeu os seguintes tratamentos: - fotoativação por 20 segundos e - fotoativação por 60 segundos. A avaliação do grau de conversão das pontes duplas de carbono (espectômetro infra-vermelho) foi feita nos tempos de 2, 5, 10, 30, 60 minutos e 24 horas após a mistura. Após análise dos resultados constatou-se que: o potencial de polimerização química e por luz dos cimentos variou de acordo com a marca comercial; a polimerização química foi significantemente menor que a polimerização por luz na maioria dos cimentos testados; a cura após 10 minutos foi semelhante a cura após 24 horas. Com relação aos cimentos fotoativados através do espaçador, verificou-se que o tempo de 60 segundos promoveu maiores valores de conversão que o tempo de 20 segundos, porém estes resultados não foram estatisticamente significantes. 
O'NEAL; MIRACLE; LEINFELDER ${ }^{88}$, em 1993, avaliaram 230 inlays e onlays de resina e cerâmica, colocadas em pacientes adultos, com a intenção de investigar a extensão da fenda marginal e o desgaste sofrido pelos agentes cimentantes. Foram utilizados dois sistemas cerâmicos (CEREC - Siemens e Cerinate - Den Mat) e duas resinas compostas (P-50 - 3M Dental e Brilliant Coltene) para a confecção das inlays. Seis agentes de cimentação resinosos foram usados para a fixação das restaurações, os quais diferiram no tamanho de suas partículas.

Após a cimentação (baseline) e nas avaliações de 6 meses, 01 e 02 anos, foram feitas moldagens para a obtenção de réplicas em resina epóxica para futura avaliação com $10 \mathrm{X}$ de aumento. Verificaram que houve uma considerável variação da extensão das fendas marginais das inlays, entre os diversos sistemas testados. Os seguintes valores médios de extensão da fenda foram reportados: Brilliant (112 ìm), P-50 (181 ìm), CEREC (169 ìm), e Cerinate (216 ìm). Para avaliação dos desgastes sofridos pelos cimentos, os pacientes foram moldados com silicona de adição nos períodos de 6 meses, 1 e 2 anos após a cimentação. Os cimentos com micropartículas apresentaram maior resistência ao desgaste do que os híbridos. Os autores atribuíram a intensidade dos desgastes sofridos pelos cimentos híbridos ao maior tamanho das partículas, responsáveis pela geração de estresse na matriz, trincando-a e deslocando as partículas maiores. 
KREJCl et al. ${ }^{64}$, em 1993, realizaram um estudo in vitro com o intuito de analisar o desgaste de inlays de cerâmica, do esmalte do dente antagonista e de agentes cimentantes. Para este estudo, cavidades clássicas de classe II foram preparadas em 24 molares superiores humanos e posteriormente restauradas com inlays de cerâmica. As inlays foram condicionadas com ácido, silanizadas e fixadas com cimentos resinosos do tipo dual. O estudo utilizou 4 grupos, a saber: grupo I - cerâmica de vidro fundido Dicor (Dentsply) polida e fixada ao dente com cimento de partículas finas (DC Inlay Cement/Dentsply); grupo II - cerâmica feldspática sinterizada Biodent (Dentsply) polida e fixada ao dente com DC Inlay Cement (Dentsply); grupo III - cerâmica de vidro prensada IPS Empress (Ivoclar), polida e fixada ao dente com Dual Cement - micropartículado (Vivadent); grupo IV - cerâmica de vidro prensada IPS Empress (Ivoclar), glazeada e fixada ao dente com Dual Cement - microparticulado (Vivadent). Posteriormente a cimentação, todos os espécimes foram submetidos a um teste que simulava 5 anos de função in vivo, expondo estas restaurações aos seguintes fatores: degradação química (solução aquosa de etanol a $75 \%$ a $37^{\circ} \mathrm{C}$ ); abrasão da pasta dental e escovação (carga de $2 \mathrm{~N}$ ); carga cíclica de mastigação (máximo de $49 \mathrm{~N}, 1,7 \mathrm{~Hz})$ e simultâneos ciclos térmicos $\left(5\right.$ a $55^{\circ} \mathrm{C}, 2$ minutos cada). As amostra foram analisadas em intervalos de tempo que correspondiam a 06 meses, 01 ano, 2,7 anos e 05 anos de uso clínico. Após análise estatística dos resultados, verificaram que o grupo I (vidro cerâmico Dicor) e o grupo II (cerâmica feldspática - Biodent) obtiveram resultado similar, com maior desgaste tanto da cerâmica quanto do esmalte do dente antagonista. 
Os grupos III e IV (cerâmicas prensadas - IPS Empress) mostraram valores de desgaste significantemente menores. Não houve diferença estatística quanto ao desgaste do esmalte do dente antagonista, entre o grupo da cerâmica polida (III) com o grupo da cerâmica glazeada (IV). Com relação aos cimentos, o de micropartículas sofreu menor desgaste do que o de partículas finas híbridas, mas esta diferença não foi estatisticamente significante.

WHITE; YU ${ }^{135}$, em 1993, salientaram que a resistência à compressão e à tração diametral são características importantes a serem avaliadas nos agentes cimentantes, uma vez que os cimentos mais resistentes promovem uma melhor distribuição de estresse e menor probabilidade de falhas quando sujeitos as forças de compressão e tração durante a mastigação. Em um estudo laboratorial os autores avaliaram a resistência àcompressão e àtração de onze cimentos a base de policarboxilato, resina composta e ionômero de vidro, tendo o cimento de fosfato de zinco como controle. Os testes ANOVA e Tukey revelaram que os cimentos resinosos, cimentos de ionômero de vidro convencional e cimentos de ionômero de vidro modificado por resina foram significantemente mais resistentes que o cimento de fosfato de zinco. O cimento resinoso Panavia apresentou excepcional resistência à compressão e a tração (168 e $40 \mathrm{MPa}$, respectivamente), comparáveis às resinas compostas para restauração.

MESAROS; EVANS; SCHWARTZ ${ }^{78}$, em 1994, procuraram determinar a influência do uso dos agentes adesivos dentinários no aumento da resistência à 
fratura da cerâmica Dicor fixada à dentina com cimentos resinosos. Para este estudo, foram utilizados 40 dentes bovinos os quais foram seccionados de forma a se obter amostras com $20 \mathrm{~mm}$ de comprimento, $5 \mathrm{~mm}$ de largura e $1 \mathrm{~mm}$ de espessura. Da mesma forma, foram construídas 60 amostras de cerâmica de vidro fundida (Dicor) com as mesmas dimensões. Vinte amostras de cerâmica constituíram o grupo controle (grupo I) e as demais foram cimentadas aos espécimes de dentina em duas diferentes formas. No grupo II, as amostras foram fixadas aos espécimes de dentina através do cimento resinoso dual Dicor. No grupo III, os espécimes de dentina foram primeiramente tratados com adesivo dentário Prisma Universal Bond 3 e, a seguir, as amostras de cerâmicas foram fixadas a estes com cimento resinoso dual Dicor. Os conjuntos foram então fotoativados durante 50 segundos e, após uma semana, foram termociclados (2 e $50^{\circ} \mathrm{C} \times 200$ ciclos). A seguir, usando-se a máquina de ensaios universal Instron, todos os conjuntos de amostras foram submetidos à fratura. Após o teste, observaram que o uso do adesivo dentinário usado previamente ao cimento resinoso aumentou significativamente a resistência à fratura das amostras de cerâmica. No grupo II, que não utilizou o adesivo dentinário, a maior parte das falhas ocorreu na interface dentina-cimento; já no grupo III, que utilizou o adesivo, $90 \%$ das amostras mostraram um tipo de fratura contínua através do conjunto cerâmica-cimento-dentina. Os autores concluíram que este tipo de fratura permitiu a transferência do estresse para a dentina, devido àunião. 
SHINKAI et al. ${ }^{115}$, em 1995, relataram que inúmeras vantagens foram obtidas com a introdução das restaurações indiretas em substituição æ̀s resinas diretas. No entanto, alertaram para a importância da adaptação marginal, uma vez que os cimentos resinosos têm mostrado pouca resistência ao desgaste. Mediante um estudo laboratorial, avaliaram a correlação entre a extensão da fenda marginal e o tipo do cimento nas características de desgaste dos agentes cimentantes em restaurações indiretas. Dois cimentos resinosos, Dual-Cement (microparticulado) e Twinlook Cement (híbrido) e um cimento de ionômero de vidro foram utilizados para a cimentação de inlays em molares humanos recém extraídos. Após cimentação, as amostras foram submetidas a um teste de desgaste sob forças mastigatórias simuladas (17 libras x 120 contatos/min. x 400.000 ciclos). O desgaste foi analisado em um "perfilômetro" e as dimensões das fendas foram traçadas. Contatou-se uma relação linear entre a dimensão da fenda marginal e o desgaste do cimento para o cimento de ionômero de vidro e para o cimento resinoso híbrido. O cimento resinoso microparticulado apresentou a maior resistência ao desgaste independentemente do tamanho da fenda marginal. Os autores reportaram que as partículas menores provavelmente transmitem menor estresse à matriz resinosa, resultando em menor indução de microfraturas. O cimento de ionômero de vidro apresentou o maior desgaste. Os resultados permitiram concluir que a redução da fenda marginal associada à escolha de um agente cimentante mais resistente ao desgaste são recomendados. 
Revisão de Literatura 57

KAWAI; ISENBERG; LEINFELDER ${ }^{59}$, em 1994, se propuseram a investigar a correlação entre o tamanho da fenda marginal e o tipo de cimento no mecanismo de desgaste, quando inlays cerâmicas foram submetidas ao estresse oclusal in vitro. Três cimentos resinosos contendo diferentes tamanhos de partículas foram utilizados para a cimentação de inlays (Dicor) fabricadas pelo sistema CAD-CAM. O espaço horizontal das fendas variaram de 50 a 400 ìm. Após a cimentação, as amostras foram armazenadas por 72 horas e polidas com lixas de papel de granulação 600. Posteriormente, as amostras foram colocadas numa máquina de desgaste por 56 horas, equivalente a 3 horas de escovação clínica. Os resultados mostraram que o cimento resinoso microparticulado apresentou desgaste significativamente menor que os cimentos híbridos. Foi constatada uma relação linear entre tamanho da fenda marginal e desgaste do cimento resinoso.

PEUTZFELDT ${ }^{91}$, em 1995, relatou que o sucesso das inlays de cerâmica e resina composta está diretamente relacionado ao cimento resinoso, o qual é responsável pela efetiva adesão entre a inlay e a estrutura dentária, e pela qualidade da adaptação marginal. As vantagens dos cimentos duais, mais comumente utilizados nestas situações, são garantir uma adequada polimerização em áreas profundas, reduzir a área de inibição e promover a cura em menor tempo. Mediante um estudo in vitro a autora determinou a quantidade de pontes duplas de carbono remanescentes e o conteúdo de carga em 8 marcas comerciais de cimentos, bem como, verificou a influência da fotoativação no desgaste e na quantidade de pontes duplas de carbono remanescentes. 
Após a investigação do grau de conversão, contagem de partículas inorgânicas e simulação de desgaste, verificou que quanto maior o grau de conversão menor quantidade de pontes duplas de carbono remanescentes, resultando em menor desgaste. Geralmente a fotoativação aumentou o grau de conversão e reduziu o desgaste dos cimentos duais. Enfatizou que uma maior quantidade de partículas de carga inorgânicas contribuiu na redução do desgaste, sendo este um critério fácil de ser acessado, facilitando a escolha do cimento.

MICHELINE; SCHERRER; RIJK ${ }^{79}$, em 1995, compararam a resistência à tração de inlays de ouro e cerâmica utilizando três agentes cimentantes: cimento resinoso, cimento de ionômero de vidro e cimento de fosfato de zinco. Quarenta e cinco cavidades com tamanho padrão foram confeccionadas na face vestibular de molares, sendo 23 com término em bisel para as inlays de ouro e 22 em ângulo reto para as inlays de cerâmica. As inlays de ouro foram fixadas com cimento de fosfato de zinco e com cimento de ionômero de vidro. As inlays de cerâmica foram fixadas com cimento resinoso e cimento de ionômero de vidro. Condicionamento ácido e silanização foram utilizados no grupo do cimento resinoso. Os resultados mostraram um aumento significativo de resistência à tração para as inlays de cerâmica fixadas com cimento resinoso. Os três grupos remanescentes não apresentaram diferença estatística.

GUZMAN; MOORE; ANDRES ${ }^{49}$, em 1997, compararam in vitro a resistência ao desgaste de agentes de cimentação com relação ao tamanho da fenda marginal de restaurações estéticas confeccionadas em resina composta 
(Concept-Ivoclar) e cerâmica (Ceramic-Vita). Esmalte bovino proveniente de incisivos centrais foram cortados com disco de diamante para produzir superfícies planas $(10 \times 3 \times 3 \mathrm{~mm})$, as quais foram unidas ao material restaurador, confeccionado nas mesmas dimensões. Os espécimes dos materiais restauradores situavam-se no meio de dois blocos de esmalte, como um sanduíche, unido aos blocos de esmalte pelos agentes cimentantes. Três cimentos resinosos: Variolink (Ivoclar-Vivadent); Vita-Duo (Vita) e Enforce (Dentsply/Caulk); e um cimento de ionômero de vidro Duet (GC America) foram utilizados. Faixas metálicas nas dimensões de $240 \pm 30$ ìm, $150 \pm 30$ ìm e $60 \pm$ 30 ìm foram colocadas entre os blocos de esmalte e o material restaurador durante o preenchimento com o agente cimentante para padronizar o tamanho das fendas. Concluída a cimentação, as superfícies foram polidas com lixa com granulação 600 para promover uma superfície uniforme. Todos os espécimes foram submetidos à ciclagem térmica $\left(8 \mathrm{a} 48^{\circ} \mathrm{C} \times 2.500\right.$ ciclos $)$ e à 3 horas de escovação simulada. Dois pontos foram aleatoriamente escolhidos para serem avaliados em microscópio com $400 \mathrm{X}$ de aumento para verificação do desgaste vertical. Após análise estatística dos resultados verificou-se um significante aumento do desgaste dos cimentos à medida que a fenda aumentava. Constatou-se que o desgaste dos cimentos ocorreu mesmo nas fendas menores, porém em menor intensidade. $\mathrm{O}$ cimento de ionômero de vidro foi o material a sofrer o menor desgaste, no entanto, este resultado pode ter sido influenciado pela absorção de água do material. Em geral os cimentos sofreram maior perda de massa vertical junto as restaurações de cerâmica do que de 
Revisão de Literatura 60

resina composta. Consideraram que os cimentos resinosos aumentam a resistência da restauração cerâmica, uma vez que promove a união da restauração cerâmica à estrutura dentária, transferindo o estresse externo para os tecidos internos do dente, reduzindo a concentração de estresse na interface dente-restauração.

Em 1997, GROTEN; PRÖBSTER ${ }^{47}$, com a intenção de estudar a influência dos agentes cimentantes na resistência à fratura de coroas de cerâmica pura, utilizaram 120 coroas de cerâmica (IPS Empress - Ivoclar) com tamanhos padronizados, as quais foram cimentadas em modelos metálicos confeccionados de maneira a simular um incisivo central superior com proporções originais. As 120 coroas foram divididas em 6 grupos de 20 amostras, que variaram nas condições de cimentação descritas a seguir: grupos A e B - cimento de fosfato de zinco; grupos C e D - cimento de ionômero de vidro e grupos $E$ e $F$ - cimento resinoso. Para os grupos $B, D, E$ e $F$, as superfícies internas das coroas foram condicionadas com ácido fluorídrico a 5\% por 60 segundos, silanizadas e pinceladas com agente adesivo fotopolimerizável. Para o grupo F, foi realizado adicionalmente o condicionamento da superfície metálica dos modelos previamente àcimentação, com o intuito de promover a adesão do metal à cerâmica, simulando a adesão da cerâmica à estrutura dentária. Para isto, foi utilizado o sistema de condicionamento (Robatec - ESPE). Após a cimentação e o armazenamento por 48 horas, as amostras foram submetidas àcarga de compressão axial, por meio de uma esfera, aplicada sobre a superfície incisal com angulação de $45^{\circ}$, à 
Revisão de Literatura 61

velocidade de $0,5 \mathrm{~mm} / \mathrm{min}$, em uma máquina de ensaios universal. Após a análise estatística dos resultados, verificaram que houve um aumento significante de resistência à fratura para as coroas que utilizaram os cimentos resinosos (grupos E e F). Os grupos que utilizaram os cimentos de ionômero de vidro e de fosfato de zinco obtiveram baixos valores de resistência à fratura, mesmo quando as superfícies internas das coroas foram tratadas previamente à cimentação. No entanto, uma diferença estatisticamente significante ocorreu entre o grupo $E$ e $F$, tendo o grupo $F$ revelado o dobro da resistência à fratura devido ao tratamento da superfície metálica dos modelos, sendo o único grupo a mostrar falhas coesivas nos testes de fratura.

LEEVAILOJ et al. ${ }^{68}$, em 1998, investigaram a influência de diversos agentes cimentantes na resistência à fratura de coroas totalmente cerâmicas, durante o período de armazenamento de 2 meses em solução salina. Cem prémolares humanos foram selecionados e preparados para receberem coroas totais - 50 In-Ceram (Vita) e 50 VitaDur Alfa (Vita). Cada sistema cerâmico teve seu grupo subdividido de acordo com o cimento utilizado: Fuji I (GC America); Fuji Plus (GC America); Vitremer (3M Dental); Advance (Caulk/Dentsply) e Panavia 21 (J. Morita). Apenas as coroas fixadas com o cimento resinoso (Panavia 21) tiveram as suas superfícies internas jateadas, condicionadas e silanizadas. Nenhum tratamento foi feito para os outros agentes cimentantes. As fraturas foram examinadas com lupa (15 X). Após dois meses, as coroas que permaneceram íntegras foram submetidas àforças compressivas até a fratura. Os resultados mostraram que, durante o período de armazenamento, apenas as 
Revisão de Literatura 62

coroas fixadas com o cimento Advance apresentaram fraturas (30\% nas coroas In-Ceram e 100\% nas coroas VitaDur Alfa). Sob ação de forças compressivas, as coroas In-Ceram foram significantemente mais resistentes (140 $\pm 21,5 \mathrm{~kg})$, independentemente do cimento usado. Já as coroas do sistema VitaDur Alfa apresentaram diferentes resultados, a depender do cimento utilizado, sendo 110,5 kg para o cimento Fuji I; 102,2 kg para o Panavia 21; 95,1 kg para o Fuji Plus e $86,6 \mathrm{~kg}$ para o Vitremer. Os autores consideraram que os cimentos influenciaram na resistência à fratura das coroas VitaDur Alfa, mas não das coroas In-Ceram.

PLATT ${ }^{94}$, em 1999, mediante uma revisão de literatura, considerou que os cimentos resinosos microparticulados e com alto conteúdo de partículas devem ser os preferidos por apresentarem menor desgaste, principalmente quando a face oclusal estiver envolvida. Salientaram que a habilidade dos cimentos resinosos em se unirem à estrutura dentária e à cerâmica aumenta a longevidade do conjunto. No entanto, chamou atenção para a necessidade do controle efetivo da umidade e contaminação quando a técnica adesiva for selecionada, devendo-se contra indicar o uso dos cimentos resinosos em situações clínicas desfavoráveis.

EL-MOWAFY; EL-BADRAWY ${ }^{31}$, em 1999, avaliaram a dureza Knoop de oito cimentos resinosos duais, submetidos à reação de polimerização dual ou química. Uma matriz circular com 2,5 mm de profundidade por $6 \mathrm{~mm}$ de diâmetro foi utilizada para a confecção dos espécimes. Após a mistura das 
pastas base e catalisadora, os cimentos foram inseridos na matriz e estocados a $37^{\circ} \mathrm{C}$, na ausência de luz. Para a polimerização dual, uma fotoativação por um tempo de 60 segundos foi utilizada. Adicionalmente, no intuito de verificar a influência do uso de espaçadores no grau de conversão dos cimentos, novos espécimes foram preparados através de incidência de luz sobre espaçadores de cerâmica com espessuras de 2,5 a 6 mm. A dureza Knoop foi verificada após os tempos de armazenagem de 01 hora, 01 dia e 01 semana. Os resultados mostraram que houve aumento da dureza para todos os cimentos com o tempo de armazenagem, para ambas as formas de polimerização. Para a polimerização química, o cimento resinoso Enforce (Dentsply) apresentou a maior dureza. Geralmente a dureza foi menor quando a polimerização química era usada sozinha. A dureza dos espécimes polimerizados sob espaçadores apresentou um decréscimo gradual à medida que aumentava-se a espessura dos espaçadores. No entanto, este decréscimo variou de acordo com o cimento testado. Significante redução na dureza dos espécimes foi observada quando espaçadores acima de 2 a $3 \mathrm{~mm}$ foram utilizados. Os autores salientaram a importância da fotoativação pelas faces proximais, vestibular e lingual, durante a cimentação de inlays e onlays, com o objetivo de compensar a redução da intensidade de luz devido a distância entre a parede gengival e a face oclusal.

ABDALLA; DAVIDSON ${ }^{1}$, em 2000, realizaram um estudo in vitro para avaliar a eficácia de três agentes cimentantes na prevenção da deterioração marginal em inlays cerâmicas. Quarenta e oito pré-molares receberam um preparo cavitário tipo MOD para futura cimentação de inlays cerâmicas IPS 
(Ivoclar-Vivadent) mediante o uso de um cimento resinoso Variolink (IvoclarVivadent); um compômero Dyract-Cem (Dentsply/DeTrey) e um cimento de ionômero Ketac-Cem (Espe). Concluída as cimentações, os dentes restaurados foram armazenados em água a $37^{\circ} \mathrm{C}$ por duas semanas. Metade dos dentes de cada grupo foi submetida à ciclagem térmica ( 5 a $55^{\circ} \mathrm{C} \times 5.000$ ciclos) e posteriormente à ciclagem mecânica $(12,5 \mathrm{~kg} \times 4.000$ ciclos). Durante a ciclagem mecânica, os dentes foram cobertos com esmalte de unha até $1 \mathrm{~mm}$ das margens da restauração e embebidos em solução de azul de metileno a $2 \%$. Réplicas em resina epóxica foram feitas para análise em MEV. Os resultados evidenciaram que sem a ciclagem não foram observadas diferenças entre os três cimentos testados, no entanto, após ciclagem o cimento ionomérico apresentou o maior grau de infiltração de corante. Os autores consideraram que devido a maior flexibilidade dos cimentos Variolink e Dyract-Cem, estes suportaram melhor as cargas oclusais que eram transferidas para eles através do alto módulo de elasticidade das cerâmicas. Também ressaltaram que devido à alta viscosidade dos cimentos de ionômero, estes têm pouca habilidade em molhar a superfície da cerâmica condicionada pelo ácido; já os outros cimentos possuem o monômero resinoso hidrofílico HEMA que melhora esta capacidade de molhamento.

CAUGHMAN; CHAN; RUEGGEBERG ${ }^{17}$, em 2001, realizaram um estudo in vitro com o intuito de avaliar o grau de conversão de seis marcas comerciais de cimentos resinosos duais: Calibra (Dentsply-Caulk), Choice (Bisco), Insure (Cosmedent), Lute-It ! (Jeneric Pentron), Nexus (Kerr) e Variolink II (Ivoclar- 
Vivadent), sob diferentes condições de polimerização (foto - dual e química). Todos os grupos, a exceção dos quimicamente polimerizados, sofreram a fotoativação sob uma matriz mylar ou sob uma pastilha de cerâmica de $3 \mathrm{~mm}$ de espessura. Após 7 dias de armazenamento na ausência de luz, os espécimes tiveram o grau de conversão determinados mediante 0 uso de um espectroscópio de luz infra-vermelha. Os resultados mostraram que um alto nível de conversão foi obtido na polimerização dual, o qual foi superior a polimerização foto. No entanto, nenhum dos seis cimentos avaliados mostrou a mesma taxa de conversão para todas as formas de polimerização testadas. Este estudo concluiu que os cimentos testados podem ser utilizados na forma dual com sucesso sob restaurações cerâmicas com até $3 \mathrm{~mm}$ de espessura. A taxa de conversão média dos cimentos foi superior à das resinas compostas, provavelmente devido a menor viscosidade destes materiais, o que facilita a difusão dos radicais livres aumentando o potencial de conversão. O cimento Variolink II apresentou alta taxa de conversão na polimerização dual sob $3 \mathrm{~mm}$ de cerâmica. No entanto, na ausência de luz apenas $62 \%$ de conversão foi obtida.

LEE; UM ${ }^{67}$, em 2001, investigaram a influência do uso de espaçadores de cerâmica com 1, 2 e 4 mm de espessura na cura de cimentos resinosos duais através da polimerização química e foto. Mediante o uso de diferentes marcas comerciais de cimentos resinosos duais, verificaram que estes diferiram entre si quanto à sensibilidade à luz e à ativação química. A utilização de espaçadores de cerâmica para a polimerização destes cimentos resultou em redução da 
intensidade de luz devido àabsorção, desvio e reflexão da luz. A atenuação da intensidade da luz está relacionada à cor e a capacidade de reflexão e transmissão da luz pela cerâmica. A fotopolimerização dos cimentos através de espaçadores de 1 e $2 \mathrm{~mm}$ resultou numa polimerização quase que completa após o tempo de exposição de 40 segundos. A reação de cura foi atingida basicamente pela ação da luz. Consideraram que, embora não se possa excluir completamente a importância da polimerização química, a velocidade de polimerização pela fotoativação, 5 a 20 vezes maior, faz com que este se transforme no fator primário na polimerização dos cimentos. Com a utilização de espaçadores de $4 \mathrm{~mm}$, o tempo de exposição de luz tornou-se de fundamental importância e concluíram que 40 segundos é um tempo insuficiente para compensar a atenuação de luz ocorrida com $4 \mathrm{~mm}$ de espaçador.

BRAGA; CESAR, GONZAGA ${ }^{11}$, em 2002, mediante um estudo in vitro, investigaram a dureza, resistência flexural e o módulo flexural dos cimentos Enforce (Dentsply), Rely X (3M), Variolink II (Ivoclar-Vivadent) e C \& B (Bisco), os quais tiveram a fotoativação feita através de um espaçador de resina de 2 $\mathrm{mm}$ de espessura. Verificaram que apenas o cimento Enforce obteve valores similares entre a ativação dual e química. O cimento Rely X obteve o maior valor de resistência flexural na ativação dual, quando comparado aos outros cimentos. O cimento Variolink II não apresentou uma polimerização adequada quando só a polimerização química foi usada. No entanto, apresentou resistência flexural similar para as ativações foto e dual. Os autores consideraram que o bom desempenho obtido pela ativação dual, apesar da pequena quantidade de 
componentes químicos, pode ser atribuído àgrande quantidade de partículas de carga, as quais elevam a resistência flexural e dureza, além da presença do uretano dimetacrilato (UEDMA), que, por ter menor viscosidade facilita a migração de radicais livres e aumenta o grau de ligações cruzadas.

\section{5 - ESTUDOS DE AVALIAÇÃO CLÍNICA}

A avaliação das propriedades mecânicas dos materiais restauradores, mediante a realização de estudos laboratoriais, permite que estes sejam enquadrados nas normas da ADA (American Dental Association) ou ISO (International Standard Organization) e possam ser aprovados após terem sido comprovadas as características básicas necessárias para o bom desempenho destes materiais. Entretanto, somente os estudos clínicos são capazes de avaliar o comportamento, a curto e longo prazo, destes materiais na cavidade bucal.

As pesquisas laboratoriais, por mais fidedignas que sejam, não conseguem fornecer dados concretos sobre o comportamento do material restaurador, quando expostos às condições da cavidade bucal. Os exames clínicos são os instrumentos de medição para a pesquisa clínica, da mesma forma que as balanças, microscópios e máquinas de testes universais são para os estudos laboratoriais ${ }^{109}$. A utilização de critérios padronizados e simplificados facilita a avaliação pelos examinadores e favorece o grau de concordância entre 
eles. Além disto, a utilização de critérios que são reconhecidos internacionalmente, a exemplos dos critérios USPHS e CDA, torna possível a comparação dos dados obtidos entre diferentes estudos.

Diversos autores têm relatado na literatura, o comportamento clínico de inlays e onlays de cerâmica, confeccionadas com diferentes sistemas, ao longo dos anos.

KREJCI; KREJCI; LUTZ ${ }^{65}$, em 1992, avaliaram o comportamento clínico da cerâmica IPS Empress após 1,5 anos. Dez inlays foram colocadas em dez pacientes na região de pré-molares. Todas as cavidades tiveram as margens localizadas em esmalte e as inlays foram fixadas com cimento resinoso dual (Dual Cement, Vivadent). No baseline e após 1,5 anos todas as dez restaurações foram examinadas, mediante o critério USPHS, e foram moldadas com silicona de adição para terem as suas réplicas examinadas em MEV. Cinco pontos foram aleatoriamente selecionados para a análise da interface. No baseline a adaptação marginal foi considerada excelente, mas significante desintegração da interface inlay-cimento foi observada após 1,5 anos, indicando uma menor resistência do cimento resinoso do que da cerâmica e do esmalte, o que possibilitou o desgaste deste, apesar da fenda marginal preenchida pelo cimento ter sido considerada pequena (< que 100 ìm). $\mathrm{O}$ autor enfatizou que 0 módulo de elasticidade da cerâmica é muito alto, resultando na transferência das forças oclusais para as margens da restauração e sugeriu que materiais com módulo de elasticidade próximo ao da dentina devem ser desenvolvidos. A 
análise em MEV foi considerada como um importante instrumento para a avaliação das margens. A taxa de sucesso clínico foi de $100 \%$.

STUDER et al. ${ }^{125}$, em 1992 e posteriormente em 1996, avaliaram o comportamento clínico de 130 restaurações de cerâmica IPS-Empress pelo período de 18 meses e 02 anos. Trinta e seis pacientes foram selecionados e receberam um total de 25 onlays e 105 inlays, sendo que 40 inlays envolviam 3 superfícies (31\%), 38 inlays 2 superfícies (29\%) e 27 inlays apenas 1 superfície (21\%). Oitenta restaurações foram cimentadas em molares (62\%) e cinqüenta em pré-molares $(38 \%)$, sob isolamento absoluto, utilizando quatro agentes cimentantes resinosos: Panavia TC (Kuraray), Porcelite (Kerr), Dicor LA (Dentsply) e VP 891 (Ivoclar). As restaurações foram avaliadas com espelho e sonda e, adicionalmente, por meio de radiografias interproximais e fotografias intra-orais, mediante o critério USPHS modificado, por dois examinadores. As primeiras doze restaurações foram avaliadas em conjunto para a calibração dos examinadores. Na presença de desacordo, o menor escore era escolhido para classificar a restauração. Após análise estatística dos resultados mediante o teste de Kaplan-Meier, uma taxa de sucesso de 98\% foi estimada após 18 meses. Após dois anos, 3 restaurações falharam por fratura, resultando em uma taxa de sucesso de $97,5 \%$. As altas taxas de escores Alfa para cor, forma anatômica e textura de superfície indicaram a excelente característica estética deste material. 
Revisão de Literatura 70

HÖGLUND; DIJKEN; OLOFSSON ${ }^{53}$, em 1992, confeccionaram 118 inlays e onlays cerâmicas (Mirage-Chamaleon), as quais foram cimentadas em cavidades classe II, com dois diferentes tipos de cimentos, com o propósito de avaliá-las clinicamente por 02 anos. Cada paciente recebeu, em média, entre 2 a 4 inlays, sendo a metade cimentada com cimento resinoso dual (Mirage) e a outra metade, com cimento de ionômero de vidro (Fuji J., GC Dental Int.). As cavidades, em sua maioria, foram forradas com cimento de ionômero de vidro (Baseline, De Trey / Dentsply) e moldadas com silicona de adição (Provil, Bayer Dental). Todas as inlays a serem fixadas com cimento resinoso foram previamente tratadas com ácido fluorídrico a $5 \%$ e silanizadas. 0 esmalte das cavidades foi condicionado com ácido fosfórico a 40\% durante 20 segundos. Após a cimentação, as inlays foram submetidas à fotoativação por 60 segundos em cada face. Os dentes, nos as inlays foram fixadas com cimento de ionômero de vidro, tiveram as cavidades limpas com ácido poliacrílico a 40\%. As inlays foram examinadas por 2 dentistas. No grupo das inlays cimentadas com cimento resinoso, apenas uma inlay fraturou (2\%), e no grupo das inlays cimentadas com cimento de ionômero de vidro, 9 inlays (15\%) foram perdidas ou fraturadas. Os autores verificaram que ambos os cimentos obtiveram boa adesão ao dente, mas diferiram com relação à adesão à cerâmica. Concluíram que, devido ao caráter frágil das cerâmicas, é necessário o uso do cimento resinoso a fim de aumentar a sua resistência à fratura. Após avaliação clínica de 02 anos, verificaram uma boa resistência ao desgaste e boa adaptação marginal. 
SJÖGREN et al. ${ }^{118}$, em 1992, examinaram 205 inlays de cerâmica do sistema CEREC CAD-CAM, (Siemens), confeccionadas por 8 dentistas na Suécia em 72 pacientes. Foram realizadas 115 inlays na região dos molares e 90 na região dos pré-molares. Estas foram avaliadas por três examinadores após 12 e 24 meses pós-cimentação, pelo critério CDA e foram consideradas excelentes com relação à cor - 57\%; à superfície - 26\%; à forma anatômica $55 \%$ e à integridade marginal - $83 \%$. Os autores consideraram que o maior problema das inlays de cerâmica estava relacionado àrugosidade de superfície e recomendaram maior atenção no polimento.

STENBERG; MATSSON ${ }^{123}$, em 1993, realizaram um estudo clínico com o objetivo de avaliar 25 inlays de cerâmica do sistema Dicor (De Tray/Dentsply) em cavidades de classe II, por um período de dois anos. Ao mesmo tempo, 25 restaurações de amálgama foram realizadas pelo mesmo operador em cavidades de tamanho semelhantes. As inlays foram fixadas nas cavidades com cimento de ionômero de vidro (Fuji I, GC Dental), sob isolamento relativo. As restaurações foram avaliadas após 6, 12 e 24 meses, de acordo com o critério USPHS. Após 24 meses, 2 inlays haviam fraturado. As 23 inlays que permaneceram demonstraram bom desempenho de cor, forma anatômica e integridade marginal. Das 25 restaurações de amálgama colocadas nenhuma fraturou, porém 2 foram trocadas devido à presença de cárie secundária. Os autores alertaram que, devido a possibilidade de fraturas, deve-se ter cuidado com as forças oclusais excessivas. 
van DIJKEN ${ }^{131}$, em 1994, avaliou, por um período de 06 anos, 100 inlays e onlays de resina composta (Brilliant DI, Còltene) fixadas com cimento resinoso dual (Brilliant Duo Cement). As restaurações foram avaliadas após 1-2 semanas (baseline) e a cada 06 meses, até completar 06 anos. Foi utilizado o critério USPHS modificado para análise da forma anatômica, adaptação marginal, cor, manchamento marginal, textura da superfície e presença de cárie secundária. Moldagens em alginato eram realizadas em associação ao exame direto, para futura avaliação do modelo em gesso em estereo-microscópio com 15 vezes de aumento. Após 06 anos 90\% das inlays mostraram boa adaptação marginal. Pela análise indireta observou-se um pequeno desgaste da inlay e do cimento, em níveis semelhantes e quase igual ao esmalte, tendo sido considerado favorável o desempenho das inlays e onlays de resina composta, nesse período de observação.

NOAK; ROULET ${ }^{87}$, em 1994, realizaram um estudo clínico com o propósito de avaliar 260 inlays fabricadas pelo sistema Dicor (Dentsply), em preparos de classe I e II, por um período de 04 anos. Foram detectadas $13 \%$ de falhas, para as quais os autores consideraram como possíveis causas: esmalte insuficiente nas caixas proximais, dentes tratados endodonticamente e cavidades muito amplas.

THORDRUP; ISIDOR; HÖRSTED-BINDSLEV ${ }^{128}$, em 1994, avaliaram, por um período de um ano, a performance clínica de inlays confeccionadas com resina composta e cerâmica. Foram selecionados 37 pacientes que 
apresentavam boa higiene oral e ausência de problemas oclusais, perfazendo um total de 58 dentes. Todas as cavidades eram supra-gengivais, com profundidade média da caixa oclusal de 1,5 a 2,0 mm. As áreas mais profundas foram cobertas com cimento de hidróxido de cálcio e cimento de ionômero de vidro fotopolimerizável, quando era necessário regularizar paredes internas. Os dentes foram restaurados com 4 sistemas: cerâmica computadorizada (CEREC, Vita-Blocks); cerâmica aluminizada (Vitadur N, Vita); resina composta para uso direto (Brilhant D.I, Coltène); e resina composta para uso laboratorial (Estilux, Kulzer). As cavidades foram moldadas com silicona de adição e as restaurações provisórias foram cimentadas com cimento sem eugenol. As inlays de cerâmica foram condicionadas com ácido fluorídrico e tratadas com silano, conforme as instruções do fabricante. Todas as cavidades tiveram as paredes de esmalte condicionadas com ácido fosfórico, sendo a dentina exposta tratada com o adesivo dentinário Gluma 2 e 3 (Bayer Dental). Após a e fixação das inlays com o cimento resinoso CEREC Dual Cement (Kulzer), os excessos foram removidos e procedeu-se a fotoativação por 3 minutos. As inlays foram avaliadas clínica e radiograficamente, nos períodos do baseline, 06 meses e 01 ano após a cimentação. Das 58 inlays colocadas, apenas uma, Vitadur N, fraturou após um ano e uma inlay, Brilhant D.J., foi trocada devido à presença de cárie secundária. A adaptação marginal oclusal das inlays situou-se em torno de 50 a $80 \%$, sendo considerada excelente. No entanto, estes valores foram menos favoráveis com relação à adaptação marginal proximal, em torno de 19 a 44\%. As inlays de cerâmica do sistema Vitadur $\mathrm{N}$ exibiram a melhor morfologia e cor, 
porém maior fragilidade. A pior textura de superfície foi observada nas inlays Estilux, sendo esta diferença estatisticamente significante. Houve 13 casos de sensibilidade pulpar, mas sem correlação com os sistemas utilizados. Após um ano de observação, os autores concluíram que todos os sistemas apresentaram desempenho clinico satisfatório.

GLADYS et al. ${ }^{45}$, em 1995, avaliaram o comportamento clínico de 32 inlays, classe II, cimentadas em molares e pré-molares, utilizando três tipos de cerâmicas fabricadas pelo sistema CEREC CAD-CAM (Siemens) e uma resina composta P-50 (3M Dental). Este sistema de cerâmica computadorizada foi introduzido no mercado em 1985 pela empresa Siemens, na Alemanha.

Após três anos, todas as restaurações foram avaliadas mediante o uso de espelhos e sondas. Nenhuma cárie recorrente foi identificada no exame clinico ou radiográfico. O melhor escore em adaptação marginal, observada em exame clínico e em MEV, foi obtido pelas inlays de resina P-50. A provável explicação para esta aparente melhora da adaptação marginal observada entre a inlay de resina composta e o cimento resinoso foi devido à similaridade de desgaste dos dois materiais. Com relação àadaptação marginal entre o esmalte e o cimento resinoso, este grupo apresentou a maior porcentagem de desgaste. Os autores concluíram que a falta de resistência ao desgaste dos cimentos resinosos foi a principal causa da deterioração marginal. Consideraram ainda que a análise em MEV é um eficiente auxiliar no diagnóstico da integridade marginal, no entanto, enfatizaram que o exame clínico é também necessário 
para a avaliação da integridade marginal e determinação da necessidade ou não da troca de restaurações. Apesar do desgaste do agente cimentante a taxa de sucesso foi de $100 \%$.

TIDEHAG; GUNNE ${ }^{130}$, em 1995, realizaram um estudo clínico para avaliar a performance de 62 inlays/onlays, do tipo prensada IPS-Empress (Ivoclar), utilizando o critério CDA, em 18 pacientes. Estes foram avaliados por dois examinadores, aproximadamente 07 e 26 meses após a fixação das restaurações com cimento resinoso (Cem-Kit, Ivoclar). Foram verificadas a superfície, cor, forma anatômica e integridade marginal. Nesse período apenas uma inlay fraturou. As inlays mostraram excelente estabilidade de cor (73\%), excelente textura de superfície (100\%), excelente forma anatômica (82\%), excelente integridade marginal (84\%) e apenas 13\% mostraram evidência de valas na interface dente/restauração.

ISIDOR; BRONDUM ${ }^{55}$, em 1995, avaliaram a performance clínica de 25 inlays cerâmicas (Mirage, Myron International Inc.) por um período de 20 a 57 meses. Estas inlays foram confeccionadas sobre o modelo refratário, obtido a partir do modelo original. As 10 primeiras inlays foram fixadas com cimento resinoso fotopolimerizável, enquanto as 11 inlays restantes foram fixadas com cimento resinoso de presa dual. Foram detectadas 10 falhas por fratura dentre as 25 inlays analisadas. Dentre as falhas, 8 pertenciam ao grupo das inlays fixadas com cimento fotopolimerizável e apenas 2 pertenciam ao grupo das inlays fixadas com cimento de presa dual, estabelecendo uma diferença 
estatisticamente significante. Os autores revelaram que as inlays fraturadas normalmente possuíam espessura inferior a 1,5 e 2,0 mm. E ressaltaram a importância do uso do cimento de presa dual como forma de complementar a polimerização na ausência de luz.

REINELT et al. ${ }^{100}$, em 1995, avaliaram 96 restaurações (73 inlays e 23 onlays) confeccionadas com o sistema IPS Empress em 34 pacientes. As restaurações foram fixadas com o sistema adesivo Syntac (Ivovlar-Vivadent) e cinco agentes cimentantes: Tetric, Duo Cement, Variolink low, Variolink high e Variolink ultra. Os procedimentos operatórios foram realizados por quatro dentistas. As restaurações foram avaliadas mediante o critério USPHS no basline, após 06 meses, 01 e 02 anos. Três inlays falharam, sendo uma por problema endodôntico (pulpite) e duas por fratura coesiva. Os autores consideraram que o sistema IPS Empress, juntamente com o sistema adesivo Syntac, apresentaram um desempenho efetivo após dois anos, mesmo em dentes com grande destruição coronária.

FRIEDL et al. ${ }^{40}$, em 1996, confeccionaram 50 inlays com o sistema de cerâmica feldspática (Mirage II), as quais foram fixadas com cimento resinoso dual (Optec Universal Bonding) em 20 pacientes. Após dois anos as restaurações foram acessadas por dois examinadores, de acordo com o critério USPHS e também avaliadas em MEV. Após dois anos nenhuma cárie recorrente ou mudança de cor foi observada. O critério a apresentar maior número de escores "Bravo" foi integridade marginal, a qual foi associada ao desgaste do 
cimento resinoso, cuja perda de material situou-se em $37 \%$ no primeiro ano e $60 \%$ no segundo ano. Os autores consideraram que embora não tenham sido detectadas cáries recorrentes, o desgaste do cimento poderia ter gerado fraturas nas margens da cerâmica pela falta de suporte e acúmulo de placa nas margens, com conseqüente desenvolvimento de cáries. Estes autores enfatizaram a importância do uso da MEV na avaliação das fendas marginais. O desempenho clínico foi considerado excelente, com taxa de sucesso de $100 \%$.

QUALTROUGH; WILSON ${ }^{96}$, em 1996, realizaram um estudo clínico para avaliar o comportamento de 50 inlays de cerâmica feldspática (Mirage, Myron Int.). Um total de 21 inlays classe I e 29 inlays classe II foram fixadas com cimento resinoso Dual-Cure (Terec), sob isolamento absoluto, após condicionamento ácido do esmalte e uso de resina fluida. Após 03 anos, 8 restaurações falharam por fratura e uma por sensibilidade dolorosa. Os autores relataram que as falhas por fraturas poderiam ter tido um índice menor se um agente adesivo dentinário tivesse sido usado. As inlays que permaneceram foram consideradas satisfatórias. $O$ aspecto adaptação marginal obteve significante deterioração, apresentando o maior índice de escores "Bravo".

THONEMANN et al. ${ }^{127}$, em 1997, avaliaram 51 restaurações cerâmicas, IPS-Empress, no baseline e após 01 e 02 anos, mediante a utilização do critério USPHS modificado e análise em MEV. Doze pacientes, quatro homens e sete mulheres, com idades entre 25 a 35 anos que apresentavam boa higiene oral foram selecionados para este estudo. Cinqüenta e uma inlays foram colocadas 
em 31 molares e 20 pré-molares, sendo 14 classe I e 37, classe II. Após a remoção de cáries, as áreas socavadas foram protegidas com cimento de ionômero de vidro (Ketac Bond, ESPE) e as cavidades foram temporariamente restauradas com Protemp (ESPE) utilizando um cimento sem eugenol (Permagum, ESPE). A cimentação foi realizada sob isolamento absoluto utilizando o sistema adesivo Syntac Classic e cimento resinoso (Variolink, Ivoclar-Vivadent). As avaliações foram executadas por um avaliador que não estava envolvido com os procedimentos restauradores. Após dois anos nenhuma fratura ou cárie secundária foi observada. Oito restaurações (15,6\%) apresentaram pequena alteração de cor e quatro $(7,8 \%)$ revelaram descoloração marginal, recebendo escore "Bravo", mas sem necessidade de intervenção. Quatorze inlays $(27,5 \%)$ apresentaram escore "Bravo" para integridade marginal, sendo esta diferença estatisticamente significante quando comparada aos resultados obtidos no baseline. As avaliações realizadas em MEV suportaram os dados encontrados na avaliação clínica. A presença de fendas foram atribuídas ao desgaste do cimento resinoso. Este desgaste ocorreu em torno de $50 \%$ no primeiro ano e aumentou para 53\% no segundo ano. Os autores concluíram que apesar do desgaste do cimento resinoso, as restaurações apresentaram um excelente comportamento clínico após dois anos com uma taxa de sucesso de $100 \%$.

FRADEANI; AQUILIANO; BASSEIN ${ }^{36}$, em 1997, reportaram uma taxa de sucesso de 95,63\% após quatro anos e meio de avaliação de 125 inlays de cerâmica, IPS Empress, as quais foram colocadas em 29 pacientes, com idade 
média de 28,4 anos. Foram considerados como critérios de exclusão: pacientes com bruxismo, severa má-oclusão, pobre higiene oral ou alta incidência de cáries. Todas as restaurações tiveram as suas superfícies internas tratadas com ácido fluorídrico e silano. O sistema adesivo Syntac Classic (Ivoclar), juntamente com os cimentos Dual Cement (Ivoclar) e Variolink (Ivoclar) foram utilizados para a cimentação das inlays, sob isolamento absoluto. As avaliações foram feitas de acordo com o critério USPHS modificado. Adicionais radiografias e slides foram feitas. Quatro inlays falharam por fratura. Os autores observaram que o critério descoloração marginal obteve o maior índice de escores "Bravo" e consideraram que a descoloração e a integridade marginal estão interrelaciondas e ambas aumentaram com o tempo, apesar da descoloração marginal ter precedido a deterioração das margens.

SCHEIBENBORG et al. ${ }^{113}$, em 1998, compararam o comportamento clínico de inlays de cerâmica e resina composta pelo período de um ano, utilizando o critério USPHS. Setenta e uma inlays [24 de cerâmica $(33,8 \%)$ e 47 de resina composta $(66,2 \%)]$ foram colocadas em 45 pacientes com idade média de 35 anos. Os procedimentos restauradores foram realizados por sete estudantes, sob a supervisão de um dentista experiente. Foi utilizado o sistema IPS Empress (Ivoclar-Vivadent) para a confecção das inlays de cerâmica e as resinas Tetric (Ivoclar-Vivadent), Blend-a-lux (Procter \& Glambe) e Pertac-Hybrid Unfil (Espe) para a confecção das inlays de resina, as quais foram fixadas com um cimento resinoso dual (Sono Cem, Espe). A decisão para a escolha das inlays baseou-se no tamanho das cavidades, tendo sido as inlays de resina 
composta colocadas em cavidades pequenas, cuja largura do istmo oclusal não excedia 2/3 da distância intercuspídea, enquanto as inlays cerâmicas foram colocadas em cavidades extensas. As superfícies internas das inlays foram tratadas com ácido fluorídrico a 5\% (15 seg. para a resina e 60 seg. para a cerâmica) e silano. O sistema adesivo Syntac (Ivoclar-Vivadent) foi utilizado para a cimentação das inlays cerâmicas. No baseline e após um ano todas as restaurações foram avaliadas por dois examinadores previamente calibrados no uso do sistema. Após um ano, significante diferença em favor das inlays cerâmicas foi constatada com relação aos critérios forma anatômica da superfície, integridade marginal e oclusão. Quatro inlays de resina composta receberam o escore "Delta" para integridade marginal, tendo os autores considerado este critério como o mais importante para o sucesso das restaurações. Relataram que as propriedades mecânicas dos cimentos resinosos são inferiores quando comparadas à resistência ao desgaste das inlays de cerâmica e resina. A taxa de sucesso das inlays de resina e de cerâmica foram 94 e 100\%, respectivamente.

van DIJKEN; HÖGLUND-ALBERG; OLOFSSON ${ }^{132}$, em 1998, avaliaram 115 inlays cerâmicas (Mirage-Chamaleon) fixadas com cimento resinoso ou cimento de ionômero de vidro, por um período de 06 anos. Verificaram a ocorrência de $2 \%$ de falhas no grupo que utilizou o cimento resinoso e $26 \%$ de falhas no grupo que utilizou o cimento de ionômero de vidro. Essas falhas envolveram fraturas parciais ou perda total das inlays. Os autores consideraram que apesar do tempo avaliado não ser considerado curto, um período de 
avaliação mais longo é necessário para que se observe a longevidade das inlays.

HAYASHI et al. ${ }^{51}$, em 1998, procuraram avaliar 46 inlays de cerâmica do tipo feldspática (G-Cera Cosmotech II), por um período de 06 anos. Foram colocadas 27 inlays nos pré-molares e 22 nos molares (sendo 2 onlays). Estas restaurações foram avaliadas nos períodos de 06 meses, 01, 02, 04 e 06 anos após a cimentação, pelo critério USPHS. Como forma complementar de avaliação foram realizadas moldagens com silicona de adição, em ambas as arcadas, e vazadas em resina epóxica para avaliação em MEV (20 a 200 X). Após 06 anos verificou-se, pela análise direta, que 92\% das restaurações apresentavam-se em condições aceitáveis. Apenas a descoloração marginal apresentou um declínio de qualidade durante o período de avaliação. Pela análise indireta (MEV) foram detectadas microfraturas marginais em $49 \%$ das restaurações. Este fato foi associado ao desgaste do cimento resinoso, responsável pela formação de fendas entre o material restaurador e o dente. Nestes locais, a cerâmica sem suporte sofria microfraturas, as quais iam gradualmente se transformando em macro-fraturas. Os autores chamaram a atenção para a necessidade do desenvolvimento de cimentos resinosos mais resistentes ao desgaste. Com relação ao desgaste da inlay e do dente antagonista, este foi verificado em $15 \%$ das restaurações, e estava normalmente associado ao local que sofreu ajuste oclusal e não foi devidamente polido. Não foram observadas diferenças estatisticamente significantes entre a região de molares e pré-molares, em nenhuma das características analisadas. 
Revisão de Literatura 82

ZUELLING-SINGER; BRYANT ${ }^{136}$, em 1998, investigaram a adaptação marginal de inlays de cerâmica usinadas (CEREC-Siemens) e fixadas com diferentes agentes de cimentação, após 03 anos de avaliação clínica. Quarenta e duas restaurações, classe II, confeccionadas com a cerâmica Vita Mark II foram colocadas em 21 pacientes e fixadas com dois dos quatro agentes cimentantes: cimento resinoso de micropartículas (Dual Cement - Vivadent); cimento resinoso de partículas híbridas finas (Duo Cement - Vita); cimento resinoso de partículas híbridas irregulares (CR inlay cement - Kuraray) e um cimento de ionômero de vidro encapsulado (Ketac Cem - Espe). Réplicas em resina epóxica foram feitas a partir de moldagens com silicona de adição nas avaliações de 06 meses, 01, 02 e 03 anos. Apenas a face oclusal foi analisada em MEV $(200$ X) com a finalidade de verificar a adaptação marginal e o desgaste dos cimentos. Após três anos, os desgastes sofridos pelos cimentos foram significantemente diferentes, tendo 0 cimento de micropartículas apresentado o menor desgaste. O cimento resinoso de partículas híbridas irregulares apresentou o maior desgaste, seguido pelo cimento de ionômero de vidro. Com relação à adaptação marginal, verificaram que esta foi mais durável na interface cimento-esmalte do que na interface cimento-cerâmica. Observaram, entretanto, que a falta de continuidade na interface cimentocerâmica promoveu descoloração marginal sem ter causado prejuízo ao dente.

FUZZI; RAPPELLI ${ }^{42}$, em 1998, analisaram dois tipos de cerâmica convencionais, Microdond Natural (Austenal Dental International Inc.) e Fortune (Williams-Ivoclar). Ambas foram fixadas com cimento resinoso dual (Ultra Bond, 
Den Mat) e avaliadas por um período de 10 anos. Uma taxa de sucesso de $99 \%$ foi obtida em pré-molares e 95\% em molares. Das 183 inlays examinadas, 5 falharam, sendo 4 falhas por problemas endodônticos e apenas 1 falha por fratura.

FUZZI; RAPPELLI ${ }^{41}$, em 1999, dando continuidade ao estudo supracitado, reavaliaram as cerâmicas após 11 anos. Dos 67 pacientes avaliados no ano anterior, apenas um não compareceu, reduzindo o número de inlays para 182. A taxa de sucesso foi estimada em $95 \%$ devido a ocorrência de falhas em seis inlays, sendo quatro falhas por problemas endodônticos, uma por fratura e uma por cárie recorrente.

KRÄMER et al. ${ }^{62}$, em 1999, mediante um estudo clínico, avaliaram a performance de 96 inlays e onlays cerâmicas, IPS-Empress, realizadas em molares e pré-molares e fixadas com quatro agentes cimentantes resinosos (Dual Cement, Variolink Low, Variolink Ultra e Tetric), sob isolamento absoluto. Durante o preparo cavitário, utilizou-se o cimento de ionômero de vidro como material de base. As restaurações foram avaliadas pelo critério USPHS por dois investigadores, mediante o uso de espelhos, sonda, radiografias interproximais e fotografias. Um número representativo de amostras foi utilizado para ser analisado com MEV (200 X), por meio de modelos confeccionados em resina epóxica. Após 04 anos sete restaurações falharam, sendo 4 falhas por fratura e 3 devido a necessidade de tratamento endodôntico. Das 85 restaurações remanescentes, $79 \%$ apresentaram deficiências marginais, independentemente 
do cimento utilizado. A principal causa dessa deficiência foi atribuída ao desgaste dos cimentos.

MANHART et al. ${ }^{72}$, em 2000, dando continuidade ao estudo anteriormente mencionado (SCHEIBENBORG et al. ${ }^{113}, 1998$ ) avaliaram o comportamento clínico de inlays de cerâmica e resina composta. Após dois anos de avaliação apenas 56 inlays foram examinadas (17 de cerâmica, 16 de resina Tetric, 13 Blend-a lux e 10 Pertac). Duas inlays de resina composta falharam após 11 meses devido à integridade marginal; e uma inlay falhou após 23 meses, por fratura. Os autores consideram que as inlays de cerâmica comportaram-se significantemente melhor com relação aos critérios: forma anatômica e integridade marginal. Observaram que houve maior índice de escores "Alfa" para integridade marginal e manchamento para as inlays colocadas em cavidades pequenas. A taxa de sucesso para as inlays de resina foi de $90 \%$, enquanto as de cerâmica obtiveram 100\%. É importante lembrar que os escores "Alfa" e "Bravo" são considerados como sucesso, sendo que a diferença entre estes escores está no grau de excelência, não comprometendo a vida útil da restauração.

FELDEM; SCHMALZ; HILLER ${ }^{34}$, em 2000, mediante um estudo de avaliação clínica de coroas parciais de cerâmica, IPS Empress, reportaram uma taxa de sucesso de $81 \%$ após 07 anos. De um total de 49 restaurações, 42 foram avaliadas após 07 anos. Duas restaurações fraturaram $(4,8 \%)$, sendo uma fratura devido à espessura insuficiente da cerâmica e a outra pelo hábito de 
bruxismo apresentado pelo paciente. Uma restauração apresentou cárie recorrente $(2,4 \%)$ e uma necessitou de tratamento endodôntico (2,4\%). Com relação à descoloração marginal, 31\% apresentaram escore "Bravo", sem necessidade de intervenção. Os autores relataram que o desgaste do cimento resinoso foi o responsável pelo acúmulo de detritos na margem, com conseqüente descoloração marginal.

MOLIN; KARLSSON ${ }^{81}$, em 2000, compararam a longevidade do ouro com três sistemas cerâmicos para a confecção de inlays. Vinte pacientes, de ambos os sexos, receberam uma inlay de ouro e três de cerâmica fabricadas com diferentes sistemas: CEREC CAD-CAM (cerâmica usinada, Siemens), IPS Empress (cerâmica prensada, Ivoclar-Vivadent) e Mirage (cerâmica convencional, Mirage). As inlays de ouro foram cimentadas com cimento de fosfato de zinco e cada uma das cerâmicas utilizou o sistema adesivo e agente cimentante proveniente do mesmo fabricante. Um total de 80 inlays foram colocadas, sendo vinte de cada sistema. Após cinco anos de avaliação, mediante o critério CDA, pôde-se verificar que cinco inlays fraturaram, sendo quatro do sistema IPS Empress e uma do sistema CEREC. Uma inlay de ouro e duas do sistema Mirage foram trocadas devido à sensibilidade dolorosa e problemas endodônticos, respectivamente. Os sistemas cerâmicos apresentaram um aumento significante de manchamento das margens das restaurações após 5 anos. Uma taxa de sucesso de 92 e 100\% foi obtida pelas inlays de cerâmica e ouro, respectivamente. Os autores consideraram que 
fatores como preparo cavitário, agentes cimentantes e força oclusal tiveram maior influência na longevidade das restaurações do que o material utilizado.

FRANKENBERGER; PETSCHELT; KRÄMER ${ }^{38}$, em 2000, avaliaram o comportamento clínico de restaurações cerâmicas do tipo IPS Empress confeccionadas por 06 professores da Universidade de Erlangen-Nuremberg, Alemanha. Noventa e seis restaurações (72 inlays e 24 onlays) foram colocadas em 34 pacientes, com idade média de 33 anos. Estas restaurações foram fixadas com 04 diferentes agentes de cimentação resinosos (Dual Cement, Variolink Low, Variolink Ultra e Tetric), sob isolamento absoluto. Previamente à cimentação os dentes foram limpos com pedra pomes, condicionados com ácido fosfórico a $37 \%$ e tratados com o sistema adesivo Syntac Classic (Vivadent). As peças foram condicionadas com ácido fluorídrico a $4,5 \%$ por um minuto e silanizadas (Monobond S - Vivadent). Após 06 anos, 67 pacientes compareceram e suas restaurações foram avaliadas por dois examinadores utilizando o critério USPHS modificado. Verificou-se que $66 \%$ dos dentes restaurados apresentaram pequenas fraturas em esmalte, no entanto, não houve necessidade de troca de restaurações por este motivo. Constatou-se $7 \%$ de falhas. Duas inlays foram trocadas por hipersensibilidade e cinco por fratura. Das restaurações remanescentes, 94\% apresentaram falhas na integridade marginal, não havendo diferença estatisticamente significante entre os quatros cimentos utilizados. 
HAYASHI et al. ${ }^{52}$, em 2000 , dando continuidade ao trabalho publicado em 1998, verificaram após 08 anos a qualidade de inlays de cerâmica feldspática (G-Cera Cosmotech II, GC). Um total de 45 inlays (26 pré-molares e 19 molares) foi colocado em 25 pacientes, sendo 12 restaurações do tipo classe I, 31 restaurações do tipo classe II e duas onlays. As avaliações prévias foram feitas nos períodos de 06 meses, 01, 02, 04 e 06 anos, mediante o critério USPHS. Após 08 anos, 11 restaurações fraturaram (24\%); 14 restaurações apresentaram descoloração marginal (31\%) e 11 restaurações mostraram pobre adaptação marginal (24\%). Na avaliação indireta por MEV, das 39 réplicas avaliadas, 30 apresentaram microfraturas marginais (77\%); 14 apresentaram desgaste da cerâmica (36\%) e 29 apresentaram desgaste do cimento (74\%). Nenhuma diferença estatística foi observada entre as restaurações cimentadas nas áreas de molares e pré-molares. Clinicamente $80 \%$ das restaurações foram consideradas aceitáveis após 08 anos como um tratamento estético e conservador. Entretanto, os autores chamaram a atenção para a possibilidade de fratura e desintegração marginal e enfatizaram a necessidade do desenvolvimento de cimentos resinosos mais resistentes ao desgaste, uma vez que a degradação marginal começa pelo desgaste do cimento.

KRÄMER; FRANKENBERGER ${ }^{63}$, em 2000 , consideraram que o maior problema ainda não solucionado das restaurações adesivas cerâmicas é o desgaste do cimento resinoso. Neste estudo procuraram verificar a perda de substância de dois cimentos resinosos, após 06 anos, nas margens de inlays de cerâmica do tipo IPS Empress. Trinta e nove inlays (17 em pré-molares e 22 em 
molares) foram realizadas em 16 pacientes, com idade média de 34,7 anos. Do total destas restaurações, 18 foram fixadas com cimento resinoso Variolink Low e 22 com resina composta híbrida Tetric, pela técnica de inserção ultra-sônica. As avaliações foram feitas nos períodos de 06, 12, 24, 48 e 72 meses. Em cada avaliação as restaurações eram moldadas para a obtenção de réplicas em resina epóxica, as quais eram escaneadas tridimensionalmente mediante o uso de um perfilômetro controlado por computador e analisados (programa Xpert). As áreas oclusais também foram avaliadas por MEV (200 X).

Verificou-se uma porcentagem de valas marginais de 32\% após 06 meses, 48\% após 12 meses, 46\% após 24 meses, 55\% após 36 meses, 59\% após 48 meses e 65\% após 06 anos. Diante do resultado pode-se concluir que, proporcionalmente, o maior desgaste do cimento resinoso foi visualizado no primeiro ano. Não houve diferença entre os desgastes ocorridos nas áreas de pré-molares e molares, nem distinção entre os desgastes dos dois cimentos resinosos. Nas análises de MEV verificou-se microfraturas tanto no esmalte como na cerâmica. Os autores concluíram que apesar do desgaste do cimento ter sido um fato incontrolável, resultando em valas marginais, este processo não comprometeu a permanência das restaurações.

THORDRUP; ISIDOR ${ }^{129}$, em 2001, mediante um estudo clínico, procuraram avaliar o comportamento clínico de inlays de resina composta e cerâmica, fabricadas pelos métodos direto e indireto, no intuito de verificar se havia diferença entre os materiais testados. Quatro diferentes sistemas foram 
utilizados: cerâmica - método direto (CEREC CAD-CAM, Siemens); cerâmica método indireto (Vita Dur N, Vita); resina composta - método indireto (Estilux, Kulzer) e resina composta - método direto (Brilliant, Còltene). Os sistemas diretos foram confeccionados diretamente na boca e depois removidos para cimentação. O cimento CEREC Dual Cement (Kulzer) foi utilizado para a cimentação de todos os sistemas. No baseline e nas avaliações seguintes todas as restaurações foram avaliadas pelo método CDA. A taxa de sucesso foi reportada de duas formas: inlays que permaneceram na boca após 05 anos sem nenhum tipo de reparo ou após algum tipo de reparo. Após 05 anos, três inlays necessitaram de reparo e seis falharam. Os reparos foram realizados nas inlays de resina composta, devido a fraturas incompletas. As falhas ocorreram por fratura de duas inlays cerâmicas, recidiva de cárie em duas inlays de resina composta e sensibilidade dolorosa em uma inlay de resina composta. Nas avaliações todos os sistemas apresentaram decréscimo dos escores "Alfa", quando comparados ao baseline, demonstrando que a boa adaptação marginal inicial não permanece estável ao longo dos anos, provavelmente devido à abrasão e desintegração superficial do cimento resinoso. Oitenta e oito por cento das inlays continuaram em função após 05 anos de serviço, sem diferença estatisticamente significante entre os sistemas testados.

MALAMENT; SOCRANSKY ${ }^{71}$, em 2001 , verificaram a influência de vários fatores no sucesso de restaurações confeccionadas com a cerâmica Dicor (Dentsply), após avaliação clínica de 16 anos. Dentre os fatores avaliados observou-se que as cerâmicas condicionadas com ácido e fixadas com cimento 
resinoso obtiveram uma taxa de sucesso maior do que as restaurações fixadas com cimento de ionômero de vidro ou de fosfato de zinco. As coroas cerâmicas condicionadas com ácido e fixadas sobre núcleos metálicos apresentaram uma taxa de sucesso maior do que as restaurações cimentadas sobre dentina. Os autores consideraram que o maior módulo de elasticidade dos núcleos metálicos protegeram a restauração cerâmica da fratura.

GEMALMAZ; ÖZCAN; ALKUMRU ${ }^{44}$, em 2001, investigaram a performance clínica de inlays de cerâmica (Duceram LFC) fixadas com três agentes cimentantes, dois resinosos e um ionomérico. Quarenta e cinco restaurações, sendo 44 inlays e 1 onlay foram colocadas em 26 pacientes de ambos os sexos, sendo 12 em pré-molares e 33 em molares. O sistema adesivo Syntac (Primer e Adhesive) e Heliobond (Ivoclar-Vivadent) foi utilizado em todas as cavidades, após o condicionamento ácido. Em seguida, 15 do total de 45 restaurações foram fixadas com um dos três agentes de cimentação: Variolink (Ivoclar-Vivadent), Enforce (Dentsply) e o cimento de ionômero de vidro Geristone (Den-Mat). As restaurações foram avaliadas dentre os períodos 03 a 46 meses, de acordo com o critério USPHS. Adicionais radiografias e análise em MEV foram realizadas. Sete cerâmicas fraturaram neste período, tendo 6 falhas ocorrido no grupo que utilizou o cimento de ionômero de vidro (Geristone) e uma falha no grupo que utilizou o cimento Variolink. De acordo com a análise em $M E V$, verificou-se uma melhor adaptação marginal na interface esmalte-cimento do que na interface cerâmica-cimento. As inlays fixadas com cimento de 
ionômero de vidro apresentaram a mais alta porcentagem de desgaste do cimento. A fenda marginal variou de 5 a 500 ìm.

Os aspectos cor e textura de superfície apresentaram escores aceitáveis nas avaliações clínicas. Três inlays foram substituídas, sendo uma devido à severa descoloração marginal, uma por sensibilidade dolorosa e uma por falha adesiva. Os autores comentaram que o maior problema das pesquisas clínicas é o não comparecimento dos pacientes nas avaliações. Neste trabalho, o número total de 45 restaurações foi reduzido para 17, em 36 meses.

OTTO; NISCO ${ }^{89}$, em 2002, avaliaram um total de 200 inlays e onlays confeccionadas pelo sistema CEREC CAD-CAM (Siemens) em 108 pacientes de ambos os sexos, com idade média de 37 anos. Os preparos foram realizados pelo mesmo operador e as restaurações foram avaliadas pelo critério USPHS. Todas inlays foram, depois de condicionadas e silanizadas, fixadas na cavidade com o cimento resinoso CEREC-Duo Cement (Heraeus Kulzer) e agente adesivo CEREC-Bond (Heraeus Kulzer). Após 10 anos, 187 (94\%) restaurações realizadas em 89 (82\%) pacientes foram avaliadas. Quinze restaurações falharam, sendo 8 por fratura. Estas fraturas foram atribuídas ao hábito de bruxismo constatado em três pacientes. As outras falhas ocorreram devido à presença de cáries secundárias ou problemas endodônticos. Das 172 inlays e onlays consideradas clinicamente satisfatórias, observou-se uma crescente degradação marginal, a qual aumentou de $12 \%$ para $74 \%$ em 10 anos. No 
Revisão de Literatura 92

entanto, a degradação marginal não foi associada ao surgimento de cáries secundárias. A taxa de sucesso foi estimada em 90,4\% após 10 anos. 


\section{3 - PROPOSIÇÃO}

Este estudo in vivo teve o objetivo de avaliar o comportamento clínico de restaurações classe II, do tipo inlay e onlay, realizadas com dois tipos de cerâmica (IPS Empress e Duceram) e comparar o desempenho destas restaurações no baseline e após 01 e 02 anos, pelo critério USPHS modificado.

As seguintes hipóteses nulas foram testadas:

- apesar dos diferentes valores de resistência flexural dos sistemas testados, ambos irão mostrar um comportamento clínico satisfatório devido ao reforço promovido às cerâmicas pela técnica adesiva;

- os dois sistemas cerâmicos apresentarão um comportamento clínico semelhante nas regiões de pré-molares e molares;

- as inlays terão um desempenho clínico semelhante às onlays;

- as técnicas de confecção das cerâmicas prensada e convencional não são fatores determinantes para o sucesso clínico das restaurações. 


\section{4 - MATERIAIS E MÉTODOS}




\section{4 - MATERIAIS E MÉTODOS}

\section{1 - SELEÇÃO DOS PACIENTES}

Para esse estudo foram selecionados 35 pacientes, na faixa etária entre 25 a 44 anos, de ambos os sexos (18 masculinos e 17 femininos) que necessitavam de restaurações de classe II. Para a seleção, os voluntários foram examinados e passaram por criteriosa anamnese. Uma ficha clínica foi elaborada com os dados gerais dos pacientes e outra com os dados relacionados às restaurações (anexos 1 e 2). Os exames clínicos foram feitos inicialmente através do uso de espelho bucal e sonda clínica. Radiografias periapicais e interproximais foram utilizadas como meios auxiliares de diagnóstico. Cada paciente deveria apresentar no mínimo dois dentes para serem restaurados, cujos dentes antagonistas estivessem presentes. A seleção dos voluntários foi realizada adotando-se os itens abaixo relacionados como critérios de exclusão:

- Alto risco à cárie éou doença periodontal;

- Portadores de aparelhos removíveis ou ortodônticos;

- Ausência de mais de uma unidade na região posterior;

- Pobre higiene oral;

- Portadores de briquismo ou apertamento;

- Grávidas ou em fase de amamentação. 
Os pacientes selecionados foram esclarecidos sobre a metodologia da pesquisa, riscos e benefícios, assim como foram informados sobre o seu direito de deixarem de fazer parte da mesma em qualquer momento. No final da entrevista os pacientes assinavam um documento, no qual confirmavam sua aceitação na participação desta pesquisa (anexo 3).

O experimento foi conduzido em concordância com as normas e diretrizes de pesquisa envolvendo seres humanos (Resolução no 196) aprovada em 10 de outubro de 1996 pelo Conselho Nacional de Saúde e submetido à aprovação pelo Comitê de Ética em Pesquisa da Faculdade de Odontologia de Bauru, FOB-USP, em 31 de março de 2000 (anexo 4).

\section{2 - PREPARO DAS CAVIDADES E PROTEÇÃO DO COMPLEXO DENTINA/POLPA}

Todos os procedimentos operatórios foram realizados por um único operador. Oitenta e seis cavidades, classe II, foram confeccionadas em dentes pré-molares e molares (Figura 4.1 e anexo 6) que necessitavam de troca da restauração antiga ou apresentavam-se cariados. Inicialmente os pacientes eram anestesiados através de agulha descartável ${ }^{1}$ montada em seringa carpule $^{2}$ com anestésico injetável loco-regional ${ }^{3}$. As cavidades foram realizadas sob isolamento absoluto seguindo-se as características de preparo

\footnotetext{
${ }^{1}$ BD - Becton Dickinson Ind. Cirúrgicas LTDA, Juiz de Fora, MG, Brasil

${ }^{2}$ Duflex, S.S. White, Artigos Dentários S.S., Rio de Janeiro, RJ, Brasil

${ }^{3}$ Mepivacaína a $2 \%$ - DFL Industria Cirúrgicas LTDA, Rio de Janeiro, RJ, Brasil
} 


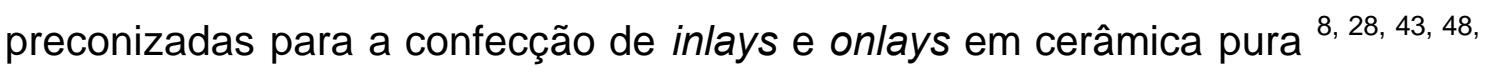
55, 56, 83 conforme descrito na Figura 4.2 e na ilustrado Figura 4.3.

\begin{tabular}{|c|c|c|c|c|c|c|c|}
\hline & \multicolumn{3}{|c|}{ IPS Empress } & \multicolumn{3}{c|}{ Duceram } & \multirow{2}{*}{ Total } \\
\cline { 2 - 7 } & $P M$ & $M$ & Total & $P M$ & $M$ & Total & \\
\hline Inlay & 11 & 14 & 25 & 10 & 18 & 28 & 53 \\
\hline Onlay & 4 & 15 & 19 & 2 & 12 & 14 & 33 \\
\hline Total & 15 & 29 & $\mathbf{4 4}$ & 12 & 30 & $\mathbf{4 2}$ & $\mathbf{8 6}$ \\
\hline
\end{tabular}

Figura 4.1 - Quadro do número total de restaurações cerâmicas (IPS Empress e Duceram) de acordo com o tipo (inlay e onlay) e região (pré-molares - PM e molares $-M)$ 


\begin{tabular}{|l|l|}
\hline \multicolumn{1}{|c|}{ Preparo Cavitário } & \multicolumn{1}{|c|}{ Características } \\
\hline Largura do istmo & $2,0-2,5 \mathrm{~mm}$ \\
\hline Profundidade da parede pulpar & $1,5-2,0 \mathrm{~mm}$ \\
\hline Profundidade da parede axial & $1,5-2,0 \mathrm{~mm}$ \\
\hline Divergência das paredes & $10-15^{\circ}$ \\
\hline Ângulos internos & Arredondados \\
\hline Ângulo cavo-superficial & Sem bisel \\
\hline Redução das cúspides & $2,0 \mathrm{~mm}$ \\
\hline Degrau ou chanfro profundo & $1,0-1,5 \mathrm{~mm}$ \\
\hline
\end{tabular}

Figura 4.2 - Quadro das características gerais do preparo cavitário

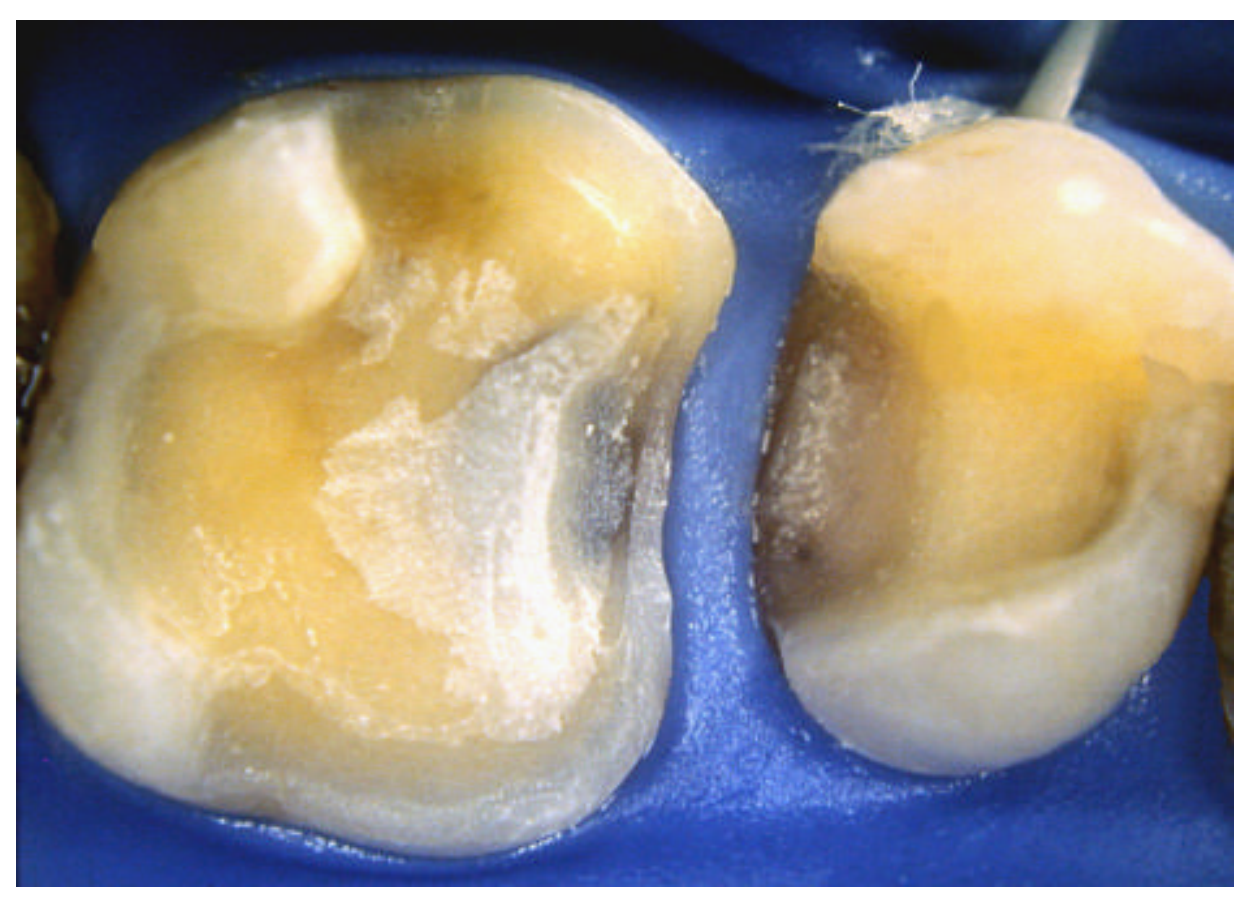

Figura 4.3 - Unidades com preparos para onlay e inlay 
As cavidades foram realizadas com pontas diamantadas em formato tronco cônico com extremo arredondado \# 3131, \# 4137, \# 2133, \#41384 utilizadas em alta rotação ${ }^{5}$, sob irrigação com spray ar/água. A proteção da superfície proximal do dente vizinho foi feita com um pedaço de tira de matriz metálica para amálgama ${ }^{6}$, a qual era constantemente renovada. A distância das paredes vestibular, lingual e gengival foram estabelecidas a aproximadamente 0,5 a $1,0 \mathrm{~mm}$ do dente vizinho. As regiões portadoras de cárie foram limpas com broca esférica de aço de tamanho compatível com a lesão em baixa velocidade com o contra-ângulo ${ }^{7}$. $O$ acabamento das paredes cavitárias foi realizado com pontas diamantadas, de formato tronco cônico com extremo arredondado, em baixa rotação. Instrumentos cortantes manuais (machado para esmalte e recortadores de margem gengival - Duflex) foram utilizados para complementar o acabamento das cavidades.

As áreas socavadas por cárie foram preenchidas com cimento de ionômero de vidro modificado por resina $\left(\right.$ Vitremer) ${ }^{8}$ com o intuito de proteger a dentina profunda e permitir a regularização das paredes pulpar, axiais e circundantes. Esta etapa permitiu que a expulsividade das paredes cavitárias fossem obtidas as custas do material de preenchimento e não da estrutura dentária, além de propiciar uma profundidade padrão para as cavidades. Em regiões onde a dentina apresentava-se muito profunda o cimento de hidróxido

\footnotetext{
${ }^{4}$ KG Sorensen Ind. Com. Ltda, São Paulo, SP, Brasil

${ }^{5}$ Kavo do Brasil S.A., Joinvile, SC

${ }^{6}$ Inodon, Rio Grande do Sul, Brasil

${ }^{7}$ Dabi Atlante S.A., Ribeirão Preto - SP

${ }^{8}$ 3M Dental Products Div., St. Paul, MN, USA
} 
de cálcio $\left(\right.$ Dycal) ${ }^{9}$ era utilizado previamente a colocação do cimento de ionômero de vidro.

\begin{tabular}{|l|l|l|}
\hline Indicação & Material & Fabricante \\
\hline Cimento de $\mathrm{Ca}(\mathrm{OH})_{2}$ & Dycal & Dentsply \\
\hline CIV modificado por resina & Vitremer & 3M Dental \\
\hline Resina acrílica & Duralay & Reliance Dental \\
\hline Cimento temporário & Temp Bond NE & Keer \\
\hline Silicona de adição & Express & 3 M Dental \\
\hline Ácido fosfórico a 37\% & Total Etch & Ivoclar-Vivadent \\
\hline Sistema adesivo & Syntac Classic & Ivoclar-Vivadent \\
\hline Cimento resinoso & Variolink II & Ivoclar-Vivadent \\
\hline Ácido fluorídrico a 10\% & Condic. de porcelanas & Dentsply \\
\hline Silano & Monobond S & Ivoclar-Vivadent \\
\hline Cerâmica & IPS Empress & Ivoclar-Vivadent \\
\hline Cerâmica & Duceram Plus/LFC & Dentsply-Degussa \\
\hline
\end{tabular}

Figura 4.4 - Quadro dos principais materiais utilizados

\section{3 - CONFECÇÃO DAS RESTAURAÇÕES PROVISÓRIAS}

Concluído o preparo, as cavidades eram isoladas com vaselina sólida.

Pó (polímero) e líquido (monômero) da resina acrílica ativada quimicamente $(\text { Duralay })^{10}$ eram levados à cavidade pela técnica do pincel e o paciente era

\footnotetext{
${ }^{9}$ Dentsply International Inc., Pennsylvania, USA

${ }^{10}$ Reliance Dental Mfg Co. Worth, IL, USA
} 
instruído a ocluir os dentes em máxima intercuspidação habitual (MIH) para a demarcação dos contatos oclusais. Finalizada a escultura e ajuste oclusal com brocas de tungstênio $^{11}$, as restaurações provisórias eram polidas com borrachas $^{12}$. A cimentação era feita com cimento provisório sem eugenol (Temp Bond NE) ${ }^{13}$ ou cimento de hidróxido de cálcio (Dycal, Dentsply).

\section{4 - MOLDAGEM}

Após a remoção das restaurações provisórias, o excesso de cimento provisório era removido com curetas e as regiões das paredes gengivais das caixas proximais tiveram a gengiva afastada com fios de retração gengival (Ultrapak, Ultradent) ${ }^{14}$ e solução adstringente (Astringident, Ultradent) por 5 minutos. Moldagens completas das arcadas dentárias portadoras dos preparos cavitários foram realizadas com silicona de adição (Express, 3M Dental), pela técnica da impressão em dois passos. Uma lâmina de polietileno era utilizada para promover o alívio na silicona pesada. A silicona leve era levada à moldera e à cavidade bucal através de seringas de auto-mistura. Após 2 horas, os moldes eram vazados com gesso pedra tipo IV (Durone, Dentsply). As arcadas antagonistas foram moldadas com hidrocolóide irreversível (Jeltrate, Dentsply) e os moldes vazados com gesso pedra tipo IV (Durone, Dentsply). Registros de mordida foram obtidos com silicona de adição (Bite Registration, 3M Dental).

\footnotetext{
${ }^{11}$ Labor Dental LTDA, São Paulo, SP, Brasil

${ }^{12}$ Silicones abrasivos para acabamento e polimento de acrílico Viking, KG Sorensen

${ }_{14}^{13}$ Keer, Karlsruhe, Germany

${ }^{14}$ Ultradent Products, Inc. South Jordan, Utah, USA
} 
Os modelos e os registros de mordida foram enviados a dois laboratórios para a fabricação das peças nas cores selecionadas, por meio da escala Vita ${ }^{15}$.

\section{5 - FABRICAÇÃO DAS INLAYS/ONLAYS - PROCEDIMENTOS LABORATORIAIS}

\subsection{1 - DUCERAM}

A cerâmica Duceram Plus é uma porcelana feldspática utilizada juntamente com a cerâmica Duceram LFC para a confecção de restaurações em cerâmica pura. De acordo com as instruções do fabricante, a cerâmica Duceram Plus é usada na construção dos 2/3 iniciais das inlays e onlays e a Duceram LFC (cerâmica de baixa fusão) é utilizada para revestir a porção mais externa, com o objetivo de gerar menor abrasão sobre o dente antagonista e, devido ao ponto de fusão mais baixo, permitir novas queimas de reparo.

Para a confecção de restaurações com este sistema, o primeiro passo consistiu na duplicação dos troquéis. Inicialmente foi aplicado um espaçador de troquel (Spacerlaquer $)^{16}$ em duas camadas, com o objetivo de criar um alívio na área interna do preparo ficando o espaçador localizado até aproximadamente 1,0 mm aquém do ângulo cavo-superficial. Em seguida, o troquel era duplicado por meio de uma silicona de adição de consistência fluida (Deguform, DentsplyDegussa), misturada na proporção de 1:1 base/catalisador. Após 30 minutos de

\footnotetext{
${ }^{15}$ Vita Zahnfabrick, Bad Sackingen, Germany

${ }^{16}$ Dentsply-Degussa Dental, Hanau, Germany
} 
espera, o troquel mestre era removido para proceder-se ao vazamento do material refratário (Ducera-Lay Superfit, Dentsply-Degussa).

Após a obtenção do troquel refratário, este era levado ao forno ${ }^{17}$ para sinterização. Neste passo os troquéis eram mantidos em pré-aquecimento a $575^{\circ} \mathrm{C}$ por 5 minutos e então a temperatura era elevada progressivamente para $1100^{\circ} \mathrm{C}, 55^{\circ} \mathrm{C}$ por minuto, sem vácuo. Os troquéis permaneciam nesta temperatura final por mais 5 minutos.

Finalizado o preparo do troquel refratário, era aplicada uma fina camada do Conector em pasta Ducera-lay (Dentsply-Degussa). Este material era levado ao forno à temperatura inicial de $620^{\circ} \mathrm{C}$ por 3 minutos e então a temperatura era elevada progressivamente para $970^{\circ} \mathrm{C}, 55^{\circ} \mathrm{C}$ por minuto, com vácuo. Após a queima, toda a área interna deveria estar com aparência brilhante. Caso contrário, uma nova camada poderia ser aplicada nas regiões sem brilho.

Para a confecção da restauração, uma mistura do pó cerâmico Duceram Plus, na cor desejada, com o líquido (Carving Liquid, DentsplyDegussa) era aplicada sobre o troquel refratário e levado ao forno para a queima e sinterização da cerâmica. A primeira queima era iniciada a $630^{\circ} \mathrm{C}$, sendo a temperatura elevada gradativamente $120^{\circ} \mathrm{C}$ por minuto até chegar a temperatura final de $970^{\circ} \mathrm{C}$, na qual o troquel permanecia por mais 1 minuto, sem vácuo. A segunda queima iniciava a $650^{\circ} \mathrm{C}$ e terminava a $920^{\circ} \mathrm{C}$. As demais queimas eram utilizadas na mesma seqüência, devendo a temperatura

\footnotetext{
${ }^{17}$ Degussa - Centurion Q 200, Yucaipa, California, USA
} 
final ser finalizada com $10^{\circ} \mathrm{C}$ a menos que a queima final do ciclo anterior. A cerâmica LFC era aplicada à temperatura inicial de $450^{\circ} \mathrm{C}$, sendo elevada $40^{\circ} \mathrm{C}$ por minuto até atingir a temperatura final de $660^{\circ} \mathrm{C}$.

Após a conclusão dos ciclos de queima, o troquel refratário era eliminado através do jateamento com partículas de óxido de alumínio ${ }^{18}$ de 50 ì m, à pressão de 40 psi, e levadas ao troquel original para a verificação da adaptação. Obtidas as formas e adaptações ideais, as restaurações cerâmicas eram glazeadas com o líquido Stain Liquid (Dentsply-Degussa) no forno à $910^{\circ} \mathrm{C}$, sem vácuo.

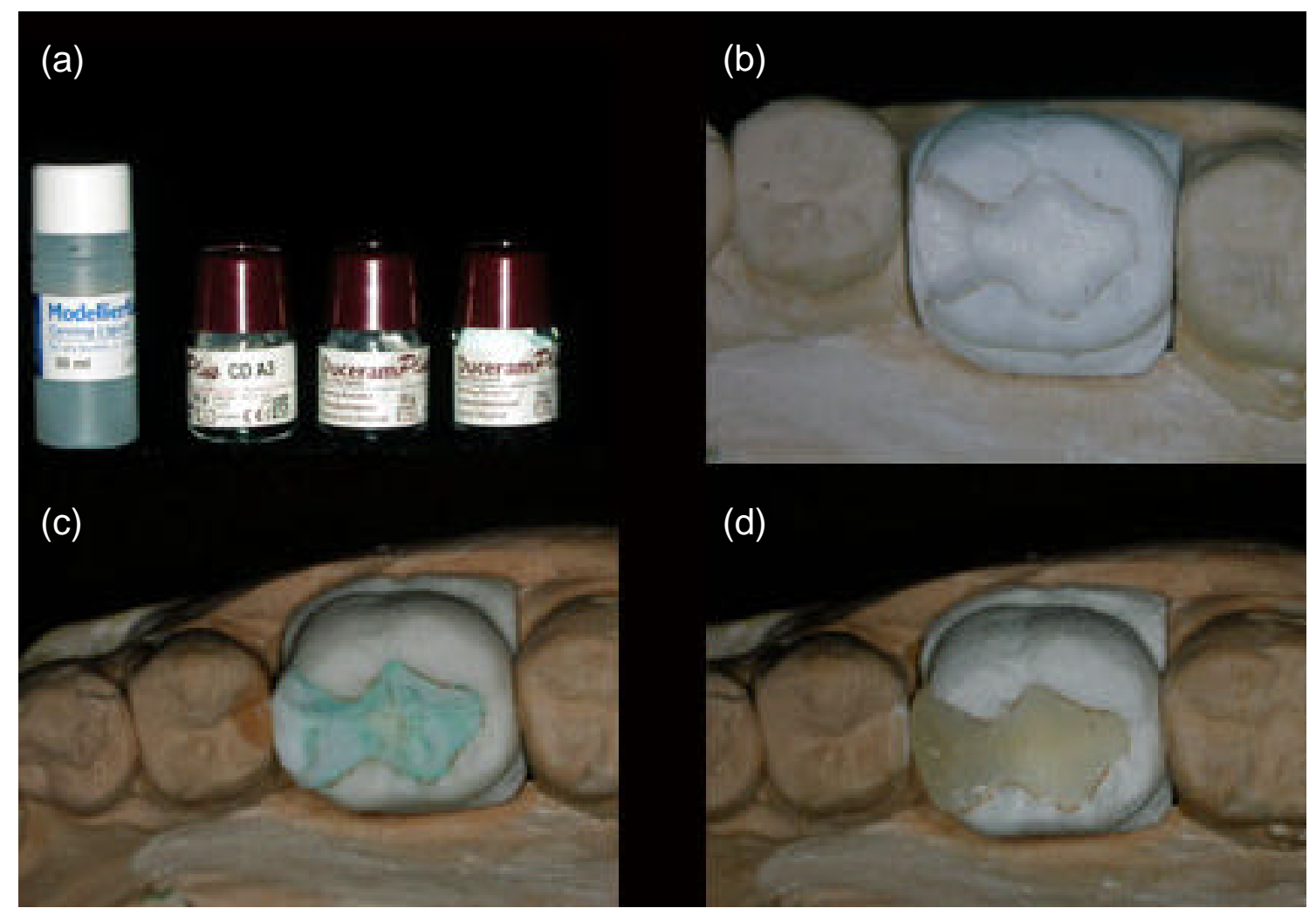

Figura 4.5 - Pó e líquido da cerâmica Duceram (a) - Troquel refratário posicionado no modelo original (b) - Cerâmica aplicada sobre o refratário (c) Cerâmica sinterizada sobre o troquel refratário (d)

\footnotetext{
${ }^{18}$ Sandstorm - Vaniman, EUA
} 


\subsection{2 - IPS EMPRESS}

Este sistema é composto basicamente por porcelana feldspática, fornecida em pastilhas cilíndricas com $10 \mathrm{~mm}$ de altura e $11 \mathrm{~mm}$ de diâmetro, em diferentes graus de opacidade e cor. Para a confecção de restaurações com este sistema, as peças eram primeiramente confeccionadas em padrões de cera ${ }^{19}$ sobre o troquel original e posteriormente incluídas no revestimento ${ }^{20}$, usando formas cilíndricas, próprias do sistema, para confecção da mufla. A mufla era então levada ao forno de anel $\left(\right.$ EDG 3000) ${ }^{21}$, para eliminação da cera. A temperatura inicialmente era elevada a $250^{\circ} \mathrm{C}, 5^{\circ} \mathrm{C}$ por minuto, mantida por 30 minutos, sendo então gradativamente elevada para $850^{\circ} \mathrm{C}, 5^{\circ} \mathrm{C}$ por minuto, na qual a mufla permanecia por mais 90 minutos.

As pastilhas de cerâmica, na cor pré-selecionada, juntamente com o êmbolo de alumina eram também aquecidos a $850^{\circ} \mathrm{C}$. Posteriormente, a mufla era colocada no forno EP 500 - IPS Empress (Ivoclar-Vivadent) junto com as pastilhas de cerâmica. As pastilhas eram posicionadas dentro do cadinho da mufla e, sobre elas, o êmbolo de alumina. O forno era fechado para o início do processo de injeção por pressão e calor, com duração média de 45 minutos. As pastilhas de cerâmica, após aquecidas e plastificadas a $1075^{\circ} \mathrm{C}$, eram prensadas dentro do molde à pressão de 5 bar, através do pistão de alumina.

Após o processo ter sido concluído, a mufla era removida do forno e deixada esfriar a temperatura ambiente. $\mathrm{O}$ revestimento era seccionado e as

\footnotetext{
${ }^{19}$ VKS WACHSE, Yeti Dental

${ }^{20}$ IPS Empress, Ivoclar-Vivadent, Schaan, Leichtenstein

${ }^{21}$ EDG Equipamentos, São Carlos, SP
} 
restaurações eram então jateadas com micro-esferas de vidro, para remoção do revestimento. Os sprues eram cortados com discos diamantados na peça de mão e as restaurações adaptadas nos modelos. Após a adaptação e o acabamento das restaurações, estas eram caracterizadas por pintura extrínseca e glazeadas (Líquido de glazeamento IPS Empress) no forno com temperatura elevada a $980^{\circ} \mathrm{C}$, com vácuo, e mantida por um minuto, sem vácuo.

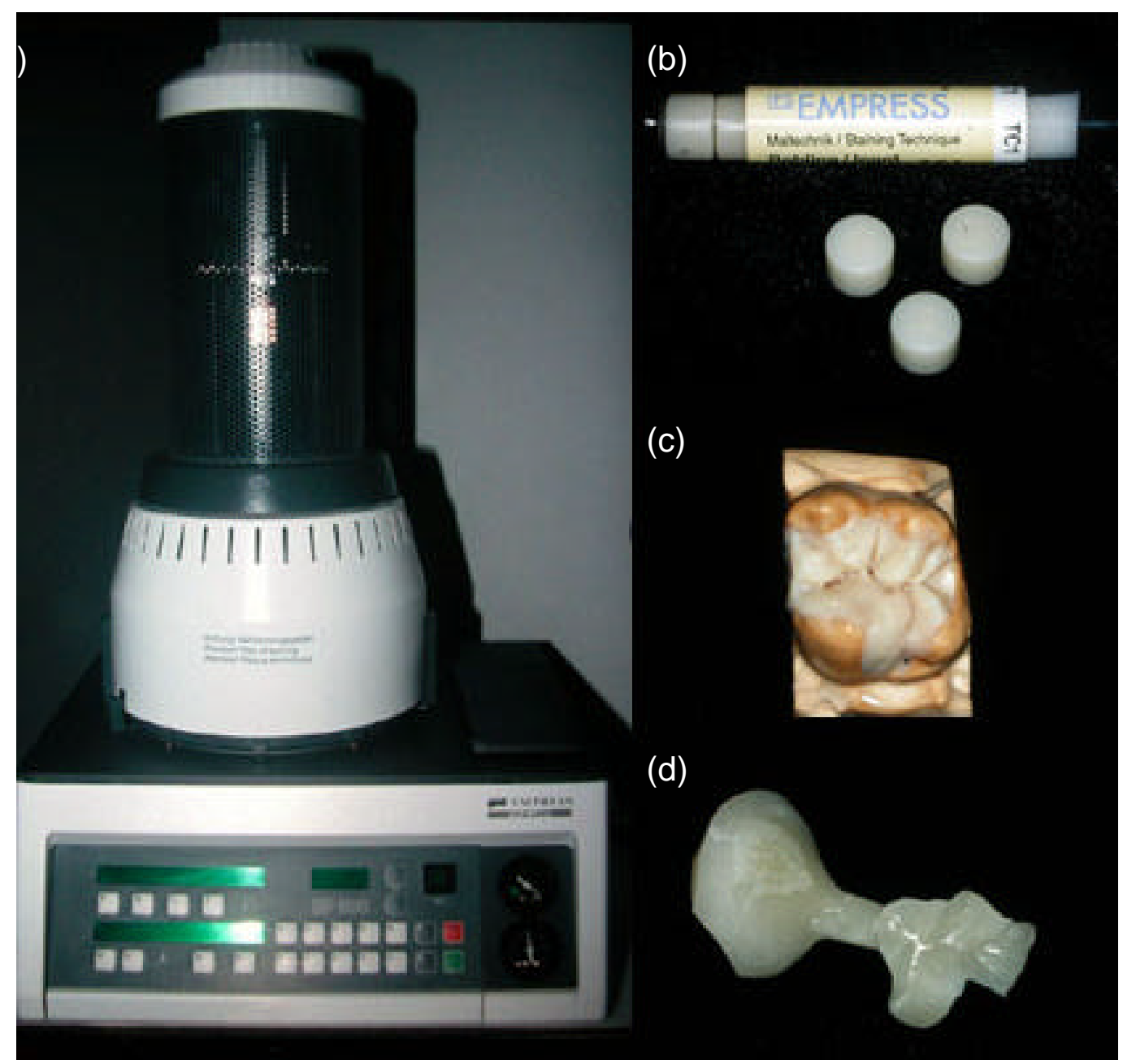

Figura 4.6 - Forno EP 500 - IPS Empress (a) - Pastilhas pré-ceramizadas IPS Empress (b) - Inlay em cera sobre o troquel de gesso (c) - Inlay em cerâmica prensada (d) 


\section{6 - PROVA E CIMENTAÇÃO}

Previamente à cimentação procedeutse ao isolamento absoluto do campo operatório. Após a remoção da restauração provisória e limpeza do dente com uma pasta de pedra pomes e água, a restauração era colocada em posição para a verificação da adaptação e realização dos ajustes necessários. Nesta etapa utilizou-se o carbono líquido spray Occlude $^{22}$ para demarcar primeiramente os contatos em excesso nas regiões proximais. Os contatos presentes eram reduzidos mediante o uso de uma ponta diamantada cilíndrica \# 716G (KG Sorensen) em baixa rotação na peça reta ${ }^{23}$. Os contatos proximais eram então checados com fio dental e as faces desgastadas eram polidas com borrachas para polimento de cerâmica ${ }^{24}$. Caso a adaptação não estivesse adequada, este mesmo procedimento era executado na superfície interna da restauração e os contatos removidos com uma ponta diamantada esférica \# 1014 (KG Sorensen) em baixa rotação.

Finalizado os ajustes, a adaptação da restauração era reavaliada e se não estivesse adequada, a moldagem era repetida para a confecção de uma nova peça. Caso a restauração fosse considerada satisfatória os seguintes passos eram realizados:

\footnotetext{
${ }^{22}$ Pascal - Bellevue, WA, USA

${ }^{23}$ Dabi Atlante S.A., Ribeirão Preto - SP

${ }^{24}$ Cerapol - Edenta AG, Dental Rotatory Instruments, Hauptstrasse, Switzerland
} 


\subsection{1 - TRATAMENTO PRÉVIO DAS RESTAURAÇÕES}

- jateamento com partículas de óxido de alumínio de $50 \mu \mathrm{m}$ de diâmetro, a uma pressão de 80 libras $^{25}$, com o intuito de promover micro-retenção;

- proteção das superfícies externas com cera utilidade;

- condicionamento das superfícies internas com ácido fluorídrico a 10\% (Dentsply), durante 1 minuto;

- lavagem e secagem;

- aplicação do silano Monobond-S (Ivoclar-Vivadent) com um pincel descartável e deixado atuar na superfície por 1 minuto;

- secagem do silano com ar por meio da seringa tríplice, por 5 segundos;

- aplicação do adesivo Heliobond (Ivoclar-Vivadent).

\subsection{2 - TRATAMENTO PRÉVIO DOS DENTES}

- profilaxia com uma mistura de pedra-pomes e água com o auxílio de uma escova de Robinson;

\footnotetext{
${ }^{25}$ Opiblast, Buffalo Dental Mfg., Inc. NY, USA
} 
- condicionamento do esmalte e dentina com ácido fosfórico a 37\% (Ivoclar-Vivadent) por 15 segundos;

- lavagem e secagem por 2 segundos, mantendo-se a dentina úmida;

- aplicação do Syntac Primer (Ivoclar-Vivadent) por 15 segundos / jato de ar por 5 segundos;

- aplicação do Syntac Adhesive (Ivoclar-Vivadent) por 10 segundos / jato de ar por 5 segundos;

- aplicação do Heliobond (Ivoclar-Vivadent).

\subsection{3 - CIMENTAÇÃO}

- manipulação do cimento resinoso Variolink II (Ivoclar-Vivadent) sobre uma placa de vidro, proporcionado em partes iguais;

- inserção do cimento na parte interna da restauração e assentamento da mesma sobre a cavidade. Em seguida, uma pressão manual por meio de um calcador $n \circ 1$ era exercida levemente sobre a restauração para que os excessos extravasassem;

- remoção dos excessos do cimento e fotoativação inicial por 10 segundos para manter a peça firme em posição e possibilitar a remoção do cimento residual das áreas proximais com fio dental; 
- fotopolimerização $0^{26}$ por 60 segundos em cada face da restauração.

Após a cimentação procedeu-se à remoção do isolamento absoluto e os contatos oclusais foram checados com uma fita de carbono AccuFilm ${ }^{27}$. Os ajustes foram realizados com pontas diamantadas de granulação fina \# 3203 F (KG Sorensen) em alta rotação, sob refrigeração ar/água. As superfícies foram cuidadosamente refinadas com pontas de borracha para acabamento intra-oral em cerâmica ${ }^{28}$ e polidas com uma pasta diamantada (KG Sorensen) e disco de feltro.

\section{7 - AVALIAÇÃO CLÍNICA DAS RESTAURAÇÕES}

As restaurações cerâmicas foram avaliadas de acordo com o Critério USPHS (United States Public Health Service) modificado preconizado por Ryge 109, em 1980. Dois examinadores sem envolvimento nos procedimentos restauradores, e previamente treinados no uso deste sistema, avaliaram as restaurações mediante o uso de sonda exploradora (Duflex) e espelho (Duflex) com o auxílio de um refletor de luz (Dabi-Atlante) e seringa tríplice (DabiAtlante) para a secagem dos dentes.

As restaurações foram avaliadas no baseline, 01 e 02 anos de acordo com os seguintes aspectos: sensibilidade pós-operatória, reincidência de cárie,

\footnotetext{
${ }^{26} \mathrm{XL} 2500$ - 3M Dental- $570 \mathrm{~mW} / \mathrm{cm}^{2}$

${ }^{27}$ Parkell, Farmingdale, NY, EUA

${ }^{28}$ Cerapol Plus - Edenta AG, Dental Rotatory Instruments, Hauptstrasse, Switzerland
} 
fratura, reprodução de cor, textura superficial, descoloração marginal e integridade marginal. Os escores foram representados pelos códigos Alfa, Bravo, Charlie e Delta conforme as características clínicas apresentadas pelas restaurações, de acordo com o aspecto avaliado (Figura 4.7). Uma ficha foi elaborada para a marcação dos escores atribuídos pelos examinadores às restaurações (anexo 5), na qual constava a identificação dos dentes a serem avaliados, mas não o tipo do material restaurador, caracterizando o exame "cego" para que não houvesse interferência da opinião pessoal do avaliador no resultado final da avaliação.

A avaliação era feita de forma individual e independente. Na presença de divergência de opinião entre os examinadores, a avaliação era refeita em conjunto até que se obtivesse um consenso. O teste de Kappa foi realizado para detectar o percentual de concordância inter examinador.

Adicionalmente, as restaurações foram fotografadas e radiografadas com o intuito de documentar as restaurações em cada fase das avaliações e poderem ser utilizadas para ilustrar alguns dos escores atribuídos. A Figura 4.8 representa a aquisição de escores "Alfa" para ambas as restaurações (IPS Empress e Duceram), para todos os critérios avaliados. A Figura 4.9 representa a presença de escore "Bravo" para o item descoloração marginal. 


\begin{tabular}{|c|c|}
\hline CLASSIFICAÇÃO & CARACTERÍSTICAS \\
\hline \multicolumn{2}{|r|}{ SENSIBILIDADE PÓS OPERATÓRIA } \\
\hline Alfa (A) & $\begin{array}{l}\text { Ausência de sintomatologia dolorosa à estímulos } \\
\text { térmicos e/ou à percussão. }\end{array}$ \\
\hline Bravo (B) & $\begin{array}{l}\text { Presença de sintomatologia dolorosa espontânea ou } \\
\text { quando da atuação de diferentes estímulos. }\end{array}$ \\
\hline \multicolumn{2}{|r|}{ REINCIDÊNCIA DE CÁRIE } \\
\hline Alfa (A) & $\begin{array}{l}\text { Não há evidência visual de cárie na interface } \\
\text { dente/restauração. }\end{array}$ \\
\hline Bravo (B) & $\begin{array}{l}\text { Há evidência visual de cárie na interface } \\
\text { dente/restauração. }\end{array}$ \\
\hline \multicolumn{2}{|r|}{ FRATURA } \\
\hline Alfa (A) & Não há evidência visual de fratura. \\
\hline Bravo (B) & Há evidência visual de fratura. \\
\hline \multicolumn{2}{|r|}{ REPRODUÇÃO DA COR } \\
\hline Alfa (A) & $\begin{array}{l}\text { A restauração reproduz a cor e a translucidez dos } \\
\text { tecidos dentários. }\end{array}$ \\
\hline Bravo (B) & $\begin{array}{l}\text { A restauração não reproduz a cor e a translucidez dos } \\
\text { tecidos dentários, mas situa-se dentro das variações } \\
\text { normais de cor da estrutura dentária. }\end{array}$ \\
\hline Charlie (C) & $\begin{array}{l}\text { A restauração não reproduz a cor e a translucidez dos } \\
\text { tecidos dentários e a diferença encontra-se fora das } \\
\text { variações de cor da estrutura dentária. }\end{array}$ \\
\hline \multicolumn{2}{|r|}{ TEXTURA SUPERFICIAL } \\
\hline Alfa $(A)$ & $\begin{array}{l}\text { A superfície da restauração tem aparência lisa. Não há } \\
\text { percepção tátil de rugosidade. }\end{array}$ \\
\hline
\end{tabular}




\begin{tabular}{|c|c|}
\hline Bravo (B) & $\begin{array}{l}\text { A superfície da restauração apresenta-se rugosa à } \\
\text { inspeção tátil, não havendo evidências de poros ou } \\
\text { crateras. }\end{array}$ \\
\hline Charlie (C) & $\begin{array}{l}\text { A superfície da restauração apresenta-se com poros ou } \\
\text { crateras. }\end{array}$ \\
\hline \multicolumn{2}{|r|}{ DESCOLORAÇÃO MARGINAL } \\
\hline Alfa (A) & $\begin{array}{l}\text { Não há evidência visual de descoloração marginal na } \\
\text { interface dente/restauração. }\end{array}$ \\
\hline Bravo (B) & $\begin{array}{l}\text { Há evidência visual de descoloração marginal na } \\
\text { interface dente/restauração, mas sua penetração não se } \\
\text { estende em direção à polpa. }\end{array}$ \\
\hline Charlie (C) & $\begin{array}{l}\text { Há evidência visual de descoloração marginal na } \\
\text { interface dente/restauração, com evidente extensão da } \\
\text { penetração em direção à polpa. }\end{array}$ \\
\hline \multicolumn{2}{|r|}{ INTEGRIDADE MARGINAL } \\
\hline Alfa (A) & $\begin{array}{l}\text { Não há evidência visual de fratura marginal e a ponta do } \\
\text { explorador não é aprisionada na interface } \\
\text { dente/restauração. }\end{array}$ \\
\hline Bravo (B) & $\begin{array}{l}\text { Há evidência visual e tátil de fissura mas a dentina e/ou } \\
\text { base não estão expostas nem a restauração apresenta } \\
\text { mobilidade. }\end{array}$ \\
\hline Charlie (C) & $\begin{array}{l}\text { O explorador penetra na interface dente/restauração, } \\
\text { apresentando dentina e/ou base expostas, mas a } \\
\text { restauração não apresenta mobilidade, fratura ou perda. }\end{array}$ \\
\hline Delta (D) & A restauração apresenta mobilidade ou não mais existe. \\
\hline
\end{tabular}

Figura 4.7 - Quadro com os critérios, características e escores do método direto de avaliação clínica (USPHS modificado) para inlays e onlays de cerâmica 

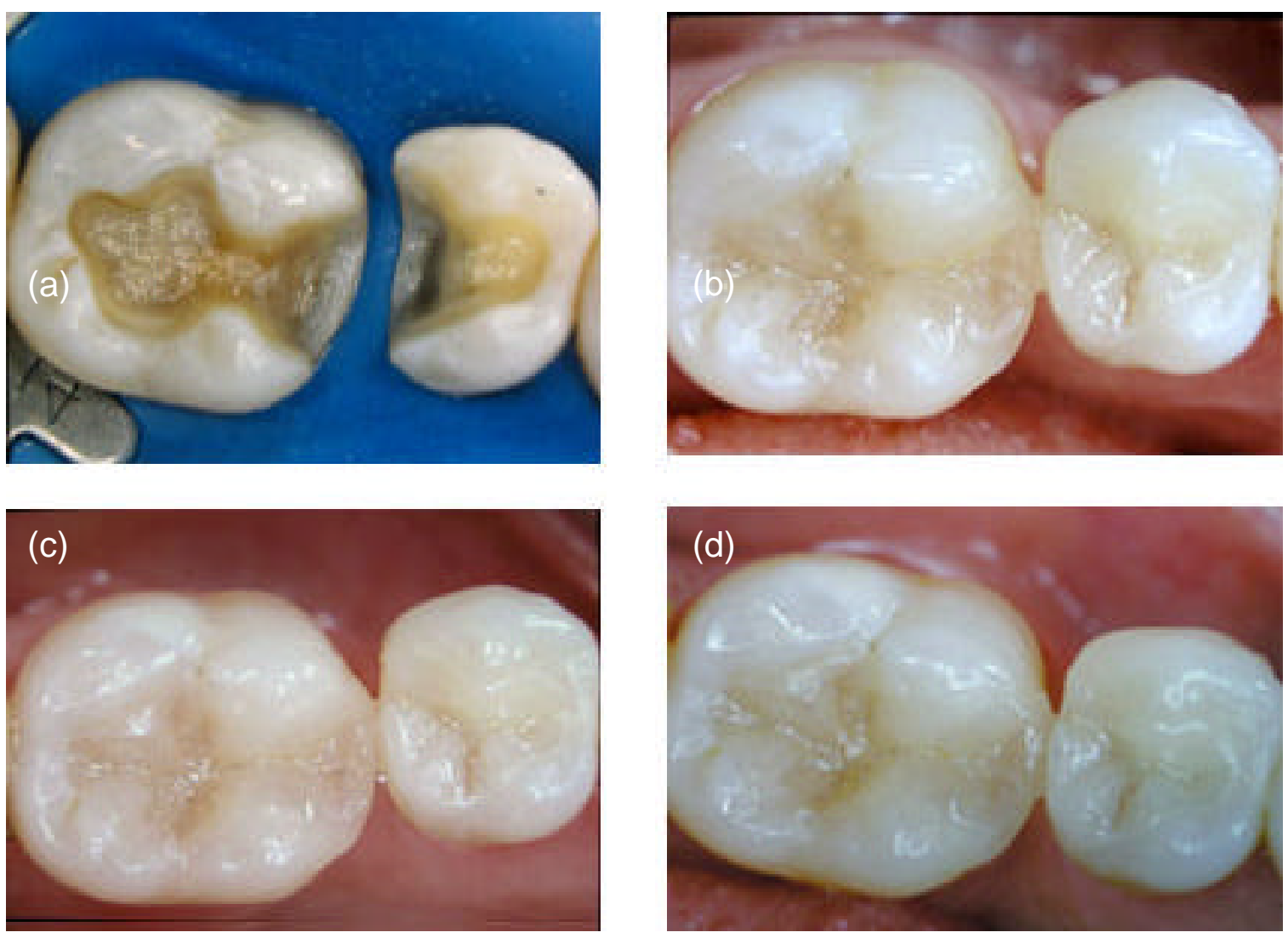

Figura 4.8 - Unidades 45 e 46 preparadas para receber inlays em cerâmica pura IPS Empress (45) e Duceram (46) - (a); baseline - (b); 01 ano - (c) e 2 anos - (d). Ambas as cerâmicas receberam escore "Alfa" para todos os aspectos avaliados 

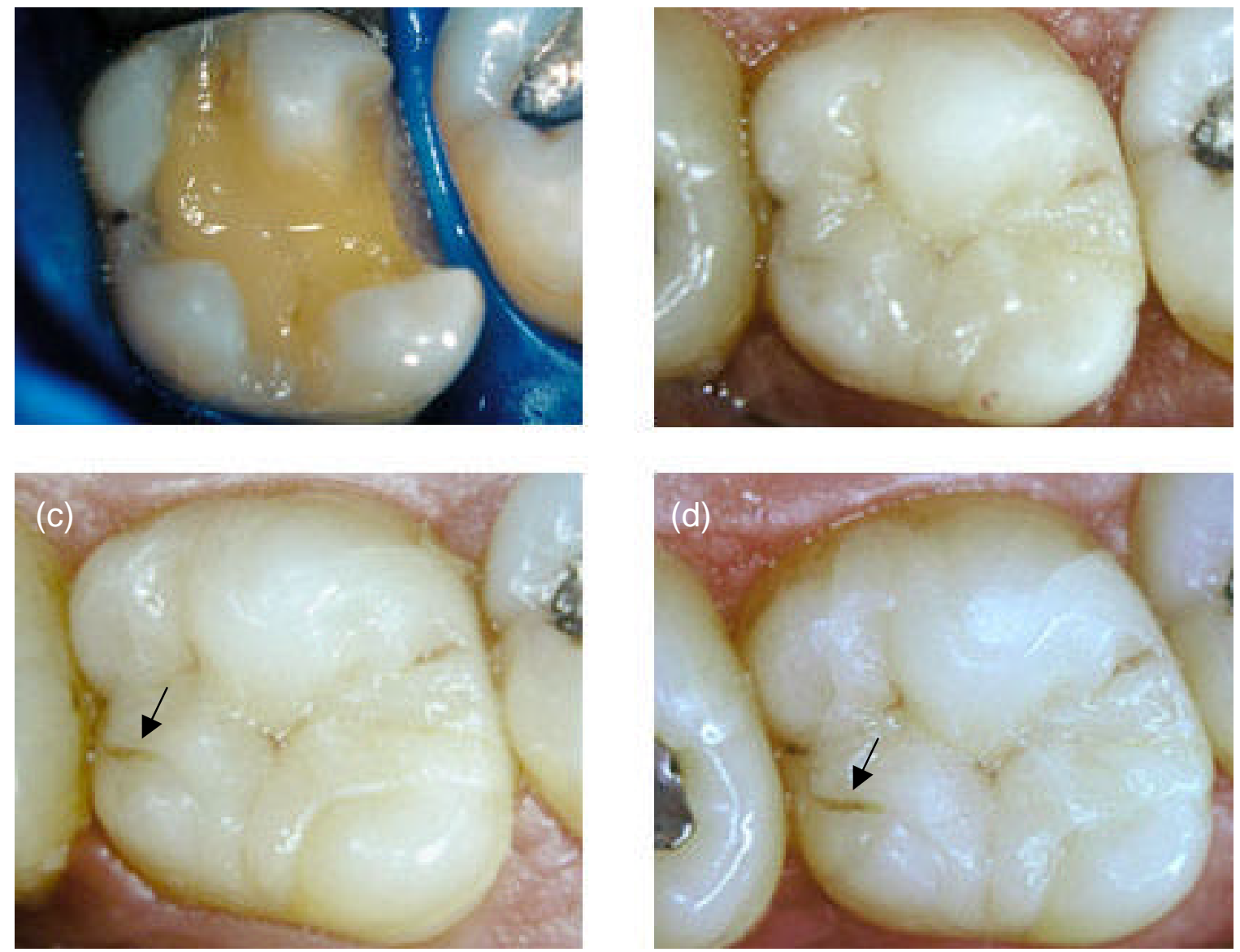

Figura 4.9 - Unidade 17 preparada para receber inlay em cerâmica pura IPS Empress - (a); baseline - (b); 01 ano - (c) e 02 anos - (d). Nas figuras (c) e (d), as setas indicam o escore "Bravo" obtido pelo item descoloração marginal 


\section{8 - CONFECÇÃO DAS RÉPLICAS E OBSERVAÇÃO EM MEV}

Moldagens com silicona de adição Express (3M Dental) foram realizadas em algumas restaurações do tipo inlay, nos períodos das avaliações, para a obtenção de réplicas em resina epóxica ${ }^{29}$. Os modelos de resina epóxica foram cobertos com uma fina camada de ouro, de aproximadamente $9 \mathrm{~nm}$ de espessura, com o aparelho Sputtering System ${ }^{30}$, de forma a tornar a superfície condutora e passível de emissão de elétrons secundários. As amostras foram observadas em microscopia eletrônica de varredura $^{31}$ com aumentos entre 100 a 200 X no intuito de ilustrar a variação do desgaste do cimento resinoso na margem oclusal destas restaurações com o tempo.

\section{9 - ANÁLISE ESTATÍSTICA}

Os escores atribuídos às restaurações foram tabulados no programa Excel e submetidos à análise estatística pelo Teste exato de Fisher, para a comparação dos sistemas cerâmicos (Duceram e IPS Empress), dos tipos de restaurações (inlays e onlays) e das áreas selecionadas (pré-molares e molares). O Teste de McNemar foi utilizado para a comparação individual dos sistemas cerâmicos em diferentes tempos de avaliação (baseline, 01 e 02 anos). O nível de significância estatística foi pré-estabelecido em 5\%.

\footnotetext{
${ }^{29}$ Araltec - Ciba Especialidades químicas LTDA, SP, Brasil

${ }^{30}$ Hummer VII, Anatech LTD, Alexandria, VA

${ }^{31}$ Scanning Microscope Jeol JSM - T220A, Japan
} 


\section{5 - RESULTADOS}




\section{5 - RESULTADOS}

\subsection{RESULTADOS DAS AVALIAÇÕES POR ESCORES}

Após a avaliação clínica das 86 restaurações (42 - Duceram -D e 44 IPS Empress -IPS) nos períodos de baseline, 01 e 02 anos, os resultados foram agrupados e submetidos à análise estatística. A figura abaixo mostra os resultados "Alfa" obtidos nos diferentes tempos de avaliação. Nenhum escore "Charlie" ou "Delta" foi atribuído aos sete critérios avaliados, durante os dois anos de avaliação clínica. Os resultados da sensibilidade pulpar foram obtidos considerando-se apenas os dentes polpados (anexo 6).

\begin{tabular}{|l|c|c|c|c|c|c|}
\hline \multirow{2}{*}{ Critérios } & \multicolumn{2}{|c|}{$\begin{array}{c}\text { Baseline } \\
\text { IPS D }\end{array}$} & \multicolumn{1}{c|}{$\begin{array}{c}\text { 01 Ano } \\
\text { Alfa (\%) }\end{array}$} & \multicolumn{2}{c|}{$\begin{array}{c}\text { 02 Anos } \\
\text { Alfa (\%) }\end{array}$} & \multicolumn{2}{c|}{$\begin{array}{c}\text { IPS } \\
\text { Alfa (\%) }\end{array}$} \\
\hline $\begin{array}{l}\text { Sensibilidade pós- } \\
\text { operatória }\end{array}$ & 97,56 & 92,10 & 100,00 & 100,00 & 100,00 & 100,00 \\
\hline Reincidência de cárie & 100,00 & 100,00 & 100,00 & 100,00 & 100,00 & 100,00 \\
\hline Fratura & 100,00 & 100,00 & 100,00 & 100,00 & 100,00 & 100,00 \\
\hline Reprodução da cor & 97,73 & 90,48 & 95,45 & 90,48 & 95,45 & 90,48 \\
\hline $\begin{array}{l}\text { Descoloração } \\
\text { marainal }\end{array}$ & 100,00 & 100,00 & 75,00 & 88,10 & 68,18 & 76,19 \\
\hline Integridade marginal & 100,00 & 100,00 & 88,64 & 90,48 & 81,82 & 88,10 \\
\hline Textura superficial & 97,73 & 88,10 & 97,73 & 88,10 & 97,73 & 85,71 \\
\hline
\end{tabular}

Figura 5.1 - Quadro dos resultados "Alfa" da investigação clínica, de acordo com o critério USPHS modificado para os dois tipos de cerâmica 
A análise estatística realizada mediante o Teste exato de Fisher demonstrou não haver diferença significante entre as cerâmicas Duceram e IPS Empress para todos os aspectos avaliados nos diferentes tempos de avaliação $(p>0,05)$. As figuras 5.2 a 5.4 mostram a incidência de escores "Alfa" para ambas as cerâmicas nas avaliações clínicas do baseline, 01 e 02 anos, de acordo com os critérios: sensibilidade pulpar (SP), reincidência de cárie (RC), fratura $(\mathbf{F})$, reprodução de cor $(\mathbf{R C})$, descoloração marginal (DM), integridade marginal (IM) e textura superficial (TS)

\section{Alfa}

(\%)

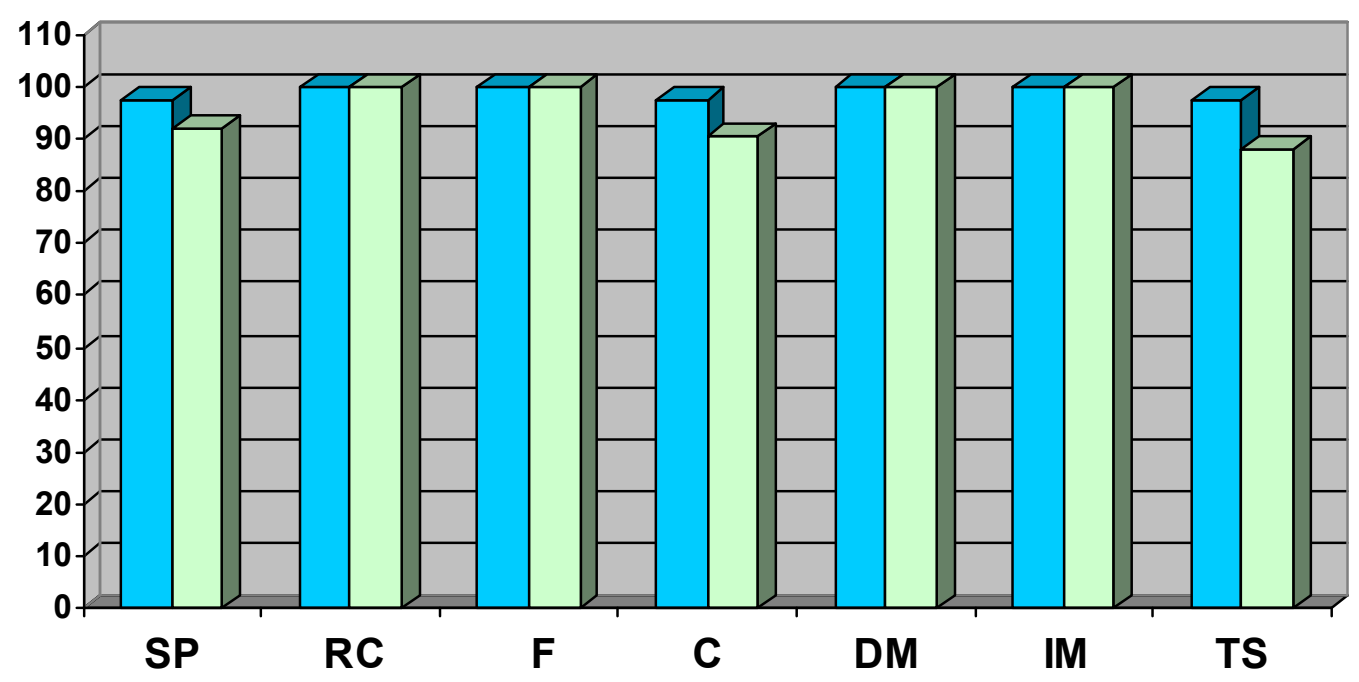

$\square$ IPS Empress $\square$ Duceram

Figura 5.2 - Gráfico ilustrativo dos resultados "Alfa" obtidos pelas cerâmicas IPS Empress e Duceram frente aos diversos aspectos analisados no baseline. Os valores foram estatisticamente semelhantes 
Alfa

(\%)

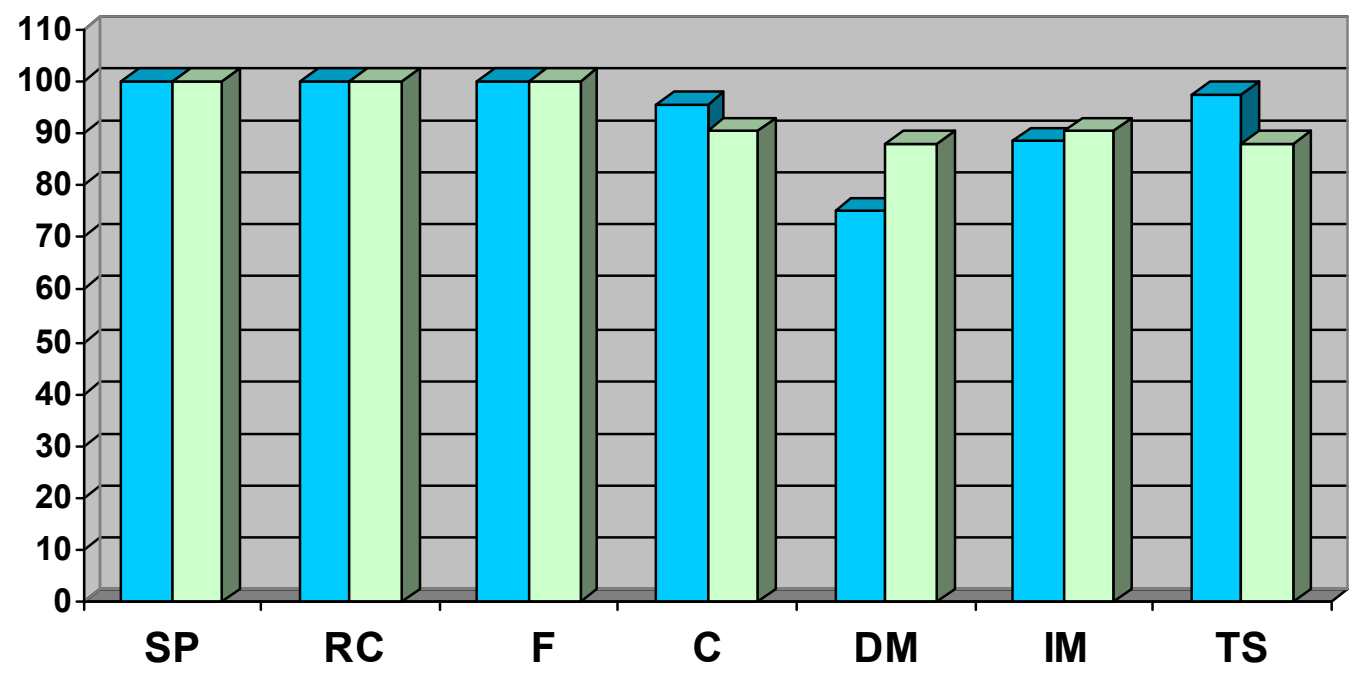

$\square$ IPS Empress $\square$ Duceram

Figura 5.3 - Gráfico ilustrativo dos resultados "Alfa" obtidos pelas cerâmicas IPS Empress e Duceram frente aos diversos aspectos analisados após 01 ano.

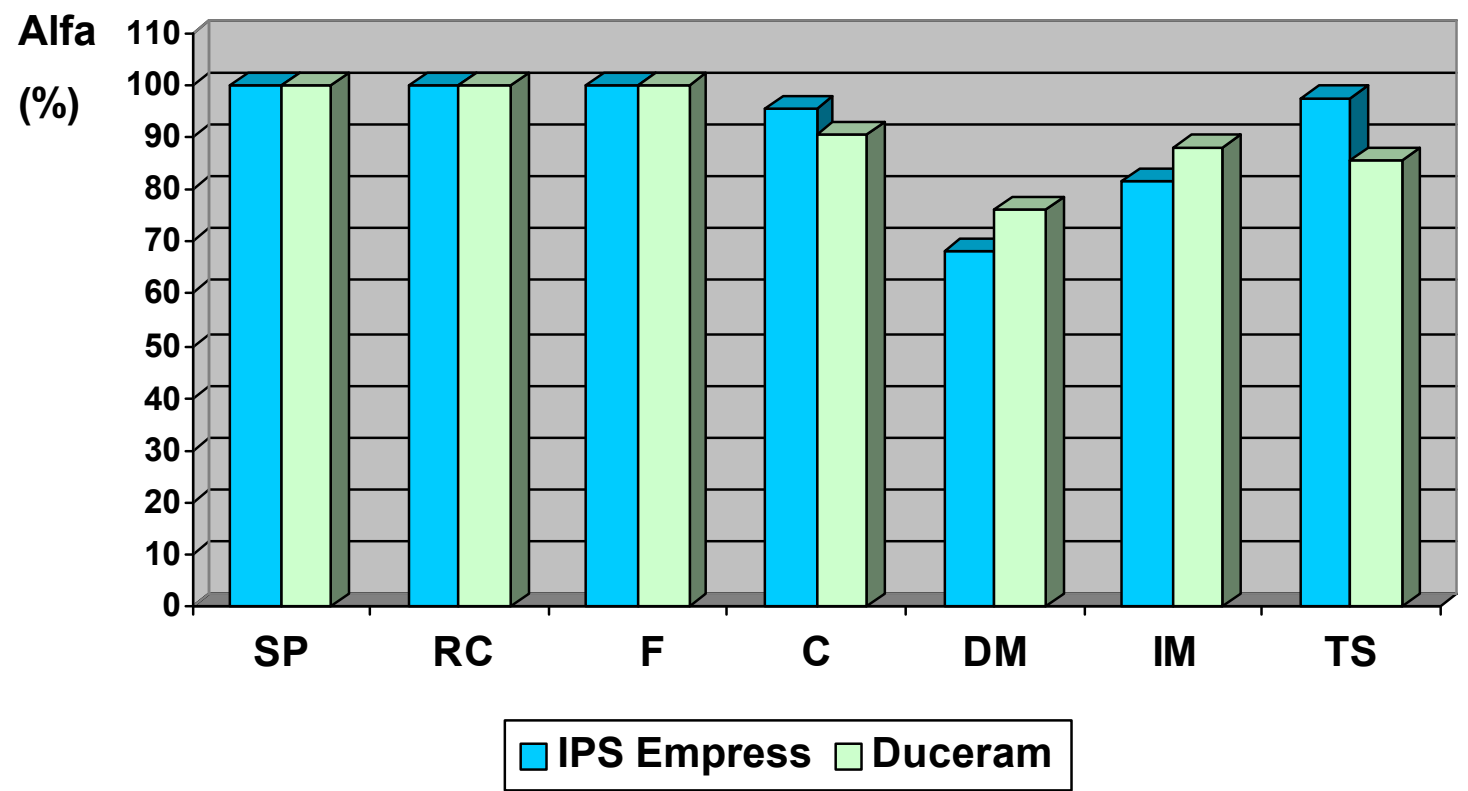

Os valores foram estatisticamente semelhantes

Figura 5.4 - Gráfico ilustrativo dos resultados "Alfa" obtidos pelas cerâmicas IPS Empress e Duceram frente aos diversos aspectos analisados após 02 anos. Os valores foram estatisticamente semelhantes 
Quanto à avaliação do comportamento clínico das restaurações cerâmicas nas regiões de pré-molares e molares optou-se por comparar estatisticamente apenas as restaurações do tipo inlay, devido ao pequeno número de restaurações do tipo onlay realizadas na região de pré-molares. 0 Teste exato de Fisher mostrou não haver diferença estatisticamente significante entre as duas regiões $(p>0,05)$ para os diferentes aspectos avaliados (Figuras 5.5 e 5.6).

\begin{tabular}{|l|c|c|c|c|c|c|}
\hline \multicolumn{1}{|c|}{ Critérios } & \multicolumn{2}{|c|}{$\begin{array}{c}\text { Baseline } \\
\text { PM }\end{array}$} & \multicolumn{2}{c|}{$\begin{array}{c}\text { 01 Ano } \\
\text { Alfa (\%) }\end{array}$} & \multicolumn{2}{c|}{$\begin{array}{c}\text { PI Alfa (\%) } \\
\text { Anos }\end{array}$} \\
\hline $\begin{array}{l}\text { Sensibilidade pós- } \\
\text { operatória }\end{array}$ & 100,00 & 89,65 & 100,00 & 100,00 & 100,00 & 100,00 \\
\hline Reincidência de cárie & 100,00 & 100,00 & 100,00 & 100,00 & 100,00 & 100,00 \\
\hline Fratura & 100,00 & 100,00 & 100,00 & 100,00 & 100,00 & 100,00 \\
\hline Reprodução da cor & 90,47 & 96,87 & 90,47 & 93,75 & 90,47 & 93,75 \\
\hline $\begin{array}{l}\text { Descoloração } \\
\text { marginal }\end{array}$ & 100,00 & 100,00 & 80,95 & 87,50 & 76,19 & 78,12 \\
\hline Integridade marginal & 100,00 & 100,00 & 80,95 & 93,75 & 80,95 & 90,62 \\
\hline Textura superficial & 95,23 & 90,62 & 95,23 & 90,62 & 95,23 & 90,62 \\
\hline
\end{tabular}

Figura 5.5 - Quadro dos resultados "Alfa" da investigação clínica das restaurações do tipo inlay, de acordo com o critério USPHS modificado nas regiões de pré-molares (PM) e molares (M) 
Alfa

(\%)

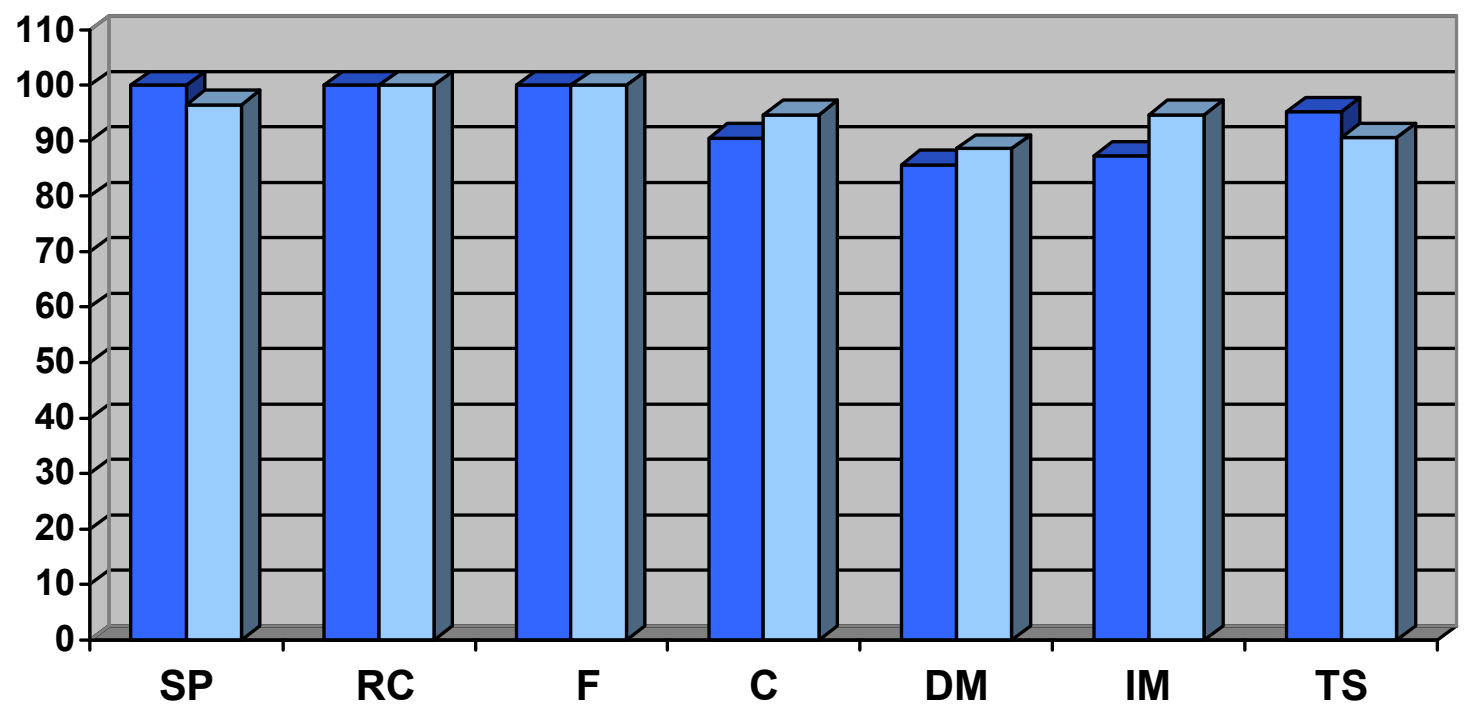

\section{$\square$ Pré-molar $\square$ Molar}

Figura 5.6 - Gráfico ilustrativo da média dos resultados "Alfa" obtidos pelas restaurações cerâmicas do tipo inlay nas regiões de pré-molares e molares frente aos diversos aspectos analisados nas três avaliações de forma conjunta. Os valores foram estatisticamente semelhantes

Com relação ao comportamento clínico das restaurações cerâmicas do tipo inlay e onlay, optou-se por comparar estatisticamente apenas as restaurações realizadas na região de molares, devido ao pequeno número de restaurações do tipo onlay realizadas na região de pré-molares. O Teste exato de Fisher mostrou não haver diferença estatisticamente significante $(p>0,05)$ entre os dois tipos de restaurações para todos os itens investigados (Figuras 5.7 e 5.8$)$. 


\begin{tabular}{|c|c|c|c|c|c|c|}
\hline \multirow[b]{2}{*}{ Critérios } & \multicolumn{2}{|c|}{ Baseline } & \multicolumn{2}{|c|}{01 Ano } & \multicolumn{2}{|c|}{$\underline{02}$ Anos } \\
\hline & IN & $\begin{array}{l}\text { ON } \\
(\%)\end{array}$ & $\begin{array}{l}\text { IN } \\
\text { Alf }\end{array}$ & $\begin{array}{l}\text { ON } \\
(\%)\end{array}$ & $\begin{array}{l}\text { IN } \\
\text { Alf: }\end{array}$ & $\begin{array}{l}\text { ON } \\
(\%)\end{array}$ \\
\hline $\begin{array}{l}\text { Sensibilidade pós- } \\
\text { operatória }\end{array}$ & 89,28 & 96,15 & 100,00 & 100,00 & 100,00 & 100,00 \\
\hline Reincidência de cárie & 100,00 & 100,00 & 100,00 & 100,00 & 100,00 & 100,00 \\
\hline Fratura & 100,00 & 100,00 & 100,00 & 100,00 & 100,00 & 100,00 \\
\hline Reprodução da cor & 96,87 & 92,59 & 93,75 & 92,59 & 93,75 & 92,59 \\
\hline $\begin{array}{l}\text { Descolaração } \\
\text { marginal }\end{array}$ & 100,00 & 100,00 & 87,50 & 81,48 & 78,12 & 66,66 \\
\hline Integridade marginal & 100,00 & 100,00 & 93,75 & 88,88 & 90,62 & 77,77 \\
\hline Textura superficial & 90,62 & 92,59 & 90,62 & 92,59 & 90,62 & 88,88 \\
\hline
\end{tabular}

Figura 5.7 - Quadro dos resultados "Alfa" da investigação clínica, de acordo com o critério USPHS modificado para restaurações do tipo inlay (IN) e onlay (ON) realizadas na região de molares 


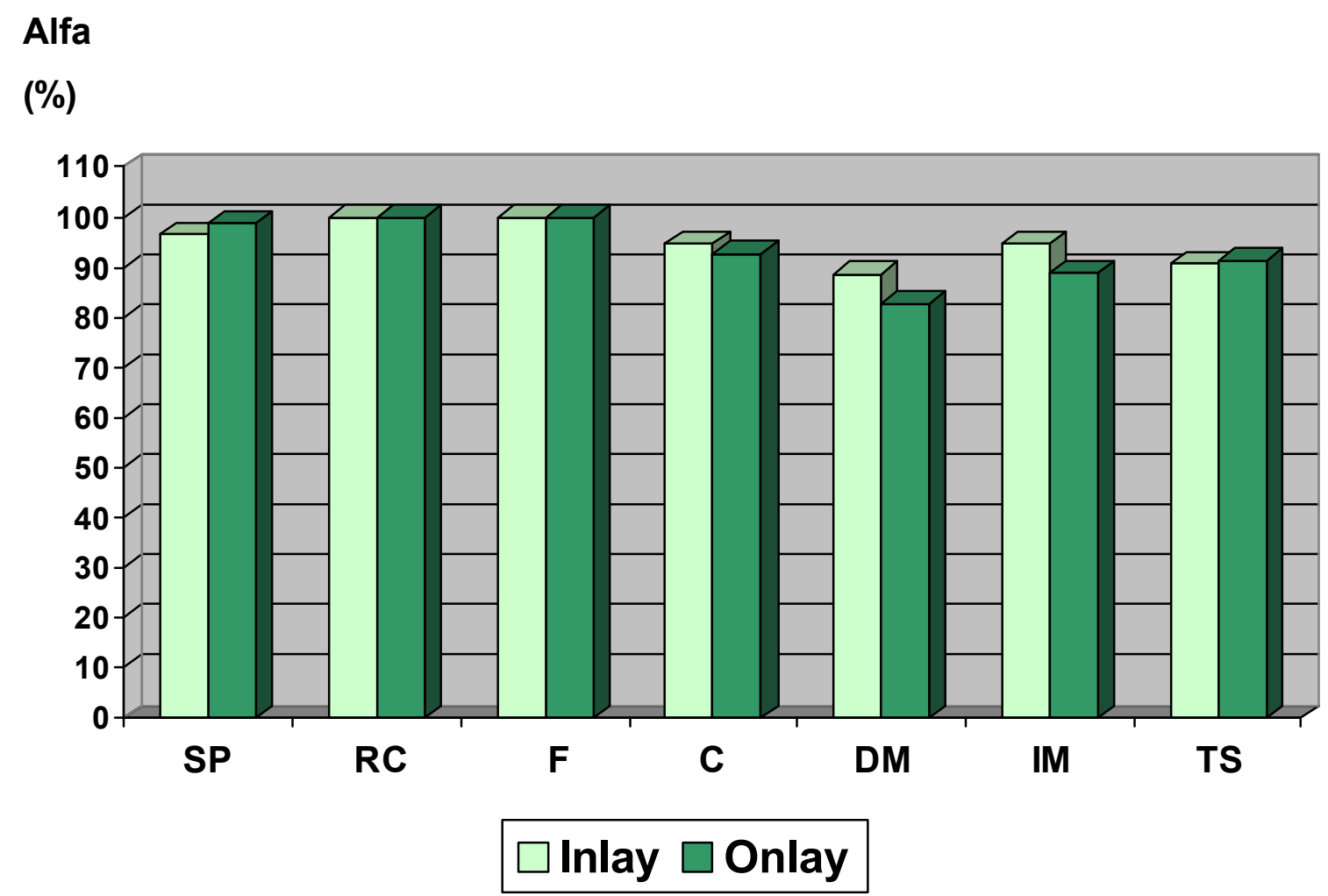

Figura 5.8 - Gráfico ilustrativo da média dos resultados "Alfa" obtidos nas três avaliações pelas inlays e onlays realizadas na região de molares, frente aos diversos aspectos analisados. Os valores foram estatisticamente semelhantes

Mediante a realização do teste estatístico para amostras pareadas de McNemar procurou-se verificar o comportamento clínico das restaurações fabricadas com cada tipo de cerâmica nos diferentes tempos de avaliação. Para as restaurações confeccionadas com a cerâmica Duceram o item descoloração marginal obteve uma porcentagem significantemente maior de escores "Bravo" na avaliação de 02 anos (Figura 5.9) quando comparada aos dados obtidos no baseline $(p=0,004)$. As restaurações confeccionadas com a cerâmica IPS Empress (Figura 5.9) também apresentaram para 0 item 
descoloração marginal uma porcentagem significantemente maior de escores "Bravo" nas avaliações de 01 ano $(p=0,002)$ e 02 anos $(p=0,0005)$, quando comparadas aos dados obtidos no baseline. A comparação dos dados das avaliações de 01 e 02 anos não resultou em diferença estatisticamente significante, para ambas as cerâmicas.

(\%)

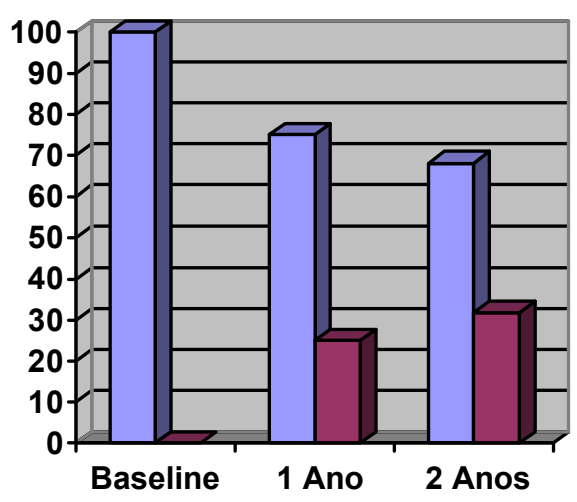

(a) (b)
(\%)

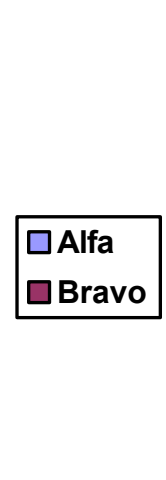

IPS Empress

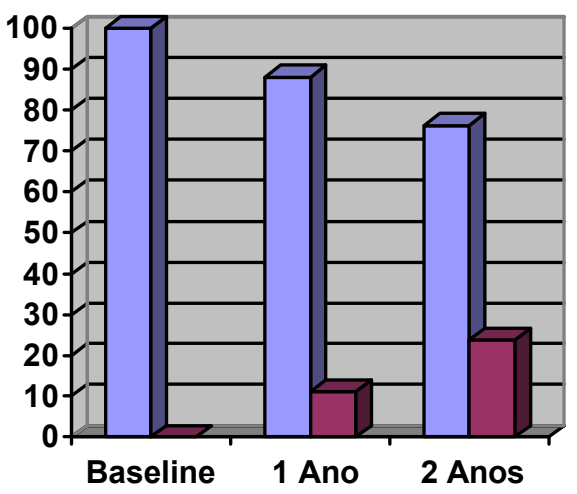

(a)

(ab)

(b)

\section{Duceram}

Figura 5.9 - Gráficos das restaurações cerâmicas IPS e D classificadas com base na porcentagem de escores ("Alfa" e "Bravo") com relação à descoloração marginal. Letras iguais representam valores estatisticamente semelhantes

As figuras relacionadas a seguir ilustram o comportamento de ambos as cerâmicas frente aos aspectos reprodução da cor, integridade marginal e textura superficial avaliados no baseline, 01 e 02 anos (Figuras 5.10 a 5.12). Os itens sensibilidade pós-operatória, cárie recorrente e fratura não estão 
ilustrados devido à ausência de escores "Bravo". O item sensibilidade pósoperatória apresentou alguns escores "Bravo" no baseline, mas esta condição passou a apresentar escores "Alfa" nas avaliações seguintes. Para os itens ilustrados nas próximas figuras o escore "Alfa" representa a condição ideal apresentada pelas restaurações, enquanto o escore "Bravo" salienta a presença de defeitos mínimos, sem necessidade de troca das restaurações.

(\%)

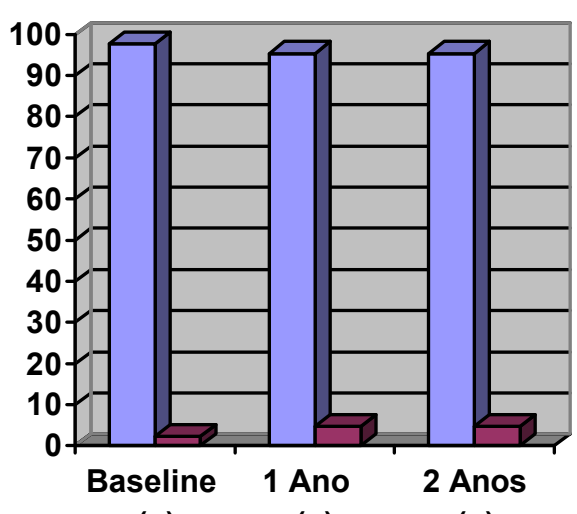

(a) (a) (a)

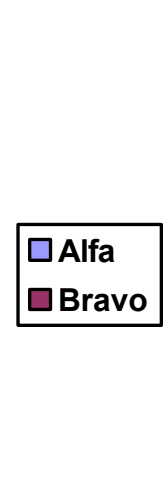

IPS Empress
$(\%)$

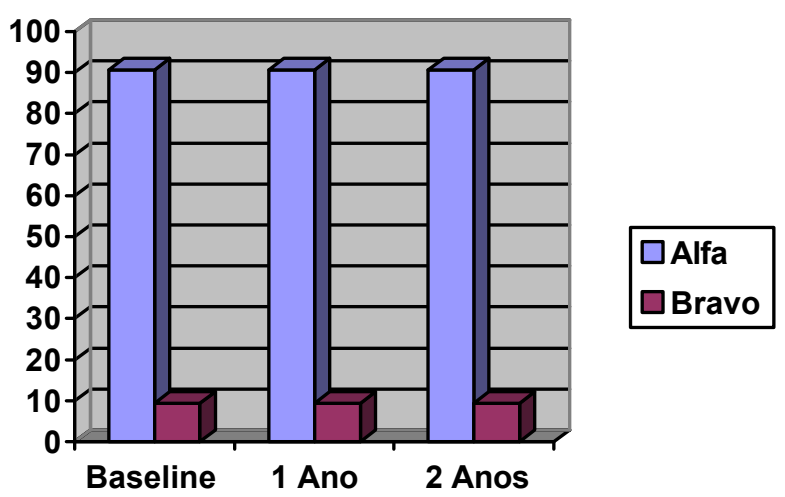

(a)

(a)

\section{Duceram}

Figura 5.10 - Gráficos das restaurações cerâmicas IPS e D classificadas com base na porcentagem de escores ("Alfa" e "Bravo") com relação à reprodução de cor. Letras iguais representam valores estatisticamente semelhantes 
(\%)

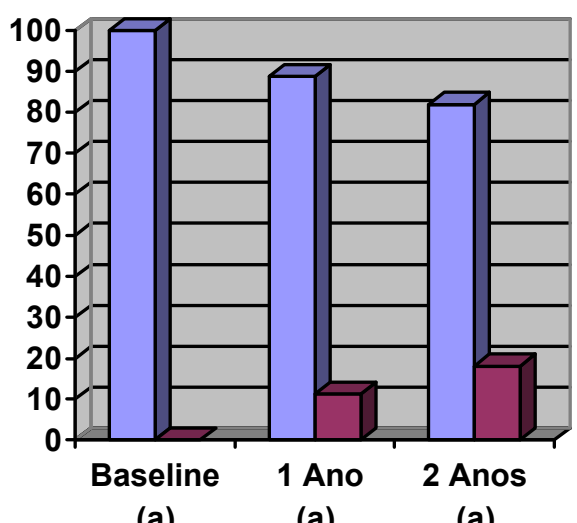

(a) (a) (a)

IPS Empress

(\%)

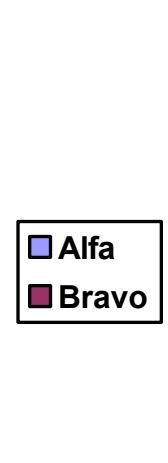

(a)

(a)

(a)

Duceram

Figura 5.11 - Gráficos das restaurações cerâmicas IPS e D classificadas com base na porcentagem de escores ("Alfa" e "Bravo") com relação àintegridade marginal. Letras iguais representam valores estatisticamente semelhantes

(\%)

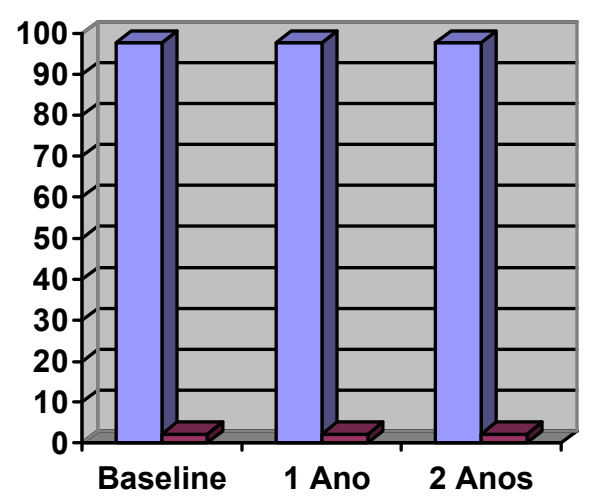

(a)

(a)

(a)

IPS Empress

$(\%)$
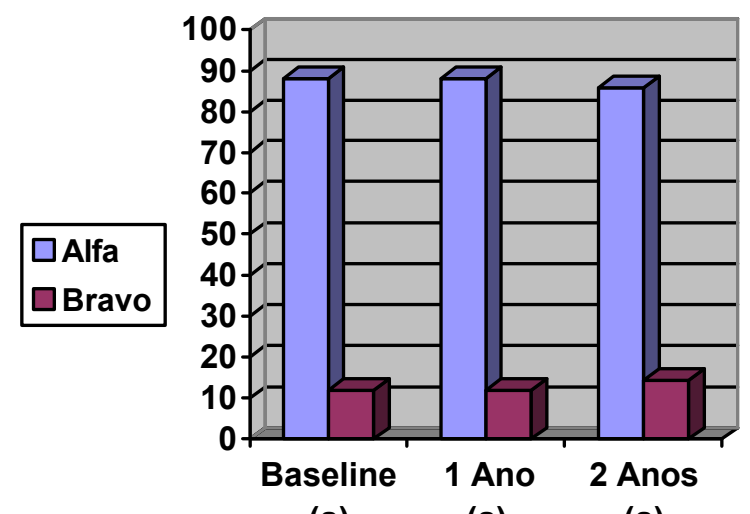

(a)

(a)

(a)

\section{Duceram}

Figura 5.12 - Gráficos das restaurações cerâmicas IPS e D classificadas com base na porcentagem de escores ("Alfa" e "Bravo") com relação à textura superficial. Letras iguais representam valores estatisticamente semelhantes 


\section{2 - RESULTADOS DO TESTE DE KAPPA}

O teste de Kappa foi realizado para detectar o percentual de concordância interexaminador nas avaliações do baseline, 01 e 02 anos. No baseline apenas os aspectos sensibilidade pulpar, reprodução de cor e textura superficial receberam escores "Bravo", denotando um percentual de concordância de $100 \%$ para os outros itens que receberam apenas escores "Alfa". Dentre os itens que obtiveram escores "Bravo", os seguintes resultados foram estabelecidos, mediante o teste de Kappa: sensibilidade pulpar - 1,0 (100\%); reprodução de cor - 0,78 (78\%) e textura superficial - 0,65 (65\%).

$\mathrm{Na}$ avaliação de 01 ano os seguintes resultados foram obtidos: reprodução de cor - 0,82 (82\%); descoloração marginal - 0,82 (82\%); integridade marginal - 0,68 (68\%) e textura superficial - 0,65 (65\%).

$\mathrm{Na}$ avaliação de 02 anos observou-se uma elevação no grau de concordância entre os dois avaliadores, conforme os resultados: reprodução de cor - 0,82 (82\%); descoloração marginal - 0,88 (88\%); integridade marginal $0,8(80 \%)$ e textura superficial $-0,82(82 \%)$. 


\section{6 - DISCUSSÃO}




\section{6 - DISCUSSÃo}

\section{1- Escolha dos sistemas cerâmicos}

Diversos sistemas utilizados na confecção de restaurações em cerâmica pura estão disponíveis no mercado atualmente. As diferenças entre eles residem na composição, método de fabricação, resistência e graus de opacidade. De acordo com ROSENBLUM; SCHULMAN ${ }^{102}$ (1997), qualquer um destes sistemas pode ser utilizado com sucesso para a confecção de inlays e onlays de cerâmica.

Dentre os sistemas atuais mais utilizados destaca-se o sistema convencional, no qual o pó cerâmico é misturado àágua para a construção da restauração por etapas. Neste processo, a cerâmica é aplicada sobre um modelo refratário e várias queimas são feitas até obter-se a forma final da restauração. A vantagem deste sistema reside na não necessidade da aquisição de um aparelho especial para a fabricação destas restaurações, uma vez que o próprio forno para a confecção de coroas metalo-cerâmicas é utilizado ${ }^{102}$. Inúmeras marcas comerciais estão disponíveis no mercado para a fabricação de inlays e onlays de cerâmica por este método. No presente estudo, a cerâmica Duceram (Plus e LFC) foi escolhida devido ao pequeno número de investigações clínicas sobre a performance deste sistema. Uma peculiaridade desta cerâmica é a possibilidade de novas queimas na fase final da confecção, uma vez que a temperatura final de $660^{\circ} \mathrm{C}$ da cerâmica de baixa fusão (LFC) possibilita maior número de queimas sem que haja alteração da cerâmica de base (Plus), em função de esta ser de alta fusão $\left(970^{\circ} \mathrm{C}\right)$. 
Um outro sistema, muito utilizado para a confecção de inlays e onlays, baseia-se na utilização da cerâmica prensada. Dentre os sistemas disponíveis no mercado, destaca-se o sistema IPS Empress (Ivoclar-Vivadent) lançado em $1990^{20}$, o qual abrange um grande número de investigações clínicas reportadas na literatura para a avaliação destes tipos de restaurações. $O$ sistema de cerâmica prensada caracteriza-se pela fundição da cerâmica, a qual é injetada por pressão sobre um molde obtido pelo processo da cera perdida ${ }^{69}$. Trata-se de um processo similar ao utilizado para a confecção de restaurações metálicas, com algumas particularidades.

GORMAN; MCDEVITT; HILL ${ }^{46}$, em 2000, consideraram que a cerâmica prensada permite uma melhor adaptação marginal devido ao processo de fabricação utilizar a cerâmica fundida que é injetada no molde por pressão e por apresentar baixo índice de contração, uma vez que o material é fornecido em pastilhas pré-ceramizadas. Já as cerâmicas fabricadas pelo sistema convencional apresentariam uma adaptação inferior em função da contração ocorrida durante o processo de sinterização. No entanto, os valores de adaptação marginal divulgados na literatura situam-se em torno de 62,77 ì m ${ }^{126}$ a 90 ì m ${ }^{85}$ para o sistema IPS Empress e próximos de 68 ì m para inlays do sistema Duceram ${ }^{101}$. O valor da fenda marginal aceitável clinicamente para inlays de cerâmica ainda não está bem definida na literatura ${ }^{6,80,119}$. Valores entre 5 a 500 ì m ${ }^{44}$ têm sido reportados. DIETSCHI; MAEDER; HOLZ ${ }^{26}$, em 1992, utilizando os sistemas cerâmicos Vitadur N e Ceranco II, verificaram que a espessura da fenda marginal variou entre 46 a 57 ì m. SULAIMAN et al. ${ }^{126}$, em 1997, constataram uma desadaptação marginal de 62,77 ì m para o 
sistema IPS Empress e 160,66 ì m para o sistema In-Ceram. O'NEAL; MIRACLE; LEINFELDER ${ }^{88}$, em 1993, obtiveram os valores de 169 e 216 ì m para os sistemas CEREC e Cerinate, respectivamente. McLEAN; von FRAUNHOFER ${ }^{77}$, em 1971, consideraram que desadaptações marginais de até 80 ì m ou menos são difíceis de serem detectadas clinicamente por sonda ou radiograficamente. AUDENINO et al. ${ }^{6}$, em 1999, consideraram que embora o valor ideal de adaptação das margens das restaurações cerâmicas ainda não tenha sido claramente definido, uma espessura de cimento uniforme de até 100 ì $\mathrm{m}$ pode ser considerada satisfatória.

Neste estudo, os dois sistemas apresentaram uma adaptação marginal altamente satisfatória pré-cimentação, sem diferença clínica visível entre eles. A adaptação marginal das restaurações foi sempre testada sob isolamento absoluto e devolvida ao laboratório quando considerada não adaptada. Apenas duas restaurações foram repetidas. Acreditamos que a adaptação marginal das restaurações possui maior dependência da precisão técnica do laboratório que as fabrica do que do sistema em si. Esta afirmativa está em concordância com outros autores $^{26,70}$. No entanto, observando-se a interface oclusal de algumas restaurações por MEV, visualizou-se áreas com fendas marginais maiores que 100 ì m, para ambas as cerâmicas, as quais podem ter sido ampliadas após o ajuste oclusal (Figura 6.1). Este fato justifica-se por, justamente na interface de união, verificarmos um menor volume de cerâmica, provavelmente devido à inclinação das paredes circundantes (10 a 15\%), bem como, pela dificuldade em se reproduzir a anatomia oclusal, principalmente com relação à correta inclinação das vertentes triturantes. 


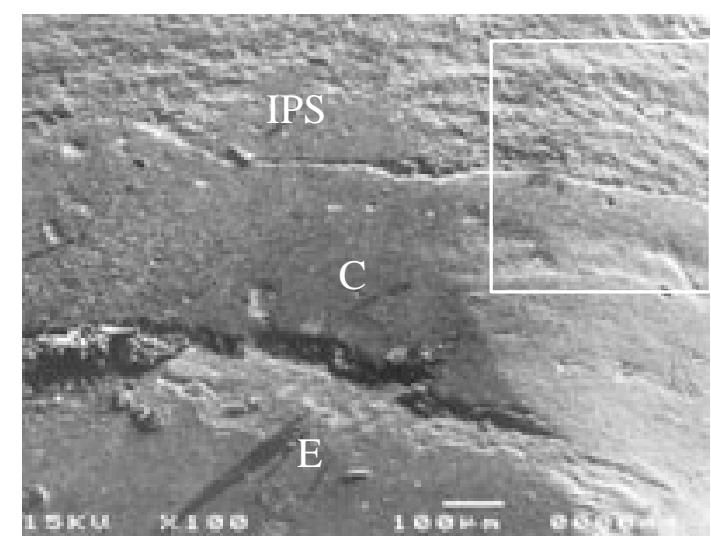

Baseline (a)

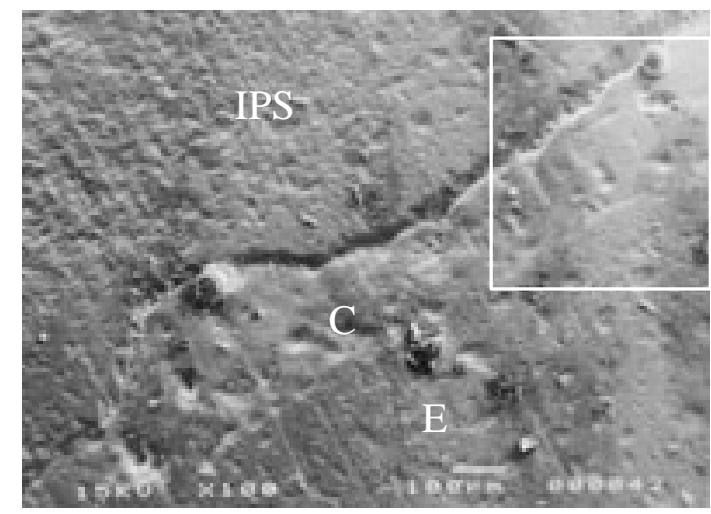

01 ano (a)

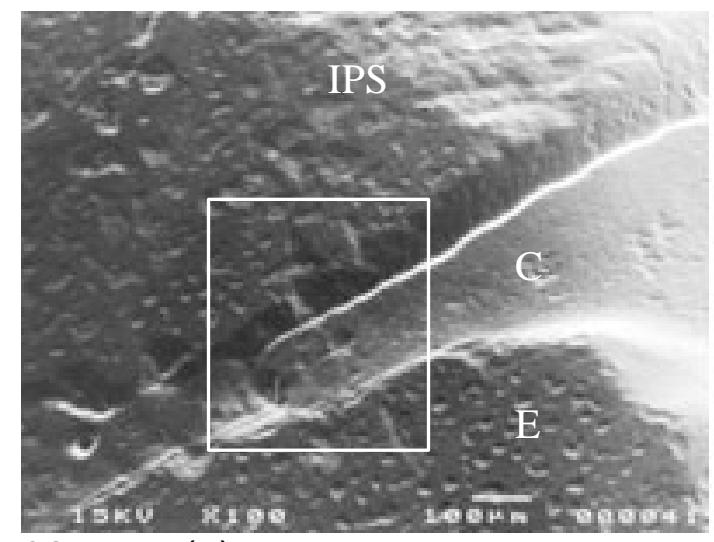

02 anos (a)

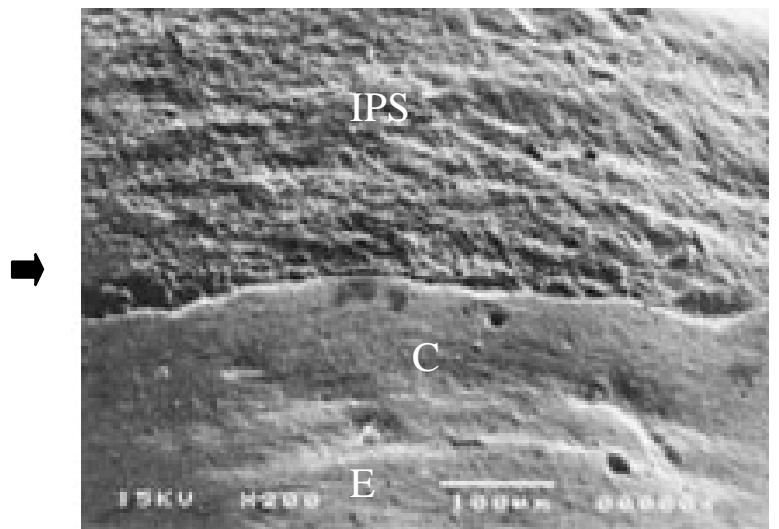

Baseline (b)
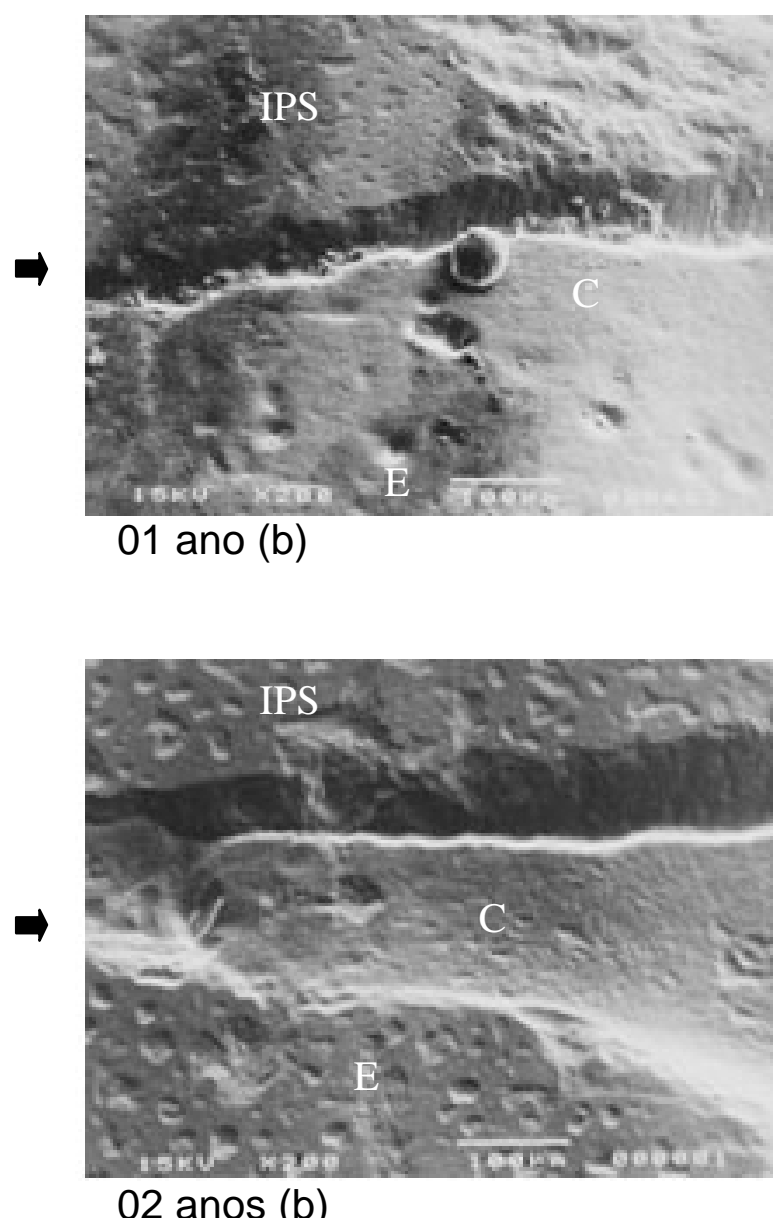

02 anos (b)

Figura 6.1 - Imagens por MEV das réplicas para a verificação do desgaste do cimento resinoso (C) da mesma restauração cerâmica (IPS) em diferentes tempos. Esmalte (E). Aumentos de $100 \mathrm{X}$ (a) e $200 \mathrm{X}$ (b) 


\section{2 - Fatores relacionados à cimentação}

O cimento resinoso tem tido o seu uso exaustivamente encorajado para a fixação de restaurações em cerâmica pura ${ }^{10,11,14,16,43,49,91,94}$. Devido à sua menor solubilidade ${ }^{67,}{ }^{94}$ acreditou-se que este poderia ser utilizado indiscriminadamente, com o intuito de compensar a discrepância marginal das restaurações e, por conseguinte, permitir a cimentação de restaurações com pobre adaptação marginal. Esta afirmação, entretanto, merece cautela uma vez que tem sido freqüentemente descrito na literatura a baixa resistência ao desgaste destes cimentos ${ }^{45,51,63,64,65,88,113,115,127}$. Alguns autores ${ }^{49,59,86,115}$ têm mostrado que há um aumento do desgaste do cimento resinoso na medida em que a extensão da fenda marginal é ampliada.

Estudos laboratoriais têm sido realizados no intuito de tentar elucidar qual o agente cimentante com características mais adequadas para a fixação de inlays e onlays de cerâmica. O cimento de ionômero de vidro tem sido considerado como uma opção secundária, apesar da suas excelentes propriedades, tais como, união à estrutura dental, liberação de flúor e coeficiente de expansão térmica semelhante à estrutura dentária ${ }^{84}$. As principais desvantagens do cimento de ionômero de vidro são a sua inabilidade em unir-se à cerâmica ${ }^{53} \mathrm{e}$ grande expansão higroscópica, a qual pode induzir fraturas nas cerâmicas puras ${ }^{117}$. A supremacia dos cimentos resinosos sobre 0

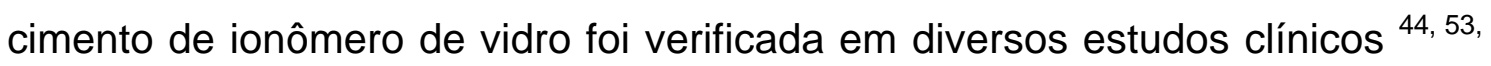
$71,131,132$. 
Os cimentos resinosos duais, por permitirem um maior tempo de trabalho e alcançarem um alto grau de conversão na ausência de luz, têm sido considerados os cimentos eleitos para a cimentação de inlays e onlays de cerâmica ${ }^{11,17,30,67,73,91}$. ISIDOR; BRONDUM ${ }^{55}$, em 1995, avaliaram 25 inlays de cerâmica por um período de 57 meses e detectaram 10 falhas por fratura, dentre as quais, 8 inlays foram fixadas com cimento fotopolimerizável e apenas 2, fixadas com cimento de presa dual, estabelecendo uma diferença estatisticamente significante. Com relação à efetividade de cura dos cimentos resinosos duais, alguns autores ${ }^{31,67,108}$ têm demonstrado que o potencial de polimerização química e por luz dos cimentos varia de acordo com a marca comercial, sendo geralmente a polimerização química inferior à polimerização por luz. Uma significante redução na dureza dos cimentos foi observada quando espaçadores de cerâmica acima de 2 a $3 \mathrm{~mm}$ foram utilizados ${ }^{30,31}$. O tempo de exposição de luz foi considerado de fundamental importância para compensar a atenuação sofrida pela luz, tendo o tempo de 40 segundos sido considerado insuficiente ${ }^{67,108}$.

Dentre as vantagens dos cimentos resinosos destaca-se a menor solubilidade no meio oral, estética, união à estrutura dental e à cerâmica ${ }^{24} \mathrm{e}$ reforço do remanescente dental e da cerâmica. Um aumento significativo de resistência àtração tem sido atribuído ao cimento resinoso quando comparado ao cimento de fosfato, ao cimento de policarboxilato e ao cimento de ionômero de vidro ${ }^{13,79,153}$. Como desvantagem destaca-se o alto índice de desgaste do cimento resinoso $45,63,64,65,88,127,133$. 
No presente estudo, o aspecto clínico mais correlacionado ao desgaste do cimento foi a descoloração marginal. Este item mostrou um aumento gradativo da sua incidência com o tempo, para ambas as cerâmicas, chegando a apresentar diferença estatística quando os dados obtidos após 01 ano ( $p=$ 0,002 - IPS) e após 2 anos $(p=0,0005$ - IPS e $p=0,004-$ D) foram comparados aos dados do baseline. As fotomicrografias obtidas em microscopia eletrônica de varredura foram feitas com o objetivo de visualizar e ilustrar o desgaste do cimento resinoso com o tempo. De acordo com KREJCI; KREJCI; LUTZ ${ }^{65}$, 1992, GLADYS et al. ${ }^{45}, 1995$, FRIEDL et al. ${ }^{40}, 1996$, THONEMANN et al. ${ }^{127}$, 1997, a microscopia eletrônica de varredura é um eficiente auxiliar no diagnóstico da integridade marginal, no entanto, o exame clínico é necessário para a determinação da necessidade ou não de troca das restaurações.

Van MEERBEEK et al. ${ }^{133}$, em 1992, verificaram, mediante análise em MEV, um significante decréscimo na qualidade marginal da interface inlaycimento, após 06 meses de vida clínica, indicando um severo desgaste do cimento resinoso.

\section{ZUELLING-SINGER; BRYANT ${ }^{136}$ (1998) e GEMALMAZ; ÖZCAN;} ALKUMRU ${ }^{44}$ (2001) verificaram que o desgaste do cimento resinoso foi mais acentuado na interface cimento - cerâmica do que na interface cimento esmalte. Este fato está associado ao alto módulo de elasticidade da cerâmica, a qual ao invés de absorver as forças mastigatórias que incidem sobre ela, transmite para o cimento, cujo módulo de elasticidade é menor ${ }^{65,99}$. Com relação ao desgaste do cimento em inlays de resina composta, diversos 
estudos ${ }^{45,131}$ observaram um desgaste similar do cimento e da inlay de resina, resultando numa aparente melhora da adaptação marginal. No entanto, o desgaste deste torna-se evidente na interface esmalte-cimento.

Diversos estudos clínicos ${ }^{34,36,38,40,45,51,52,62,63,72,89,96,113,127,129}$ têm mostrado que a descoloração marginal, seguida pela integridade marginal são os itens com maior incidência de escores "Bravo" demonstrando que a boa adaptação marginal inicial pode não permanece estável ao longo dos anos. No entanto, o alto índice de descoloração marginal, na maioria das vezes, não implica na necessidade de troca das restaurações 40,45, 63, 65, 127 . Nestes estudos, o desgaste do cimento resinoso foi sempre considerado o fator responsável pela descoloração e solução de continuidade da integridade marginal. O alto índice de desgaste do cimento resinoso pode, entretanto, deixar a cerâmica na margem da restauração sem suporte podendo acarretar em microfraturas ${ }^{51,63}$. Dentre os cimentos resinosos disponíveis, os com alto conteúdo de carga inorgânica ${ }^{91,94}$ e os de micropartículas ${ }^{33,59,88,94,115,136}$ têm sido considerados mais resistente ao desgaste.

\section{3 - Fatores relacionados ao sucesso das restaurações cerâmicas}

Inúmeros fatores são responsáveis pelo sucesso clínico das inlays e onlays cerâmicas, destacando-se como principais: preparo e cimentação efetivos. Uma espessura de cerâmica uniforme ${ }^{93}$, mínima de 1,5 a 2,0 mm, 
deve ser promovida pelo preparo cavitário $8,28,43,48,55,83$. A união da restauração cerâmica ao dente, através do cimento resinoso, permitirá não apenas a retenção da restauração, mas contribuirá para o aumento da resistência desta ${ }^{8,47,53,60,78,106}$.

Devido àcaracterística de friabilidade dos materiais cerâmicos, a união destes à estrutura dentária pela técnica de cimentação adesiva torna-se um mecanismo eficaz no aumento da resistência à fratura destes materiais ${ }^{78,} 95$. Através do mecanismo de união da cerâmica à estrutura dental, as forças mastigatórias são transmitidas aos tecidos dentais subjacentes, evitando que a concentração de forças incida isoladamente sobre o material friável ${ }^{49,} 78$. GARBER; GOLDSTAIN ${ }^{43}$ (1996) compararam a restauração cerâmica, précimentação, ao esmalte sem suporte, o qual apresenta-se, nesta situação, altamente susceptível à fratura. Entretanto, no momento em que a cerâmica é unida aos tecidos dentários, através do sistema adesivo e cimento resinoso, esta passa a se comportar como o esmalte suportado por dentina, sobre o qual o estresse externo é transmitido ao conjunto de forma harmônica. O princípio do uso de uma substância elástica sob uma friável é bastante utilizado em engenharia, como meio de suportar e reforçar o material frágil ${ }^{93}$.

O potencial de reforço promovido ao elemento dental ${ }^{43,57,70,112}$ e à cerâmica $^{8,14,47,53,60,78,106}$ pelos cimentos resinosos através da técnica adesiva têm sido considerado primordial na longevidade das restaurações. BLATZ; DENT 9 , em 2002, creditaram às técnicas adesivas e ao surgimento de cerâmicas mais resistentes, o alto índice de sucesso das avaliações clínicas. No presente estudo, o cimento resinoso dual Variolink II (Ivoclar-Vivadent) foi 
utilizado juntamente com o sistema adesivo Syntac Classic na fixação das restaurações cerâmicas. Nenhuma fratura foi evidenciada após dois anos de avaliação clínica. Apesar das cerâmicas utilizadas apresentarem valores diferentes de resistência flexural de $134,4 \mathrm{MPa}{ }^{46}$ a $182 \mathrm{MPa}{ }^{69}$ para o sistema IPS Empress e 70 MPa e 120 MPa (Degussa) ${ }^{\star}$ para as cerâmicas Duceram Plus e Duceram LFC, respectivamente, ambas apresentaram um excelente comportamento clínico, sem diferença estatisticamente significante entre elas. De acordo com HÖGLUND; DIJKEN; OLOFSSON ${ }^{53}$, 1992; ANUSAVICE ${ }^{5}$, 1997, SINDEL et al. ${ }^{117}, 1999$, o cimento resinoso deve sempre ser usado quando almeja-se o reforço do sistema cerâmico.

NEIVA et al. ${ }^{85}$ (1998) verificaram num estudo in vitro a resistência à fratura de três sistemas cerâmicos com diferentes valores de resistência flexural (IPS Empress - $170 \mathrm{MPa}$; In-Ceram - $450 \mathrm{MPa}$ e Procera - $600 \mathrm{MPa}$ ) fixados aos dentes com cimento resinoso pela técnica adesiva. Apesar dos diferentes valores de resistência flexural dos sistemas testados, não houve diferença significante na resistência à fratura entre os sistemas. Este fato foi atribuído ao reforço promovido pelo cimento resinoso àcerâmica IPS Empress, bem como, a inabilidade do cimento resinoso em unir-se às cerâmicas com alto teor de alumina (In-Ceram e Procera), uma vez que o condicionamento com ácido fluorídrico e a silanização não são efetivos nestes sistemas, devido ao baixo conteúdo de fase vítrea e de sílica ${ }^{7,21,23,61,85,90,97}$. Na realidade, alguns estudos mostraram uma redução na força de união do cimento resinoso com as

\footnotetext{
* Informação fornecida pela empresa Degussa.
} 
cerâmicas com alto teor de alumina, quando o condicionamento com o ácido fluorídrico foi utilizado ${ }^{7,90}$.

Para que a adesão seja eficaz, as interfaces: - cerâmica x cimento resinoso; - cimento resinoso $\mathrm{x}$ sistema adesivo; e - sistema adesivo $\mathrm{x}$ dente devem ser cuidadosamente trabalhadas. A ligação cerâmica $x$ cimento resinoso tem sido exaustivamente descrita na literatura. $\mathrm{O}$ uso do jateamento com partículas de óxido de alumínio e do condicionamento com ácido fluorídrico tem sido considerado responsável pela união mecânica, assim como, o silano, promotor da união química $3,7,22,58,66,107,116,120$. O silano é uma molécula bifuncional que reage com a cerâmica através do radical inorgânico e por intermédio do radical orgânico do grupo metacrilato é capaz de co-polimerizar com o cimento resinoso ${ }^{92}$. As cerâmicas utilizadas neste estudo são do tipo convencional e prensada, ambas feldspáticas com baixo conteúdo de alumina, o que reforça a indicação do uso do jateamento, do condicionamento ácido e silanização nestas cerâmicas. Valores de resistência de união entre o cimento resinoso e a cerâmica de 6,8 e $20 \mathrm{MPa}$ foram relatados ${ }^{22,90}$.

A interface de união sistema adesivo $x$ cimento resinoso já é conhecida e assemelha-se ao mecanismo de união da resina composta ao sistema adesivo, no qual radicais semelhantes (metacrilato de metila) se unem quimicamente e estabelecem uma união duradoura ${ }^{92}$. Alguns estudos têm mostrado que o baixo $\mathrm{pH}$ dos sistemas adesivos pode interferir na compatibilidade entre os sistemas adesivos e cimentos resinosos de marcas diferentes. O intercâmbio entre diferentes sistemas pode, entretanto, ser utilizado sem prejuízo à adesão, desde que os sistemas intercambiados 
tenham sido previamente testados quanto a sua compatibilidade ${ }^{37}$. Neste estudo, utilizou-se o sistema adesivo Syntac Classic e o cimento resinoso Variolink II, ambos provenientes da Ivoclar-Vivadent, pela facilidade na aquisição e segurança no uso do kit de cimentação.

A interface de união sistema adesivo $\mathrm{x}$ dente representa o ponto de maior complexidade, uma vez que inúmeros fatores estão presentes e podem ajudar ou comprometer a durabilidade desta união. Dentre estes fatores podese destacar o tipo de dentina (esclerótica ou não); o ressecamento da dentina com conseqüente colapso das fibrilas colágenas; o grau de umidade necessário ao sistema adesivo; e a resistência da força de união do sistema adesivo àdentina.

Durante os dois anos de avaliação clínica das inlays e onlays cerâmicas, estudos laboratoriais paralelos foram realizados com o intuito de elucidar alguns fatores direta ou indiretamente relacionados à durabilidade clínica destas restaurações. Num estudo laboratorial ${ }^{\star}$ procurou-se determinar, pelo ensaio de microtração, a força de união de alguns sistemas adesivos disponíveis no mercado, indicados para a cimentação de restaurações indiretas. Paralelamente, verificou-se a influência da fotoativação do sistema adesivo na espessura deste, por meio da microscopia eletrônica de varredura. Sete marcas comerciais de sistemas adesivos foram utilizadas, incluindo para os adesivos duais, duas formas de fotoativação - antes e após a inserção da restauração indireta. Este estudo se fez pertinente pela grande variedade de

\footnotetext{
- Estudo realizado durante o estágio do Doutorado sanduíche na Universidade de Toronto, Canadá. Artigo em fase de publicação na revista Operative Dentistry.
} 
sistemas adesivos disponíveis atualmente no mercado, com formulações e modos de aplicação distintos, o que gera dúvidas com relação à escolha do sistema mais apropriado para o uso clínico. Neste estudo laboratorial pôde-se concluir que a fotoativação prévia dos sistemas adesivos não aumentou a força de adesão para todos os materiais testados, sendo a elevação da força de união pela fotoativação prévia dependente do material. Já FRANKENBERGER 39 (1999), utilizando adesivos de $3^{\circ}, 4^{\circ}$ e $5^{\circ}$ geração, verificaram um aumento significativo na resistência de união de restaurações diretas e indiretas, sempre que o adesivo era fotoativado previamente a inserção dos materiais restauradores.

Dentre os sistemas adesivos testados no estudo laboratorial, o sistema adesivo fotopolimerizável Single Bond apresentou a maior força de adesão $(43,4 \pm 9,8 \mathrm{MPa})$ e os sistemas adesivos duais, Syntac Classic e Scotchbond Multipurpose Plus, que utilizam vários passos no intuito de evitar a fotoativação prévia, mostraram o pior desempenho. No entanto, apesar do sistema adesivo Syntac Classic ter apresentado baixos valores de adesão in vitro quando comparado aos outros sistemas, este resultado não gerou nenhum tipo de influência negativa no presente estudo clínico, com até dois anos de acompanhamento. Até a presente data, a força de união de $11,7 \pm 4,5 \mathrm{MPa}$ obtida pelo sistema Syntac Classic tem mostrado ser suficiente para suportar as exigências clínicas. Nenhuma restauração foi perdida por falha adesiva ou apresentou índices de degradação maiores que os relatados na literatura. Esses resultados assemelham-se aos resultados obtidos por THONEMANN et al. ${ }^{127}$, em 1997, em que as restaurações cerâmicas foram fixadas com o 
sistema adesivo Syntac Classic e cimento resinoso Variolink e apresentaram um índice de sucesso de 100\% após 02 anos.

A influência da baixa resistência de união de alguns sistemas adesivos no desempenho clínico das restaurações necessita ser avaliada a longo prazo. De acordo com AUDENINO ${ }^{6}$ (1999) a diferença da força de união entre os adesivos pode não ser diretamente relevante nos primeiros anos de serviço clínico, no entanto, este fator pode eventualmente afetar a longevidade destas restaurações. A constante renovação de sistemas adesivos no mercado, com a introdução de agentes de união dentinários com valores de adesão cada vez mais altos podem ser considerados aliados na longevidade das futuras restaurações cerâmicas.

Com relação à espessura de película do sistema adesivo, pesquisada no estudo paralelo, in vitro, pôde-se verificar uma faixa visível da camada do adesivo abaixo da linha de cimento para todos os sistemas fotoativados. A maior espessura da camada de adesivo fotopolimerizado foi constatada previamente em outros estudos ${ }^{39,50}$. Nos sistemas sem fotoativação prévia, a exemplo do sistema Syntac Classic, nenhuma linha de adesivo foi visualizada, provavelmente pela mistura do agente adesivo ao cimento resinoso, colocado imediatamente acima. A real influência da linha de adesivo na adaptação e longevidade deste tipo de restauração necessita, entretanto, de maiores investigações. 


\section{4 - Discussão dos resultados}

Oitenta e seis restaurações cerâmicas (100\%) foram avaliadas no baseline e após 01 e 02 anos por dois examinadores treinados no uso do sistema USPHS modificado. O percentual de concordância interexaminador foi verificado pelo teste de Kappa e os valores foram determinados para cada aspecto clínico analisado. O teste de Kappa é considerado o mais apropriado para avaliar a confiabilidade do exame clínico, uma vez que acrescenta à sua fórmula o grau de concordância que pode ter ocorrido ao acaso entre os examinadores ${ }^{54}$. Desta forma, o teste consegue quantificar o grau de concordância entre os examinadores que ocorreu além do acaso, no momento de verificar a presença ou a ausência do aspecto avaliado.

De acordo com FLEISS; CHILTON ${ }^{35}$ (1983) valores de Kappa abaixo de 0,4 indicam uma pobre porcentagem de concordância; entre 0,4 a 0,75, uma confiabilidade boa e acima de 0,75 até 01 , representam uma excelente concordância entre os examinadores. Diante dos resultados obtidos pelo teste de Kappa, pôde-se verificar que o item textura superficial obteve 0,65 de concordância no baseline e 01 ano, e 0,82 após 02 anos. Da mesma forma, o item reprodução de cor apresentou uma porcentagem de concordância 0,78 no baseline e esta porcentagem aumentou para 0,82 nas avaliações seguintes.

$\mathrm{Na}$ avaliação de 01 ano os itens integridade marginal e descoloração marginal apresentaram 0,68 e 0,82 de concordância, respectivamente. No entanto, esta consistência se elevou para 0,80 e 0,88 em 02 anos. Este teste levou em consideração os escores obtidos pela avaliação individual e 
independente de cada examinador ${ }^{54,110}$. No entanto, toda vez em que houve discordância entre os escores atribuídos pelos examinadores, uma segunda avaliação foi realizada com o objetivo de se chegar a um acordo. Neste estudo, o grau de concordância foi classificado entre bom a excelente, dependendo da época e do aspecto avaliado, tendo os aspectos textura superficial e integridade marginal apresentado os índices de concordância mais críticos. SCHEIBENBOGEN et al. ${ }^{113}$ (1998), avaliando restaurações indiretas estéticas, apresentaram um percentual de concordância a partir de 0,62 para os critérios avaliados, exceto para o aspecto cor, cujo grau de concordância situou-se em 0,29 .

Os materiais cerâmicos investigados apresentaram resultados plenamente satisfatórios após dois anos de serviço clínico, sem diferença estatisticamente significante entre eles $(p>0,05)$. A taxa de sucesso das restaurações foi de $100 \%$ para ambas as cerâmicas. Estes resultados estão de acordo com os trabalhos de FRIEDL et al. ${ }^{40}$ (1996); THONEMANN et al. ${ }^{127}$ (1997), cujos trabalhos avaliaram inlays e onlays de cerâmica pelo mesmo período. E apresentaram resultados superiores aos trabalhos de REINELT et al. ${ }^{100}$ (1995), cuja avaliação de restaurações cerâmicas IPS Empress pelo período de 02 anos revelou falha em três inlays, sendo uma por problema endodôntico e duas por fratura. TIDEHAG; GUNNE ${ }^{130}$, em 1995, após 26 meses de avaliação clínica de inlays e onlays confeccionadas pelo sistema IPS Empress detectaram fratura em uma onlay. STUDER et al. ${ }^{124}$, em 1996, após 02 anos de avaliação de 130 restaurações cerâmicas, IPS Empress, apresentaram 3 restaurações que falharam por fratura, resultando em uma taxa 
de sucesso de 97,5\%. STENBERG; MATSSON ${ }^{123}$, em 1993, avaliaram 25 inlays confeccionadas pelo sistema Dicor fixadas nas cavidades com cimento de ionômero de vidro. Após 24 meses 2 inlays haviam fraturado.

Dentre os aspectos avaliados mediante o critério USPHS modificado, nenhum escore "Bravo" foi atribuído aos itens reincidência de cárie e fratura. 0 item sensibilidade pulpar obteve alguns escores "Bravo" no baseline $(2,27 \%$ IPS e $7,14 \%$ - D), no entanto, os pacientes relataram que esta sensação dolorosa foi de baixa intensidade e não ultrapassou o período de duas semanas. A presença de sensibilidade pós-operatória tem sido reportada em alguns estudos clínicos e tem sido relacionada ao incompleto selamento

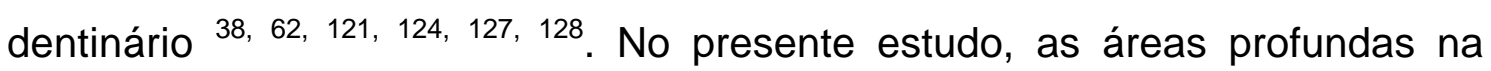
dentina foram sempre protegidas com cimento de hidróxido de cálcio e cimento de ionômero de vidro modificado por resina (Vitremer).

O uso cimento de ionômero de vidro modificado por resina (Vitremer) também visou o preenchimento das áreas socavadas por cárie, no intuito de preservar estrutura dental durante a determinação da expulsividade das paredes axial e circundantes, além de ajudar na padronização da profundidade da parede pulpar (1,5 a 2,0 mm). De acordo com MOSCOVICH et al. ${ }^{82}$ (1998) e SENE ${ }^{114}$ (2001) uma significante quantidade de estrutura dental é removida durante a transformação de uma restauração direta em indireta.

O item reprodução de cor obteve alguns escores "Bravo" no baseline (2,27\% - IPS e 9,52\% - D) e estes permaneceram estáveis nas avaliações seguintes. A textura superficial obteve maior número de escores "Bravo" para a cerâmica Duceram $(11,9 \%)$ no baseline, aumentando para $14,29 \%$, após 02 
anos. A cerâmica IPS Empress obteve menor número de escores "Bravo" para o item textura superficial no baseline $(2,27 \%)$ e permaneceu estável com o tempo. TIDEHAG; GUNNE ${ }^{130}$ (1995) e STUDER et al. ${ }^{124}$, (1996) reportaram um alto índice de escores "Alfa" no aspecto textura superficial para a cerâmica IPS Empress. Não houve diferença estatística entre as cerâmicas para todos os itens avaliados. Os itens descoloração e integridade marginal apresentaram $100 \%$ de escores "Alfa" no baseline, no entanto, estes foram os aspectos que apresentaram a maior incidência de escores "Bravo" com o tempo, conforme relatado anteriormente.

Para a comparação estatística das restaurações do tipo inlay e onlay considerou-se apenas as restaurações realizadas na área de molares devido ao pequeno número de restaurações do tipo onlay colocadas na região de prémolares. Pela mesma razão, para a avaliação do comportamento clínico das restaurações nas regiões de pré-molares e molares, optou-se por comparar estatisticamente apenas as restaurações do tipo inlay, uma vez que um número reduzido de restaurações do tipo onlay foram realizadas na região de prémolares. Não foi observada diferença estatisticamente significante entre os aspectos abordados, tendo sido alcançado um índice de sucesso de $100 \%$ (escores "Alfa" e "Bravo") até o presente momento. O escore "Alfa" representou a condição ideal das restaurações avaliadas, enquanto que o escore "Bravo" foi atribuído às restaurações que apresentavam algum defeito de pequena intensidade sem, entretanto, necessidade de troca das restaurações. Nenhum escore "Charlie" ou "Delta" foi atribuído às restaurações. Estes resultados estão de acordo com os achados de HAYASHI et al. ${ }^{51,52}$, que nas avaliações clínicas 
realizadas em 1998 e 2000, não observaram diferenças estatisticamente significantes entre as restaurações cerâmicas colocadas nas regiões de prémolares e molares, dentre todas as características analisadas. KRÄMER; FRANKENBERGER ${ }^{63}$, em 2000, através de análise indireta por MEV, avaliaram o desgaste do cimento resinoso ao longo do tempo e verificaram que não houve distinção entre os desgastes ocorridos nas áreas de pré-molares e molares. Já FUZZI; RAPPELLI ${ }^{42}$, em 1998, após um período de 10 anos de avaliação de 183 inlays de cerâmica (Microbond e Fortune), relataram um sucesso de $99 \%$ em pré-molares e $95 \%$ em molares. MANHART et al. ${ }^{72}$, em 2000, observaram uma melhor integridade marginal e menor descoloração nas inlays colocadas em cavidades pequenas, bem como menor número de falhas na região de pré-molares do que em molares. No presente estudo, os aspectos descoloração e integridade marginal foram visualizados em ambos os tipos de restaurações, com e sem cobertura de cúspides, e em ambas as regiões de pré-molares e molares, sem diferença estatisticamente significante entre os aspectos abordados. Apesar dos molares estarem sujeitos a forças mastigatórias de maior intensidade, este fato não mostrou influência significativa até o período de avaliação de 02 anos. Até a presente investigação, as inlays e onlays apresentaram um excelente desempenho clínico em ambas as regiões, sem diferença entre os sistemas cerâmicos testados. 


\section{7 - CONCLUSÕES}




\section{7 - CONCLUSÕES}

Verificando as hipóteses propostas, após os dados obtidos e respectiva análise estatística, pôde-se concluir que:

7.1 - Ambas as cerâmicas IPS Empress e Duceram apresentaram um excelente desempenho clínico após dois anos;

7.2 - Nenhuma fratura ou cárie recorrente foi detectada, tendo apenas o item descoloração marginal apresentado diferença estatisticamente significante quando estes dados foram comparados aos dados do baseline, porém sem necessidade de troca das restaurações;

7.3 - Não houve diferença estatisticamente significante entre o comportamento clínico das restaurações do tipo inlay e onlay, bem como, entre as restaurações localizadas nas áreas de pré-molares e molares;

7.4 - Os sistemas de cerâmica prensada e convencional apresentaram um comportamento clínico similar, mostrando a eficácia de ambos os sistemas para restaurar dentes posteriores, em cavidades do tipo inlay e onlay.

As hipóteses testadas devem ser aceitas. 
Anexo 1 - Ficha clínica utilizada para anamnese

\section{Ficha Clínica -1}

\section{Nome:}

Rua $\mathbf{N}^{0}$

Bairro Cidade CEP

Telefone (Res.) Telefone (Trab.)

Telefone (Parente) Telefone (Amigo)

SEXO: F ( ) M ( ) Data de nascimento: I I

Tem ou teve algum problema de saúde? S ( ) N ( )

Qual?

Está tomando algum medicamento? S ( ) N ( )

Qual?

É alérgico a algum medicamento? S ( ) N ( )

Qual?

É diabético? S( ) N ( ) Está grávida? S（）Ｎ（）

É cardíaco? S ( ) N ( )

Sua pressão é alta ( ) baixa ( ) normal ( )

Já teve hemorragia? S ( ) N ( )

Suas gengivas sangram? S ( ) N ( )

Range ou aperta os dentes? S ( ) N ( )

Faz uso do fio dental? S ( ) N ( )

Qual a sua frequência de escovação? ( ) vezes ao dia.

Você se importa com a aparência dos seus dentes? S ( ) N ( )

Observações

Bauru, / / Assinatura do paciente 
Anexo 2 - Ficha clínica relativa aos procedimentos operatórios

Ficha Clínica - 2

Nome:

Rua $\mathbf{N}^{\circ}$

Bairro Cidade CEP

Telefone (Res.) Telefone (Trab.)

Telefone (Parente) Telefone (Amigo)

SEXO: F ( ) M ( ) Data de nascimento: l l

CERÂMICA - Unidade

PREPARO TIPO: Inlay( ) Onlay( )

CONDIÇÃO DA UNIDADE: Vital ( ) Tratada endodonticamente ( ) NÚCLEO DE PREENCHIMENTO Nenhum（） Vitremer ( )

CERÂMICA - Unidade

PREPARO TIPO: Inlay( ) Onlay( )

CONDIÇÃO DA UNIDADE: Vital ( ) Tratada endodonticamente ( ) NÚCLEO DE PREENCHIMENTO Nenhum ( ) Vitremer ( )

\begin{tabular}{|l|l|}
\hline DATAS DE ATENDIMENTO & PROCEDIMENTOS \\
\hline & \\
\hline & \\
\hline & \\
\hline & \\
\hline & \\
\hline
\end{tabular}

RADIOGRAFIAS PERIAPICAL E INTERPROXIMAL:

$\begin{array}{lcccccc}\text { Inicial } & 1 & 1 & 1 & 1 & 1 \\ \text { Final } & 1 & 1 & 1 & 1 & 1 & 1\end{array}$


Anexo 3 - Termo de Consentimento para pesquisa em humanos.

\section{Termo de consentimento para tratamento e pesquisa}

Por este instrumento particular declaro, para efeitos éticos e legais, que eu (nome)

(nacionalidade) , (profissão)

portador(a) de R.G. , C.I.C. , residente e domiciliado (a) àRua

Cidade Estado , concordo com absoluta consciência dos procedimentos a que vou me submeter para a realização da fase experimental dessa pesquisa realizada na Clínica Odontológica - área de Dentística da Faculdade de Odontologia de Bauru - USP, intitulada "Avaliação Clínica de Inlays/Onlays em cerâmica", tendo como responsáveis a cirurgiã-dentista Maria Jacinta Moraes Coelho Santos e a Profa. Dra. Maria Fidela de Lima Navarro, nos termos abaixo relacionados:

1- Esclareço que recebi todas as informações sobre minha participação nesse experimento, possuindo plena liberdade para me abster em particular da referida pesquisa em qualquer momento, sem prejuízo financeiro, hierárquico ou de qualquer natureza;

2- Esclareço, também, que fui amplamente informado, sobre os possíveis benefícios e riscos aos quais estou me submetendo durante esse experimento, tomando conhecimento de que meu consentimento não exime a responsabilidade do profissional que está executando a pesquisa; 
3- Todas as normas estão de acordo com o Código de Ëtica Profissional Odontológico, segundo à Resolução de Conselho Federal de Odontologia 179/93, com a declaração de Helsinque II e com a resolução no 196 de 10 de Outubro de 1996 do Conselho Nacional de Saúde do Ministério da Saúde.

Por estar de pleno acordo com o teor do presente termo, assino abaixo 0 mesmo.

Bauru, de de

Assinatura do Voluntário

Assinatura do Pesquisador 


\section{ANEXO 4 - Parecer do Comitê de Ética em Pesquisa - Bauru}

\section{FACULDADE DE ODONTOLOGIA DE BAURU COMITE DE ETICA EM PESQUISA}

Bauru, 31 de manço de 2000

Ilma. Sra.

Profa. Dra. Maria Fidela de Lima Navarro

Disciplina de Dentística

FOB USP

Senhora Professora.

projeto de pesquisa encaminhado a este Comitê de Ética denominado "AVALIAGAOO OLÁNTCA DE INLAYSIONLAYS BM CERAMYA" de autoria da C.D. Maria Jacinta Moraes Coelho Santos sob sua orientaça, foi reavaliado por este Comitè, sob o ponto de vista ético.

Na reuniäo de 30 de março último, o parecer do relator foi julgado pelo Comitê que o aprovou, considerando que năo existem mais questöes éticas pendentes.

Atenciosamente

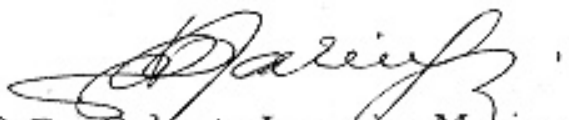

Prof. Dr. Reberto Loureiro Maringoni Coordenador do Comitê de Ética 
Anexo 5 - Ficha de avaliação clínica

FACULDADE DE ODONTOLOGIA DE BAURU- USP

Departamento de Dentística, Endodontia e Mat. Dentários

Ficha de Avaliação Clínica

Data: Avaliador:

Paciente:

\begin{tabular}{|c|c|c|c|c|}
\hline DENTE: & INLAY（） & ONLA & & \\
\hline Critérios & Alfa & Bravo & & \\
\hline Sensibilidade pulpar & & & & \\
\hline Reincidência de cárie & & & & \\
\hline Fratura & & & Charlie & \\
\hline Reprodução de cor & & & & \\
\hline Textura superficial & & & & \\
\hline Descoloração marginal & & & & Delta \\
\hline Integridade marginal & & & & \\
\hline
\end{tabular}

\begin{tabular}{|c|c|c|c|c|}
\hline DENTE: & \multicolumn{4}{|c|}{ INLAY（） ONLAY（） } \\
\hline Critérios & Alfa & Bravo & & \\
\hline \multicolumn{5}{|l|}{ Sensibilidade pulpar } \\
\hline \multicolumn{5}{|l|}{ Reincidência de cárie } \\
\hline Fratura & & & Charlie & \\
\hline \multicolumn{5}{|l|}{ Reprodução de cor } \\
\hline \multicolumn{5}{|l|}{ Textura superficial } \\
\hline Descoloração marginal & & & & Delta \\
\hline Integridade marginal & & & & \\
\hline
\end{tabular}


Anexo 6 - Dados dos pacientes e das restaurações executadas.

\begin{tabular}{|c|c|c|c|c|c|c|c|}
\hline PACIENTE & IDADE & N'REST. & CERĀMICA & DENTE & TIPO & TRAT.END. & PREPARO \\
\hline \multirow[t]{2}{*}{1} & 25 & 1 & IPS & 16 & ON & & MOP \\
\hline & & 2 & DUCERAM & 15 & IN & & MOD \\
\hline \multirow[t]{2}{*}{2} & 36 & 3 & IPS & 17 & IN & & $\mathrm{MO}$ \\
\hline & & 4 & DUCERAM & 16 & IN & & MOD \\
\hline \multirow[t]{3}{*}{3} & 35 & 5 & IPS & 15 & IN & & MOD \\
\hline & & 6 & DUCERAM & 14 & IN & & DO \\
\hline & 35 & 7 & DUCERAM & 16 & ON & & MODP \\
\hline \multirow[t]{2}{*}{4} & & 8 & DUCERAM & 26 & IN & $\mathrm{X}$ & $\mathrm{MO}$ \\
\hline & & 9 & IPS & 46 & IN & & $\mathrm{MO}$ \\
\hline \multirow[t]{4}{*}{5} & 34 & 10 & DUCERAM & 15 & ON & & MOVDP \\
\hline & & 11 & IPS & 14 & IN & & MOD \\
\hline & & 12 & DUCERAM & 17 & ON & & MODP \\
\hline & & 13 & IPS & 16 & ON & & MODP \\
\hline \multirow[t]{2}{*}{6} & 28 & 14 & DUCERAM & 27 & IN & & $\mathrm{MO}$ \\
\hline & & 15 & IPS & 26 & ON & & OVERLAY \\
\hline \multirow[t]{2}{*}{7} & 34 & 16 & DUCERAM & 14 & IN & & DO \\
\hline & & 17 & IPS & 17 & ON & & MODL \\
\hline \multirow[t]{2}{*}{8} & 39 & 18 & DUCERAM & 16 & $\mathrm{ON}$ & & MOLV \\
\hline & & 19 & IPS & 15 & IN & $x$ & $\mathrm{DO}$ \\
\hline \multirow[t]{3}{*}{9} & 37 & 20 & DUCERAM & 16 & ON & & MOLV \\
\hline & & 21 & IPS & 15 & ON & $x$ & MODP \\
\hline & & 22 & DUCERAM & 17 & IN & & $\mathrm{MO}$ \\
\hline \multirow[t]{3}{*}{10} & 33 & 23 & IPS & 34 & ON & & $\overline{D O L}$ \\
\hline & & 24 & DUCERAM & 35 & IN & & MOD \\
\hline & & 25 & DUCERAM & 36 & IN & & $\mathrm{MO}$ \\
\hline \multirow[t]{3}{*}{11} & 36 & 26 & DUCERAM & 46 & ON & & OVERLAY \\
\hline & & 27 & IPS & 47 & ON & & OVERLAY \\
\hline & & 28 & IPS & 48 & IN & & $\mathrm{MO}$ \\
\hline \multirow[t]{2}{*}{12} & 36 & 29 & IPS & 36 & ON & & $\mathrm{OL}$ \\
\hline & & 30 & DUCERAM & 26 & IN & & $\mathrm{OL}$ \\
\hline \multirow[t]{2}{*}{13} & 39 & 31 & IPS & 47 & ON & & MODL \\
\hline & & 32 & DUCERAM & 46 & IN & $x$ & MOD \\
\hline \multirow[t]{2}{*}{14} & 44 & 33 & IPS & 25 & ON & & MODVP \\
\hline & & 34 & DUCERAM & 26 & IN & & $\mathrm{MO}$ \\
\hline \multirow[t]{2}{*}{15} & 32 & 35 & IPS & 14 & IN & & $\mathrm{MOD}$ \\
\hline & & 36 & DUCERAM & 15 & IN & & MOD \\
\hline \multirow[t]{2}{*}{16} & 30 & 37 & IPS & 36 & IN & & MOD \\
\hline & & 38 & DUCERAM & 37 & IN & & $\mathrm{MO}$ \\
\hline \multirow[t]{2}{*}{17} & 27 & 39 & IPS & 17 & IN & & $\mathrm{MO}$ \\
\hline & & 40 & DUCERAM & 18 & ON & & DOV \\
\hline \multirow[t]{2}{*}{18} & 42 & 41 & IPS & 15 & IN & & MOD \\
\hline & & 42 & DUCERAM & 16 & IN & & $\mathrm{MO}$ \\
\hline \multirow[t]{2}{*}{19} & 34 & 43 & IPS & 17 & IN & & $\mathrm{MOP}$ \\
\hline & & 44 & DUCERAM & 16 & ON & & MODP \\
\hline 20 & 33 & 45 & IPS & 45 & IN & & $\mathrm{DO}$ \\
\hline
\end{tabular}




\begin{tabular}{|c|c|c|c|c|c|c|c|}
\hline & & 46 & DUCERAM & 46 & $\mathrm{IN}$ & & $\mathrm{MO}$ \\
\hline \multirow[t]{6}{*}{21} & 34 & 47 & IPS & 15 & $\mathrm{IN}$ & & MOD \\
\hline & & 48 & DUCERAM & 35 & IN & & DO \\
\hline & & 49 & IPS & 16 & $\mathrm{IN}$ & & MOD \\
\hline & & 50 & DUCERAM & 36 & IN & & $\mathrm{MO}$ \\
\hline & & 51 & IPS & 17 & ON & & MODV \\
\hline & & 52 & DUCERAM & 37 & $\mathrm{ON}$ & $x$ & MOVL \\
\hline \multirow[t]{2}{*}{22} & 31 & 53 & IPS & 27 & $\mathrm{ON}$ & & MOD \\
\hline & & 54 & DUCERAM & 26 & $\mathrm{ON}$ & & MODP \\
\hline \multirow[t]{2}{*}{23} & 41 & 55 & IPS & 37 & $\mathrm{ON}$ & & $\mathrm{MOL}$ \\
\hline & & 56 & DUCERAM & 47 & ON & & $\mathrm{MOL}$ \\
\hline \multirow[t]{2}{*}{24} & 33 & 57 & IPS & 16 & $\mathrm{IN}$ & & $\mathrm{MOP}$ \\
\hline & & 58 & DUCERAM & 15 & IN & & MOD \\
\hline \multirow[t]{2}{*}{25} & 30 & 59 & IPS & 26 & $\mathrm{ON}$ & & DOVP \\
\hline & & 60 & DUCERAM & 16 & IN & & MOP \\
\hline \multirow[t]{2}{*}{26} & 30 & 61 & IPS & 25 & IN & & MOD \\
\hline & & 62 & DUCERAM & 24 & IN & $x$ & DO \\
\hline \multirow[t]{5}{*}{27} & 31 & 63 & IPS & 14 & IN & & MOD \\
\hline & & 64 & DUCERAM & 46 & $\mathrm{IN}$ & & MOD \\
\hline & & 65 & IPS & 16 & IN & & $\mathrm{MO}$ \\
\hline & & 66 & DUCERAM & 47 & IN & & DO \\
\hline & & 67 & IPS & 17 & IN & & $\mathrm{MO}$ \\
\hline \multirow[t]{3}{*}{28} & 31 & 68 & DUCERAM & 25 & $\mathrm{ON}$ & & MODP \\
\hline & & 69 & IPS & 26 & $\mathrm{ON}$ & & $\mathrm{MO}$ \\
\hline & & 70 & IPS & 27 & $\mathrm{ON}$ & & DOV \\
\hline \multirow[t]{2}{*}{29} & 36 & 71 & IPS & 36 & IN & & $\mathrm{MO}$ \\
\hline & & 72 & DUCERAM & 37 & IN & & MOD \\
\hline \multirow[t]{2}{*}{30} & 25 & 73 & IPS & 16 & IN & $X$ & $\mathrm{MOP}$ \\
\hline & & 74 & DUCERAM & 46 & IN & & $\mathrm{MO}$ \\
\hline \multirow[t]{2}{*}{31} & 32 & 75 & IPS & 36 & ON & & MODL \\
\hline & & 76 & DUCERAM & 37 & IN & & $\mathrm{MO}$ \\
\hline \multirow[t]{2}{*}{32} & 31 & 77 & IPS & 24 & IN & & DO \\
\hline & & 78 & DUCERAM & 25 & IN & & $M O D$ \\
\hline \multirow[t]{3}{*}{33} & 33 & 79 & IPS & 25 & IN & & MOD \\
\hline & & 80 & DUCERAM & 24 & IN & & DO \\
\hline & & 81 & IPS & 26 & IN & & $\mathrm{MO}$ \\
\hline \multirow[t]{2}{*}{34} & 33 & 82 & DUCERAM & 46 & $\mathrm{ON}$ & & MODVP \\
\hline & & 83 & IPS & 17 & IN & & MOVP \\
\hline \multirow[t]{3}{*}{35} & 38 & 84 & DUCERAM & 46 & $\mathrm{ON}$ & & OVERLAY \\
\hline & & 85 & IPS & 34 & ON & & MODL \\
\hline & & 86 & IPS & 36 & ON & & OVERLAY \\
\hline
\end{tabular}

TOTAIS:

35 PACIENTES - IDADE MÉDIA DE 33,6 ANOS

86 RESTAURAÇÕES - 31 DE 02 FACES; 30 DE 03 FACES E 25 DE 04 OU MAIS FACES 07 DENTES TRATADOS ENDODONTICAMENTE

53 INLAYS - 33 ONLAYS / 27 PRÉ-MOLARES - 59 MOLARES / 44 IPS E 42 DUCERAM 


\section{REFERÊNCIAS BIBLIOGRÁFICAS}




\section{REFERÊNCIAS BIBLIOGRÁFICAS}

1. ABDALLA, A.I.; DAVIDSON, C.L. Marginal integrity after fatigue loading of ceramic inlay restorations luted with three different cements. Amer. J. Dent., v.13, n.2, p.77-80, Apr. 2000.

2. ADEPT REPORT. Ceramic materials. v.6, n.2, p.1-19, Spring 1999.

3. AIDA, M.; HAYAKAWA, T.; MIZUKAWA, K. Adhesion of composite to porcelain with various surface conditions. J. prosth. Dent., v.73, n.5, p.464-9, May 1995.

4. ANUSAVICE, K.J. Recent developments in restorative dental ceramics. J. Amer. dent. Ass., v.124, n.2, p.72-84, Feb. 1993.

5. ANUSAVICE, K.J. Reducing the failure potential of ceramic-based restorations. Gen. Dent., v.45, n.1, p.30-5, Jan./Feb. 1997.

6. AUDENINO, G. et al. In vitro evaluation of fit of adhesively luted ceramic inlays. Int. J. Prosthodont., v.12, n.4, p.342-7, July/Ago. 1999.

7. AWLIYA, W. et al. Shear bond strength of a resin cement to densely sintered high-purity alumina with various surface conditions. Acta. odont. scand., v.56, n.1, p.9-13, Feb. 1998.

8. BANKS, R.G. Conservative posterior ceramic restorations: a literature review. J. prosth. Dent., v.63, n.6, p.619-26, June 1990.

9. BLATZ, M.B.; DENT, M. Long-term clinical success of all-ceramic posterior restorations. Quintessence Int., v.33, n.6, p.415-26, June 2002.

10. BLIXT, M. et al. Bonding to densely sintered alumina surfaces: effect of sandblasting and silica coating on shear bond strength of luting cements. Int. J. Prosthodont., v.13, n.3, p.221-6, May/June 2000. 
11. BRAGA, R.B.; CESAR, P.F., GONZAGA, C.C. Mechanical properties of resin cements with different activation modes. J. oral Rehab., v.29, n.3, p.25762, Mar. 2002.

12. BROWN, D. The status of indirect restorative dental materials. Dent. Mat., v.25, n.1, p.23-34, Jan./Feb.1998.

13. BROWNING, D.W. et al. Comparison of luting cements for minimally retentive crown preparations. Quintessence Int., v.33, n.2, p.95-100, Feb. 2002.

14. BURKE et al. Are adhesive technologies needed to support ceramics? An assessment of the current evidence. J. Adhes. Dent., v.4, n.1, p.7-22, 2002.

15. BURKE et al. Current status and rationale for composite inlays and onlays. Brit. dent. J., v.170, n.7, p.269-73, Apr. 1991.

16. BURKE, F.J.T. The effect of variations in bonding procedure on fracture resistance of dentin-bonded all ceramic crowns. Quintessence Int., v.26, n.4, p.875-80, Apr. 1995.

17. CAUGHMAN, W.F.; CHAN, D.C.N.; RUEGGEBERG, F.A. Curing potential of dual-polymerizable resin cements in simulated clinical situations. $\mathbf{J}$. prosth. Dent., v.85, n.5, p.480-4, May 2001.

18. CHRISTENSEN, G.J. Marginal fit of gold inlay castings. J. prosth. Dent., v.16, n.1, p.297-305, Jan./Feb. 1966.

19. CHRISTENSEN, G.J. The coming demise of the cast gold restorations. J. Amer. dent. Ass., v. 127, n.8, p.1233-6, Aug. 1996.

20. CULP, L. Empress 2 - First year clinical results. J. dent. Technol., v.16, n.2, p.12-5, Mar. 1999. 
21. DELLA BONA, A.; ANUSAVICE, K.J. Microstructure, composition and etching topography of dental ceramics. Int. J. Prosthodont., v.15, n.2, p.159-67, Mar./Apr. 2002.

22. DELLA BONA, A.; ANUSAVICE, K.J.; HOOD, J.A.A. Effect of ceramic surface treatment on tensile bond strength to a resin cement. Int. J. Prosthodont., v.15, n.3, p.248-53, May/June 2002.

23. DÉRAND, P.; DÉRAND, T. Bond strength of luting cements to zirconium oxide ceramics. Int. J. Prosthodont., v.13, n.2, p.131-5, Mar./Apr. 2000.

24. DIETSCHI, D. et al. In vitro resistance to fracture of porcelain inlays bonded to tooth. Quintessence Int., v.21, n.10, p.823-31, 1990.

25. DIETSCHI, D.; SPREAFICO, R. Restaurações adesivas: conceitos atuais para o tratamento estético de dentes posteriores. São Paulo, Quintessence, 1997.215p.

26. DIETSCHI, D.; MAEDER, M.; HOLZ, J. In vitro evaluation of marginal fit and morphology of fired ceramic inlays. Quintessence Int., v.23, n.4, p.271-8, Apr. 1992.

27. DIETSCHI, D.; MOOR L. Evaluation of the marginal and internal adaptation of different ceramic and composite inlay systems after an in vitro fatigue test. J. Adhes. Dent., v.1, n.1, p.41-56, Spring 1999.

28. DONOVAN, T.E.; CHEE, W.W.L. Conservative indirect restorations for posterior teeth cast versus bonded ceramic. Dent. Clin. N. Amer., v.37, n.3, p.433-43, July 1993.

29. DUKE, E.S.; PLATT, J.A.; RHODES, B. Investigation of adhesive system used with direct and indirect applications. Comp. Continuing Educ. Dent., v.21, n.12, p.1043-53, Dec. 2000. 
30. EL-BADRAWY, W.A.; EL-MOWAFY, O.M. Chemical versus dual curing of resin inlay cements. J. prosth. Dent. v.73, n.6, p.515-24, June 1995.

31. EL-MOWAFY, O.M.; EL-BADRAWY, W.A. Hardening of new resin cements cured through a ceramic inlay. Oper. Dent., v.24, n.1, p.38-44, Jan./Feb. 1999.

32. ESQUIVEL-UPSHAW, J. et al. Fracture resistance of all-ceramic and metalceramic inlays. Int. J. Prosthodont., v.14, n.2, p.109-14, Mar./Apr. 2001.

33. ESSIG, M.E. et al. An in-vivo evaluation of duo-cured cements with CAD/CAM ceramic inlays. J. dent. Res., v.70, p.296, Jan./Apr. 1991. /Abstract n. 244/

34. FELDEM, A.; SCHMALZ, G.; HILLER, K.A. Retrospective clinical study and survival analysis on partial ceramic crowns: results up to 7 years. Clin. oral Invest., v.4, n.4, p.199-205, Dec. 2000.

35. FLEISS, J.L.; CHILTON, N.W. The measurement of interexaminer agreement on periodontal disease. J. Periodont. Res., v.18, n.6, p.601-6, Nov. 1983.

36. FRADEANI, M.; AQUILIANO, A.; BASSEIN, L. Longitudinal study of pressed glass-ceramic inlays for four and a half years. J. prosth. Dent. v.78, n.4, p.346-56, Oct.1997.

37. FRANCO, E.B. et al. Evaluation of compatibility between different types of adhesives and dual-cured resin cement. J. Adhes. Dent., v.4, n.4, p.1-5, 2002.

38. FRANKENBERGER, F.; PETSCHELT, A.; KRÄMER, N. Leucite-Reinforced glass ceramic inlays and onlays after six years: clinical behavior. Oper. Dent., v.25, n.6, p. 459-65, Nov./Dec. 2000. 
39. FRANKENBERGER, R.; SINDEL, J.; KRAMER, N.; PETSCHELT, A. Dentin bond strength and marginal adaptation: Direct composite resin vs ceramic inlays. Oper. Dent., v.24, n.3, p.147-55, May/June 1999.

40. FRIEDL, K.H. et al. In-vivo evaluation of a feldspathic ceramic system: 2-year results. J. Dent., v.24, n.1-2, p.25-31, Jan./Mar. 1996.

41. FUZZI, M.; RAPPELLI, G. Ceramic inlays: clinical assessment and survival rate. J. Adhes. Dent., v.1, n.1, p.71-9, Spring 1999.

42. FUZZI, M.; RAPPELLI, G. Survival rate of ceramic inlays. J. Dent., v.26, n.7, p.623-6, Sept. 1998.

43. GARBER, D.A.; GOLDSTEIN, R.E. Preparo do dente. In:

Inlays e onlays de porcelana e resina composta. São Paulo, Quintessence, 1996. Cap.4, p.38-55.

44. GEMALMAZ, D.; ÖZCAN, M.; ALKUMRU, H.N. A clinical evaluation of ceramic inlays bonded with different luting agents. J. Adhes. Dent. v.3, n.3, p.273-83, Fall 2001.

45. GLADYS, S. et al. Clinical and semi quantitative marginal analysis of four tooth-coloured Inlay systems at 3 years. J. Dent., v.23, n.6, p.329-38, Dec. 1995.

46. GORMAN, C.M.; McDEVITT, W.E.; HILL, R.G. Comparison of two heatpressed all-Ceramic dental materials. Dent. Mat., v.16, n.16, p.389-95, Nov. 2000.

47. GROTEN, M.; PRÖBSTER, L. The influence of different cementation procedures on the fracture resistance of feldspathic ceramic crowns. Int. J. Prosthodont., v.10, n.2, p.169-77, Mar./Apr. 1997.

48. GÜREL, G. Porcelain inlays and onlays. Dent. Clin. N. Amer., v.45, n.1, p.117-25, Jan. 2000. 
49. GUZMAN, A.F.; MOORE, B.K; ANDRES, C.J. Wear resistance of four luting agents as a function of marginal gap distance, cement type, and restorative material. Int. J. Prosthodont. v.15, n.1, p.415-25, Sept./Oct. 1997.

50. HAHN, P.; SCHALLER, H.; HAFNER, P.; HELLWING, E. Effect of different luting procedures on the seating of ceramic inlays. J. oral Rehab., v.27, n.1, p.1-8, Jan. 2000.

51. HAYASHI, M. et al. 6-year Clinical Evaluation of Fired Ceramic Inlays. Oper. Dent., v.23, n.6, p.318-31, Nov./Dec. 1998.

52. HAYASHI, M. et al. Eight-year clinical evaluation of fired ceramic inlays. Oper. Dent., v.25, n.6, p.549-54, Nov./Dec. 2000.

53. HÖGLUND, C.; DIJKEN, J.V.; OLOFSSON, A.L. A clinical evaluation of adhesively luted ceramic inlays - a two year follow-up study. Swed. dent. J., v.16, n.4, p.169-71, 1992.

54. HUNT, R.J. Percent Agreement, Pearson's Correlation, and Kappa as measures of inter-examiner reliability. J. dent. Res., v.65, n.2, p.128-30, Feb. 1986.

55. ISIDOR, F.; BRONDUM, K. A clinical evaluation of porcelain inlays. J. prosth. Dent., v.74, n.2, p.140-4, Aug. 1995.

56. JACKSON, R.D.; FERGUSON, R.W. An esthetic, bonded inlay/onlay technique for posterior teeth. Quintessence Int., v.21, n.1, p.7-12, Jan. 1990.

57. JENSEN, M.E. et al. Posterior etched-porcelain restorations: an in vitro study. Comp. Continuing Educ. Dent., v.8, n.8, p.615-22, Sept. 1987. 
58. KAMADA, K.; YOSHIDA, K.; ATSUTA, M. Effect of ceramic surface treatments on the bond of four resin luting agents to a ceramic material. J. prosth. Dent., v.79, n.5, p.508-13, May 1998.

59. KAWAI, K.; ISENBERG, B.P.; LEINFELDER, K.F. Effect of gap dimension on composite resin cement wear. Quintessence Int., v.25, n.1, p.53-8, Jan. 1994.

60. KELLY, J.R.; NISHIMURA, I.; CAMPBELL, S.D. Ceramic in dentistry: historical roots and current perspectives. J. prosth. Dent., v.75, n.1, p. 1832, Jan. 1996.

61. KERN, M.; THOMPSON, V.P. Bonding to glass infiltrated alumina ceramic: Adhesive methods and their durability. J. prosth. Dent., v.73, n.3, p.2409, Mar. 1995.

62. KRÄMER, N. et al. IPS Empress inlays and onlays after four years - a clinical study. J. Dent., v.27, n.5, p.325-31, July 1999.

63. KRÄMER, N; FRANKENBERGER, F. Leucite-Reinforced glass ceramic inlays after six years: wear of luting composites. Oper. Dent., v.25, n.6, p.44672, Nov./Dec. 2000.

64. $\mathrm{KREJCl}$, I. et al. Wear of ceramic inlays, their enamel antagonists and luting cements. J. prosth. Dent., v.69, n.4, p.425-30, Apr. 1993.

65. KREJCI, I.; KREJCI, D.; LUTZ, F. Clinical evaluation of a new pressed glass ceramic Inlay material over 1.5 years. Quintessence Int., v.23, n.3, p.1816, Mar. 1992.

66. LACY, A.M.; LALUZ, J.; WATANABLE, L.G.; DALLINGES, M. Effect of porcelain surface treatment on the bond to composite. J. prosth. Dent., v.760, n.3, p.288-91, Sept. 1988. 
67. LEE, I.B.; UM, C.M. Thermal analysis on the cure speed of dual cured resin cements under porcelain inlays. J. oral Rehab., v.28, n.2, p.186-97, Feb. 2001.

68. LEEVAILOJ, C. et al. In vitro study of fracture incidence and compressive fracture load of all-ceramic crowns cemented with resin-modified glass ionomer and other luting agents. J. prosth. Dent., v.80, n.6, p.699-707, Dec. 1998.

69. LUTHY, H.; WOHLWEND, A.; SCHÁRER, P. Heat-pressed ceramics: technology and strength. Int. J. Prosthodont., v.5, n.1, p.9-16, Jan./Feb. 1992.

70. MABRITO, C.; ROBERTS, M. Porcelain onlays. Curr. Opinion Dent., p.1-8, 1995.

71. MALAMENT, K.A.; SOCRANSKY, S.S. Survival of Dicor glass-ceramic dental restorations over 16 years. Part III: Effect of luting agent and tooth or tooth-substitute core structure. J. prosth. Dent., v.86, n.5, p.511-9, Nov. 2001.

72. MANHART, J.; SCHEIBENBORG, A.; CHEN, H.Y.; HICKEL. R. A 2-year clinical study of composite and ceramic inlays. Clin. Oral Invest., v.4, n.4, p.192-8, Dec. 2000.

73. McCOMB, D. Adhesive luting cements - classes, criteria, and usage. Comp. Continuing Educ. Dent., v.17, n.8, p.759-73, Aug. 1996.

74. McLEAN, J.W. The science and art of dental ceramics. Oper. Dent., v.16, n.4, p.149-56, July/Aug. 1991.

75. McLEAN, J.W.; HUGHES, T.H. The reinforcement of dental porcelain with ceramic oxides. Brit. dent. J., v.67, n.6, p.119-251, Sept. 1965. 
76. McLEAN, J.W. Evolution of dental ceramics in the twentieth century. J. prosth. Dent., v.85, n.1, p.61-6, Jan. 2001.

77. MCLEAN, J.W.; von FRAUNHOFER, J.A. The estimation of cement film thickness by an in vitro technique. Brit. dent. J., v.131, n.3, p.107-1, Aug. 1971.

78. MESAROS, A.J.; EVANS, D.B.; SCHWARTZ, R.S. Influence of a dentin bonding agent on the fracture load of Dicor. Amer. J. Dent., v.7, n.3, p.137-40, June 1994.

79. MICHELINE, F.S.; SCHERRER, S.S.; RIJK, W.G. Tensile bond strength of gold and porcelain inlays to extract teeth using three cements. Int. J. Prosthodont., v.8, n.4, p.324-31, July/Ago. 1995.

80. MOLIN, M.; KARLSSON, S. The fit of gold inlays and three ceramic inlay systems. A clinical and in vitro study. Acta odont. scand., v.51, n.4, p.201-6, Aug. 1993.

81. MOLIN, M.K.; KARLSSON, S.L. A randomized 5-year clinical evaluation of 3 ceramic inlay systems. Int. J. Prosthodont., v.13, n.3, p.194-200, May/June 2000.

82. MOSCOVICH, H. et al. Loss of Sound Tooth Structure When Replacing Amalgam Restorations by Adhesive Inlays. Oper. Dent., v.23, n.6, p.32731, Nov./Dec. 1998.

83. NASEDKIN, J.N. Ceramic inlays and onlays: update 1995. Restorat. Dent., v.61, n.8, p.676-82, Aug. 1995.

84. NAVARRO, M.F.L.; PASCOTTO, R.C. Cimentos de ionômero de vidro Aplicações clínicas em odontologia. São Paulo, Artes Médicas, 1998.

85. NEIVA, G. et al. Resistance to fracture of three all-ceramic systems. J. Esthet. Dent., v.10, n.2, p.60-6, 1998. 
86. NOACK, M.J. et al. Interfacial wear of luting composites of ceramic inlays in vitro. J. dent. Res., v.71, p.113, Jan./Apr. 1992. /Abstract n. 58/

87. NOACK, M.J.; ROULET, J.F. Survival rates and mode of failure of Dicor inlays after 4 years. J. dent. Res., v.73, n.1, p.196, Jan./Mar. 1994. /Abstract n. 759/

88. O'NEAL, S.J.; MIRACLE, R.L.; LEINFELDER, K.F. Evaluating interfacial gaps for esthetic inlays. J. Amer. dent. Ass., v.124, n.12, p.48-54, Dec. 1993.

89. OTTO, T.; NISCO, D.S. Computer-aided direct ceramic restoration: a 10-year prospective clinical study of Cerec CAD/CAM inlays and onlays. Int. J. Prosthodont., v.15, n.2, p.122-8, Mar./Apr. 2002.

90. ÖZCAN, M.; ALKUMRU, H.N.; GEMALMAZ, D. The effect of surface treatment on the shear bond strength of luting cement to a glass-infiltrated alumina ceramic. Int. J. Prosthodont., v.14, n.4, p.335-9, July/Aug. 2001.

91. PEUTZFELDT A. Dual-cure resin cements: in vitro wear and effect of quantity of remaining double bonds, filler volume, and light curing. Acta. odont. scand., v.53, n.1, p.29-34, Feb. 1995.

92. PEUTZFELDT A. Indirect Resin and Ceramic Systems. Oper. Dent., p.15376, 2001. Supplement 6.

93. PHILLIPS, R. W. Porcelanas odontológicas. In: Skinner: materiais dentários. 9.ed. Rio de Janeiro, Guanabara Koogan, 1993. Cap.26, p.291-304.

94. PLATT, J.A. Resin Cements: into the $21^{\text {st }}$ century. Comp. Continuing Educ. Dent., v.20, n.12, p.1173-82, Dec. 1999.

95. QUALTROUGH, A.J.E.; WILSON, N.H.F.; SMITH, G.A. Porcelain inlay: a historical view. Oper. Dent., v.15, n.2, p.61-70, Mar./Apr. 1990. 
96. QUALTROUGH, A.E.J.; WILSON, N.H.F. A 3-year clinical evaluation of a porcelain inlay system. J. Dent., v.24, n.5, p.317-23, Sept. 1996.

97. QUALTROUGH, A.J.E.; PIDDOCK, V. Dental ceramics: what's new? Dent. Update, v.29, n.1, p.25-33, Jan./Feb. 2002.

98. QUALTROUGH, A.J.E.; PIDDOCK, V. Recent advances in ceramic materials and systems for dental restorations. Dent. Update, v.26, n.2, p.65-72, Mar. 1999.

99. REES, J.S.; JACOBSEN, P.H. Stresses generated by luting resins during cementation of composite and ceramic inlays. J. oral Rehab., v.19, n.2, p.115-22, Mar. 1992.

100. REINELT, C. et al. In vivo performance of IPS Empress inlays and onlays after two years. J. dent. Res. v.74, p.552, 1995.

101. ROCHA, P.V.B. Avaliação "in vitro" da fenda e da infiltração marginal de restaurações “inlays”de cerâmicas puras. Bauru, 1997. 206p. Dissertação (Doutorado) - Faculdade de Odontologia de Bauru Universidade de São Paulo.

102. ROSENBLUM, M. A.; SCHULMAN, A. A review of all-ceramic restorations. J. Amer. dent. Ass., v.128, n.3, p.297-307, Mar. 1997.

103. ROULET, J. F.; DEGRANGE, M. Inlay restorations. J. Calif. dent. Ass., v.24, n.9, p.48-62, Sept. 1996.

104. ROULET, J.F.; LÖSCHE, G.M.; NOACK, M. Inlays and Onlays. Curr. Opinion Dent., p.41-54, 1993.

105. ROULET, J.F.; HERDER, S. Bonded ceramic inlays. Chicago, Quintessence, 1991.

106. ROULET, J.F. JANDA, R. Future Ceramic Systems. Oper. Dent., p.211-28, 2001. Supplement 6. 
107. ROULET, J.F.; SÖDERHOLM, K.J.M.; LONGMATE, J. Effects of treatment and storage conditions on ceramic/composite bond strength. J. Dent., v.74, n.1, p.381-7, Jan. 1995.

108. RUEGGEBERG, F.A.; CAUGHMAN, W.F. The influence of light exposure on polymerization of dual-cure resin cements. Oper. Dent., v.18, n.2, p.4855, Mar./Apr. 1993.

109. RYDE, G. Clinical criteria. Int. dent. J., v.30, n.4, p.347-58, 1980.

110. RYDE, G. et al. Standardization of clinical investigators for studies of restorative materials. Swed. dent. J., v.5, p.225-39, 1981.

111. SANTOS, M.J.M.C. et al. Restauração em cerâmica IPS EMPRESS - Relato de um caso clínico. JBC, v.4, n.24, p.12-6, nov./dez. 2000.

112. SANTOS, M.J.M.C. Resistência à fratura de pré-molares superiores íntegros, preparados e restaurados por duas técnicas adesivas, direta e indireta. Salvador, 1999. 117p. Dissertação (Mestrado) Faculdade de Odontologia - Universidade Federal da Bahia.

113. SCHEIBENBORG, A. et al. One-year clinical evaluation of composite and ceramic inlays in posterior teeth. J. prosth. Dent. v.80, n.4, p.410-6, Oct. 1998.

114. SENE, F. Análise comparativa da quantidade de estrutura dentária removida em preparos cavitários para restaurações diretas e indiretas. Avaliação da resistência àfratura do remanescente. Bauru, 2001. 152p. Dissertação (Mestrado) - Faculdade de Odontologia de Bauru - Universidade de São Paulo.

115. SHINKAI, K. et al. Effect of gap dimension on wear resistance of luting agents. Amer. J. Dent., v.8, n.3, p.149-51, June 1995 
116. SIMONSEN, R.J.; CALAMIA, J.R. Tensile bond strength of etched porcelain. J. dent. Res., v.62, p.297, Jan./June. 1983. /Abstract n. 1154/

117. SINDEL, J. et al. Crack formation of all-ceramic crowns dependent on different core build-up and luting materials. J. Dent., v.27, n.3, p.175-81, Mar. 1999.

118. SJÖGREN, G. et al. A clinical evaluation of ceramic (Cerec) inlays. Acta odont. scand., v.50, n.3, p.171-8, June 1992.

119. SJÖGREN, G. Marginal and internal fit of four different types of ceramic inlays after luting. Acta odont. scand., v.53, n.1, p.24-8, Feb. 1995.

120. SORENSEN, J.A. et al. Shear bond strength of composite resin to porcelain. Int. J. Prosthodont. v.4, n.1, p.17-23, Jan./Feb. 1991.

121. SORENSEN, J.A.; MUNKSGAARD, E.C. (a) Relative gap formation of resincemented ceramic inlays and dentin bonding agents. J. prosth. Dent. v.74, n.4, p.374-8, Oct. 1996.

122. SORENSEN, J.A.; MUNKSGAARD, E.C. (b) Relative gap formation adjacent to ceramic inlays with combination of resin cements and dentin bonding agents. J. prosth. Dent. v.74, n.4, p.472-6, Oct. 1996.

123. STENBERG, R.; MATSSON, L. Clinical evaluation of glass ceramic inlays (Dicor). Acta odont. scand., v.51, n.2, p.91-7, Apr. 1993.

124. STUDER, S. et al. Short-term results of IPS-Empress Inlays and onlays. J. Prosthodontics, v.5, n.4, p.277-87, Dec. 1996.

125. STUDER, S.; LEHNER, C.; SCHÄRER, P. Glass -Ceramic Inlays and Onlays made by IPS-Empress: First Clinical Results. J. dent. Res., v.71, n.1, p.658, 1992. /Abstract n. 1144/ 
126. SULAIMAN, F. et al. A comparison of the marginal fit of In-Ceram, IPS Empress and Procera crowns. Int. J. Prosthodont., v.10, n.5, p.478-4, Sept./Oct. 1997.

127. THONEMANN, B. et al. A Clinical evaluation of heat-pressed glass-ceramic inlays in vivo: 2 years results. Clin. oral Invest. v.1, n.1, p.27-34, Feb. 1997.

128. THORDRUP, M.; ISIDOR F.; HÖRSTED-BINDSLEV, P. A one year clinical study of indirect and direct composite and ceramic inlays. Scand. J. dent. Res., v.102, n.186, p.186-92, June 1994.

129. THORDRUP, M.; ISIDOR, F. A 5-year clinical study of indirect and direct resin composite and ceramic inlays. Quintessence Int., v.32, n.3, p.199-205, Mar. 2001.

130. TIDEHAG, P.; GUNNE, J. A 2-year Clinical follow-up study of IPS Empress ceramic inlays. Int. J. Prosthodont., v.8, n.5, p.456-60, Sept. 1995.

131. van DIJKEN, J.W.V. A 6-year evaluation of a direct composite resin inlay/onlay system and glass ionomer cement-composite resin sandwich restorations. Acta odont. scand., v.52, n.6, p.368-76, Dec. 1994.

132. van DIJKEN, J.W.V.; HÖGLUND-ABERG, C.; OLOFSSON, A.L. Fired ceramic inlays: a 6-year follow up. J. Dent., v.26, n.3, p.219-25, Mar. 1998.

133. van MEERBEECK, B. et al. Marginal adaptation of four tooth-coloured inlay systems in vivo. J. Dent., v.20, n.1, p.18-26, Feb. 1992.

134. WALTON, J.N. Esthetic alternatives for posterior teeth: porcelain and laboratory-processed composite resins. J. Canad. dent. Ass., v.58, n.10, p.820-3, Oct. 1992. 
135. WHITE, S. N.; YU, Z. Compressive and diametral tensile strengths of current adhesive luting agents. J. prosth. Dent., v.69, n.6, p.568-72, June 1993.

136. ZUELLING-SINGER, R.; BRYANT, R.W. Three-year evaluation of computermachined ceramic inlays: influence of luting agent. Quintessence Int., v.29, n.9, p.573-82, Sept. 1998. 


\section{ABSTRACT}




\section{ABSTRACT \\ Clinical evaluation of ceramic inlays and onlays made with two systems after 2 years}

The dental ceramics have been a restorative option, largely utilized in posterior teeth, due to an excellent esthetics. Several types of all ceramic systems are available in the market to fabricate partial restorations and crowns. The aim of this study was to evaluate the clinical performance of ceramic inlays and onlays made with two systems: sintered (Duceram, Dentsply-Degussa) - D and pressable (IPS Empress, Ivoclar-Vivadent) - IPS for two years. Eighty-six restorations, being 44 IPS and $42 \mathrm{D}$, were cemented in 35 patients from both sexes, mean age of 35 years. Twenty-seven premolars and 59 molars received class II cavities, totaling 33 onlays and 53 inlays. All restorations were cemented with the dual-resin cement (Variolink II, Ivoclar-Vivadent) and Syntac (Primer and Adhesive) and Heliobond adhesive system (Ivoclar-Vivadent), under rubber dam. The operative procedures were made by one operator. The evaluations were done by two independent investigators at the baseline, after one and two years, using the modified USPHS criteria for postoperative sensitivity, secondary caries, fracture, color match, marginal discoloration, marginal integrity and surface texture. Additionally radiographs and slides were made. After two years $100 \%$ of the restorations were assessed and all the restorations were considered clinically excellent or acceptable. Among the analyzed criteria the fallowing received Bravo ratings: marginal discoloration IPS (31.82\%); D (23.81\%); marginal integrity - IPS (18.18\%); D (11.9\%); color match - IPS (4.55\%); D (9.52\%) and surface texture - IPS (2.27\%); D (14.29\%). No "Charlie" or "Delta" scores were attributed to the restorations. The results were submitted to the Fisher and McNemar Statistical Tests. No significant differences were noticed between both ceramics after two years. Among the analyzed criteria only the marginal discoloration aspect presented an increased percentage of "Bravo" scores, which enhanced with time for both 
ceramics. Compared to the baseline data, the difference was statistically significant ( $p>0.05$ ). No difference was found between inlays and onlays restorations or between the restorations placed in premolar or molar region. At 2 years, the interexaminer reliability yielded Kappa values above 0.8 for all criteria. In conclusion, these two types of ceramics demonstrated excellent clinical performance after two years. 